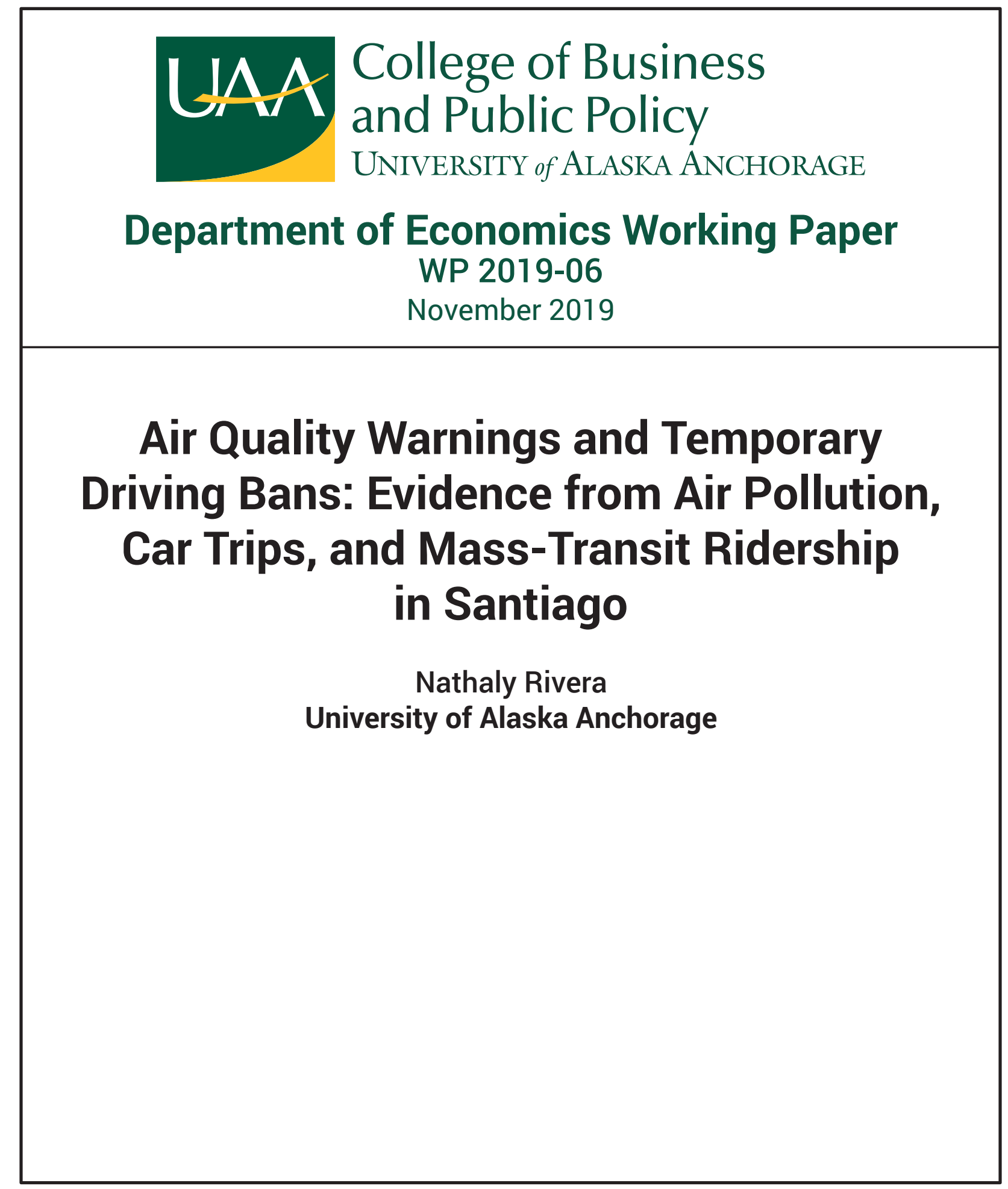

UAA DEPARTMENT OF ECONOMICS

3211 Providence Drive

Rasmuson Hall 302

Anchorage, AK 99508

http://econpapers.uaa.alaska.edu/ 


\title{
Air Quality Warnings and Temporary Driving Bans: Evidence from Air Pollution, Car Trips, and Mass-Transit Ridership in Santiago
}

\author{
Nathaly M. Rivera*
}

November 27, 2019

\begin{abstract}
Driving restrictions are a common governmental strategy to reduce airborne pollution and traffic congestion in many cities of the world. Using high-frequency data on air pollution, car trips, and mass-transit systems ridership, I evaluate the effectiveness of temporary driving bans triggered by air quality warnings in Santiago, Chile. I employ a fuzzy regression discontinuity design that uses the thresholds in the air quality index used to announce these warnings as instruments for their announcement. Results show that these temporary bans reduce car trips by 6-9\% during peak hours, and by $7-8 \%$ during off-peak hours. This is consistent with air pollution reductions during peak hours, and with increases in the use of Santiago's mass-transit systems during hours the systems run with excess capacity. Increments in mass-transit ridership uncover the importance of alternatives modes of transportation in securing the effectiveness of temporary driving bans.
\end{abstract}

Keywords: Air Pollution, Pollution Alerts, Environmental Episodes, Driving Restrictions, Latin America.

JEL Classification: Q52, Q53, R41

*Department of Economics and Public Policy, University of Alaska Anchorage, Anchorage, AK 99508. Email: nmrivera@alaska.edu 


\section{Introduction}

This paper evaluates a command-and-control policy aimed at reducing mobile source pollution in Santiago during days of critical air pollution. Heavy air pollution severely affects health (Chay and Greenstone, 2003; Neidell, 2004; Currie and Neidell, 2005; Knittel et al., 2016), educational outcomes (Currie et al., 2009; Stafford, 2015), labor supply (Ostro, 1983; Hausman et al., 1984; Hanna and Oliva, 2015), and productivity (Crocker and Horst, 1981; Zivin and Neidell, 2012; Chang et al., 2016; Lichter et al., 2017), particularly in developing countries (Greenstone and Hanna, 2014; Greenstone and Jack, 2015; Hanna and Oliva, 2015). In Latin America alone, air pollution puts at risk the health of more than 80 million inhabitants, generating annual losses of about 65 million working days (United Nations Environment Programme, 2002). Among countries in this region, Chile ranks second after Mexico in exposure to coarse particulate matter $\left(\mathrm{PM}_{10}\right)$ in urban areas, and first in exposure to fine particulate matter $\left(\mathrm{PM}_{2.5}\right)$, with Santiago ranked as one of the most polluted cities in the country (World Health Organization, 2014).

As in many metropolitan areas, poor air quality in Santiago is primarily due to mobile source pollution. Mobile sources account for 60 to 95 percent of the city's annual $\mathrm{PM}_{10}$ and $\mathrm{PM}_{2.5}$ emissions, and contribute substantially to the concentration of other pollutants, such as nitrogen oxides $\left(\mathrm{NO}_{X}\right)$, carbon monoxide $(\mathrm{CO})$, and volatile organic compounds (VOCs). ${ }^{1}$ Temporary driving restrictions aimed at curbing this pollution prohibit the driving in Santiago of a share of light-duty private vehicles based upon the last digits of their license plates. ${ }^{2}$ As a deviation from similar schemes in other countries, however, these bans affect both dirty and clean cars as part of a set of daily mitigation actions put into place during spikes in air pollution. ${ }^{3}$ These actions are part of 24 -hour preventive measures called "environmental episodes" (hereafter called "air quality warnings" or simply "episodes"),

\footnotetext{
${ }^{1}$ Data from the Register on Pollutant Release and Transfer (Registro de Emisiones y Transferencias de Contaminantes - RETC)'s website: http://www.retc.cl. Retrieved on March 15, 2017.

${ }^{2}$ Temporary driving restrictions complement a permanent ban that has restricted dirty cars since 1990 . Further details are given in Section 3.

${ }^{3}$ Clean cars are those that hold a green sticker, used to designate vehicles that meet specific emissions standards. These stickers are mandatory self-adhesive sticker added to the windshields of all fuel-efficient vehicles (e.g., eco-diesel, electric cars, etc.), and vehicles with catalytic converters, which certifies vehicles' compliance with the emission standards needed to drive in Santiago's Metropolitan Region. Vehicles earning a green sticker are brand new vehicles sold after September 1st, 1992, and emitting less than $0.25 \mathrm{~g} / \mathrm{km}$ of hydrocarbons, less than $2.11 \mathrm{~g} / \mathrm{km}$ of $\mathrm{CO}$, less than $0.62 \mathrm{~g} / \mathrm{km}$ of $\mathrm{NO}_{X}$, and less than $0.125 \mathrm{~g} / \mathrm{km}$ of particulate matter. Drivers obtain these stickers when getting their vehicle permits, issued after annual mandatory cars inspections that certify their emissions. During 2005, $70 \%$ of Santiago's vehicles were classified as clean vehicles, dropping to $30 \%$ the number of dirty cars, which were responsible for $54 \%$ and $24 \%$ of $\mathrm{CO}$ and $\mathrm{PM}_{10}$ emissions from mobile sources, respectively (Atal, 2009). Since then, the number of dirty vehicles in the city has dropped dramatically. Similar calculations in 2015 numbers reveal that these vehicles are currently responsible for $3.6 \%$ of current $\mathrm{CO}$ and $1.6 \%$ of current $\mathrm{PM}_{10}$ emissions from mobile sources.
} 
implemented in Santiago whenever the authorities foresee worrisome levels of the city's air quality index. Different index thresholds lead to a three-tier system of episodes (alerts, preemergencies, and emergencies), whose temporary driving bans further tighten the permanent driving restriction on dirty vehicles, as well as impose new restrictions on clean vehicles. ${ }^{4}$ Taking advantage of the discontinuities in the issuance of these events, I empirically evaluate the effectiveness of their short-term driving bans in curbing air pollution and traffic flows.

License plate-based driving restrictions constitute a common governmental strategy to reduce airborne pollution and traffic congestion in many cities of the world (e.g. Athens, Beijing, Berlin, Bogota, Mexico City, Milan, New Delhi, São Paulo). ${ }^{5,6}$ Mixed conclusions about their causal impact, however, still cast doubt on their effectiveness as an instrument to improve local air quality. Evidence of drivers bypassing these bans by either shifting their driving towards hours or days unaffected by the policy, or purchasing a second car to fully avoid these restrictions, are the main caveats to the effectiveness of this policy (Davis, 2008; Gallego et al., 2013; Bonilla, 2016; Zhang et al., 2017). Notwithstanding, most of the literature relies on evidence of mobile source pollution while little is known about the impact of these bans on vehicle flows and alternative modes of transportation.

If driving bans are effective, they would get cars off the roads and push their drivers towards cleaner and uncrowded transportation modes. An effective policy is, therefore, expected to produce a measurable impact not only on airborne pollution concentrations but on car use and mass-transit ridership as well. Simultaneously, a reduction in congestion because of these bans also could induce unaffected drivers to drive more, offsetting some of the initial reductions in pollution. This paper sheds light on these effects by approximating the causal impact that temporary driving bans, triggered by air quality warnings, generate on hourly pollution, vehicle flows, and mass-transit systems ridership, as a substitute for driving. While other works already have used a cross-sectional version of similar datasets to evaluate Santiago's driving bans (e.g., de Grange and Troncoso (2011)), the present study adds to the previous literature by adopting a causal framework that informs on the effectiveness of these bans as a policy mechanism, instead of delivering averages for days with and without the policy. In this sense, and as far as the author's knowledge, this is the first paper that evaluates the impact of driving bans on car trips and mass-transit ridership that prioritizes causality. As an additional feature, I study this policy over a longer time period in addition to incorporating the whole set of temporary restrictions into the analysis.

\footnotetext{
${ }^{4}$ For instance, clean private vehicles with license plates ending in 0 and 1 may not be used during the first pre-emergency episode of the year.

${ }^{5}$ Another common type of driving restriction is the low emission zone program mostly used to reduce congestion. Under this program, drivers are banned from entering some specific zones of the city.

${ }^{6}$ I use license plate-based driving restrictions and driving restrictions interchangeably throughout.
} 
Innovations in Santiago's policy also help to understand whether temporary driving restrictions reduce spikes in air pollution and traffic flows - a question sparsely attended to in the literature. Useful insights on the efficacy of short-term measures to curb surges in airborne pollution are in Mullins and Bharadwaj (2015), who evaluate the impact of Santiago's environmental episodes on particulate matter concentrations. While informative, however, the analysis in Mullins and Bharadwaj (2015) focuses on the entire suite of actions implemented by these episodes, without unraveling the particular role that short-term driving bans have on improving the city's air quality. Environmental episodes trigger not only driving restrictions, but also a set of other actions that target stationary source pollution. Hence, a deeper understanding of these episodes is necessary for correct advising to policymakers on devising mechanisms for curbing airborne contamination.

To evaluate the impact of short-term driving bans, I use high-frequency data from 2000 to 2015 on ambient concentrations of four major pollutants from automotive emissions: heavy and fine particulate matter $\left(\mathrm{PM}_{10}\right.$ and $\mathrm{PM}_{2.5}$, respectively), carbon monoxide $(\mathrm{CO})$, and nitrogen oxides $\left(\mathrm{NO}_{X}\right)$. A nice feature of high-frequency data on the concentration of these pollutants is the possibility of controlling for atmospheric persistence, widely known to affect pollution concentrations (Gibson and Carnovale, 2015; Zhang et al., 2017). Additionally, I look at hourly vehicle trips recorded by counting stations, and at the number of trips taken in both Santiago's Metro and Santiago's bus rapid transit system Transantiago.

I explore causality through a fuzzy regression discontinuity (FRD) design that uses the air quality index as the variable forcing the probability of an episode. The FRD approach exploits the arbitrary cutoffs in the air quality index that define the different episodes, and accounts for potential confounding factors by defining a narrow window around these cutoffs. I evaluate both the overall episodes' impact in a pooled FRD design, and their individual effectiveness in a multiple cutoff FRD design. The time span between the issuance of an episode and the implementation of its mitigation actions rules out potential unobservables that could simultaneously affect both the forcing and the outcome variables. Additionally, the use of high-frequency data on traffic flows allows me to isolate the effects of driving restrictions from other mitigation actions triggered by these episodes but targeting stationary source emissions. The robustness of the data available represents one of the main contributions of this study.

Results show that temporary driving restrictions effectively keep drivers off the roads during days of critical air pollution. Specifically, environmental episodes reduce average vehicle trips by roughly 6-9 percent during peak hours and by 7-8 percent during off-peak hours, rejecting the existence of a shift in driving towards unrestricted hours. The results indicate an increase in the daily use of mass-transit systems as well, mostly in Santiago's sub- 
way and during off-peak hours, suggesting that restricted drivers trend towards substituting alternative modes of transportation that run with excess capacity. Average pollution concentrations also decrease by 1-2 percent, mostly $\mathrm{PM}_{10}$, while the results on hourly maximum concentrations indicate a 2-3 percent reduction in $\mathrm{PM}_{10}, \mathrm{PM}_{2.5}$, and $\mathrm{CO}$. A back-of-theenvelope calculation based on these results indicates that the impact of this policy on heavy particulate matter is valued at US\$3.1-6.2 billion.

When allowing for heterogeneous effects, the results indicate reductions in hourly average and hourly maximum vehicle trips, mostly during the most severe episode when temporary driving bans restrict a significant amount of cars. For days with pre-emergencies (and emergencies), average car trips are curtailed by $5-15$ percent during peak-hours, and by 8 percent during early off-peak hours. Results on average pollution concentrations offer mixed findings, although further estimations controlling for pollution trends suggest reductions in airborne concentrations of all the four pollutants, particularly of $\mathrm{CO}$ and $\mathrm{NO}_{X}$. The results also indicate a positive impact on mass-transit ridership during the most severe episode and notably during off-peak hours, which uncover the importance of alternatives modes of transportation in securing the effectiveness of this policy while shedding light on the significance of complementary efforts when it comes to curbing local air pollution.

The plan of this paper is laid out as follows. Section 2 reviews the literature on driving restrictions and highlights the contributions of the present study. Section 3 provides background details on Santiago's air quality episodes and driving restrictions, while Section 4 describes the data. Section 5 describes the empirical strategy, Section 6 presents the results and the robustness checks, and Section 7 concludes.

\section{Related Literature}

Despite the vast literature on license plate-based driving restrictions and local air quality, conclusions on their effectiveness are still not conclusive. Eskeland and Feyzioglu (1997) look at the 1989 Hoy No Circula (HNC) driving restriction in Mexico City, suggesting an unintentional increase in driving due to a greater use of old cars, congestion effects, and to the purchasing of a second car after the program implementation. Davis (2008) reinforces this conclusion by adopting a causal approach on the impact of HNC on local air pollution. The author finds no evidence of pollution reductions due to the policy, suggesting instead a shift in driving towards hours or days unaffected by the policy, as well as an increase in the number of dirty vehicles in the city. ${ }^{7}$ With a focus on the heterogeneous effects of the

\footnotetext{
${ }^{7}$ Salas (2010) revisits Davis (2008)'s estimations and finds that both the sign and significance of the HNC impact vary greatly with the time window and the length of the time trend polynomial used in the author's
} 
policy, Gallego et al. (2013) document a 5-13 percent reduction in CO concentrations due to HNC, but only among middle-income groups and during the first months of the policy implementation. These effects vanish after twelve months of the HNC adoption, time after which the policy increases CO concentrations.

Similar works emphasizing the ineffectiveness of driving bans are Cantillo and De Dios Ortúzar (2014), Bonilla (2016) and Zhang et al. (2017), analyzing the case of Bogota's Pico y Placa (PyP) program. PyP was created in 1998 with the intention of reducing traffic congestion in the city. Empirical evidence on its effectiveness, however, question some of the PyP outcomes highlighting its long-run failure. For example, Bonilla (2016) analyzes the impact of different phases of this policy on CO concentrations documenting no evidence of air quality improvements and, instead, finding an increase in pollution concentrations during the PyP most drastic phase. Likewise, (Zhang et al., 2017) suggest an increase in airborne pollution due to PyP, emphasizing the role of the pollutants' atmospheric chemistry as one of the mechanisms that explains the failure of this policy.

In spite of the previous evidence, several other works underline the success of driving bans as a mechanism to curb mobile source pollution. Carrillo et al. (2016) study the effects of Quito's Pico y Placa (PyP) program on CO ambient concentrations, suggesting a 9-11 percent reduction due to this policy and, contrary to the findings for Mexico City, claim no evidence of shifts in traffic towards unrestricted hours. Similar conclusions are in Viard and $\mathrm{Fu}$ (2015) for Beijing's driving restriction plan. The authors evaluate the every-other-day and the one-day-a-week restrictions in this city, finding an 18 and 21 percent reduction, respectively, in particulate matter concentrations due to these policies. These results are corroborated by Chen et al. (2013) on Beijing's short-term driving bans imposed during the 2008 Olympic Games. Wolff (2014) obtains similar conclusions for the low-emission zones (LEZ) program that restricts dirty vehicles from driving on specific roads in Germany. The author finds a 9 percent reduction in heavy particulate matter concentrations due to this program, rejecting the option that dirty vehicles drive more outside the LEZ. The success of these policies, as opposed to the failure of the previous designs, has been linked to factors such as the population's general propensity to comply with restrictions, as in the case of Beijing's bans (Viard and Fu, 2015), and to specific characteristics of the policy design, which might foster compliance at a higher degree as in the case of the LEZ's emission-levels car differentiation that incentivizes drivers to adopt cleaner vehicles (Wolff, 2014). ${ }^{8}$

empirical specification. Particularly, smaller time windows around the HNC implementation reveal positive and significant effects of the program on several airborne pollutants, which exposes a potential behavioral distinction between short-term and long-term drivers' adaptation to this policy.

${ }^{8}$ Barahona et al. (2018) document similar incentives in the case of Santiago's driving bans. The authors show that Santiago's permanent driving restriction pushes the city's vehicle composition toward vehicles 
In regards to Santiago's policy, previous evidence suggests a positive relationship between environmental episodes and air quality improvements (Atal, 2009; Troncoso et al., 2012; Mullins and Bharadwaj, 2015), as well as discouragement of the use of private cars in the city (de Grange and Troncoso, 2011). In particular, Atal (2009) finds CO and $\mathrm{PM}_{10}$ reductions during pre-emergencies, while Troncoso et al. (2012) suggest $\mathrm{PM}_{10}, \mathrm{PM}_{2.5}, \mathrm{CO}$ and $\mathrm{NO}_{X}$ reductions during the same episodes, although only during weekdays. Using crosssectional evidence on urban traffic flows, de Grange and Troncoso (2011) show that days with pre-emergency episodes exhibit 5.3 percent fewer cars on the roads, and 3.3 percent more ridership of the subway.

Using a causal approach, Mullins and Bharadwaj (2015) analyze the effects of Santiago's episodes on heavy particulate matter concentrations and mortality rates. Combining a difference-in-difference (DID) approach with propensity score matching, the authors construct a control group of days with similar pollution levels before the policy enforcement, finding suggestive evidence that environmental episodes lead to a 20 percent short-term reduction in $\mathrm{PM}_{10}$ concentrations. This reduction is persistent on subsequent days, which unveils the long-term persistence of this pollutant in the atmosphere. Their findings also suggest a reduction in mortality rates of the elderly, especially when comparing days that follow these announcements.

The present study is similar in spirit to Mullins and Bharadwaj (2015), as it uses a quasi-experimental approach to derive causal effects of Santiago's environmental episodes, although with a focus on the effectiveness of short-term driving restrictions, instead of the broad set of measures triggered with these episodes. While the use of $\mathrm{PM}_{10}$ as the main outcome is informative on the overall effect of an episode on airborne pollution, it fails to provide guidance on the relative effectiveness of each of their protocols. Table 1 indicates the set of mitigation actions triggered by each of these short-term episodes, which not only target mobile sources of pollution, but also stationary sources in addition to prohibit domestic biomass combustion, an important source of particulate matter. The present work attempts to provide some answers to this puzzle by complementing air pollution data with information on traffic flows and on alternative modes of transportation. As an extra feature, the use of high-frequency data on air pollution allows me to control for some of its atmospheric persistence that affects the dissemination speed of some pollutants (Gibson and Carnovale, 2015). The inclusion of dynamics in the concentration of pollutants also fills an existing gap in the literature studying pollution concentrations.

\section{[INSERT TABLE 1 ABOUT HERE]}

with a green sticker, which are not affected by this policy. Indeed, $56 \%$ of 2001 registered cars in Santiago had a green sticker. These cars now represent $98 \%$ of registered cars in the city (INE, 2015). 


\section{Background Information}

The severity of Chile's air contamination has prompted implementation of multiple actions to mitigate air pollution, especially in the metropolitan area of Santiago, home of nearly half of the country's population. Santiago is located in the central part of Chile, in a basin surrounded by mountains with an altitude that ranges between 1,500 and 4,500m. These mountains prevent strong wind formation, which in combination with thermal inversions reduce the dispersion of pollutants, particularly during colder months (World Health Organization, 2006). ${ }^{9}$

\subsection{Air Pollution Prevention and Clean-Up Plan}

During the late 80s and early 90s, the Special Decontamination Commission of the Metropolitan Region and the Air Pollution Prevention and Clean-up Plan (PPDA) in Santiago, introduced several mitigation actions aimed at targeting emissions from stationary and mobile sources (OECD, 2005). Emission standards, tradable permits, and emissions taxes manage emissions from stationary sources, while the Critical Episodes Management (Gestión de Episodios Críticos - GEC) program addresses mobile source pollution. This program, establishes license-plate based driving restrictions on light-duty private cars annually from April 1st to August 31st. In particular, the GEC employs a permanent (seasonal) license plate-based restriction that since 1990 prohibits the driving of dirty vehicles in Santiago during weekends from 7:30am to $9 \mathrm{pm} .{ }^{10}$ When meteorological conditions prevent the dispersion of pollutants, and lead to particulate matter concentrations that exceed the PPDA tolerable ceilings, the GEC complements the permanent prohibition with a short-term driving ban on both dirty and clean vehicles. ${ }^{11}$ In these cases, the PPDA considers the issuance of a 24-hour environmental episode, or air quality warning, which activates a set of short-term actions aimed at improving air quality in the city, along with recommendations to avoid outdoor exposure to pollution. ${ }^{12}$ Since the introduction of this clean-up plan, Santiago's air quality has shown progress regarding daily $\mathrm{PM}_{10}$ and $\mathrm{CO}$ concentrations (see Figure A2 in Appendix

\footnotetext{
${ }^{9}$ Winter goes from April 1st through August 31st.

${ }^{10}$ Santiago's metropolitan area is administratively divided in 6 provinces and 52 municipalities. Specifically, driving bans affect cars circulating in the province of Santiago plus cars driving in the municipalities of Puente Alto and San Bernardo. In total, 34 municipalities are affected by these bans. Figure A1 (Appendix A) shows this administrative division. Shaded areas represent the municipalities affected by driving restrictions.

${ }^{11}$ Despite that these short-term actions were established by the PPDA during the early 90s, their full enforcement did not start until 1997 (Mullins and Bharadwaj, 2015).

${ }^{12}$ The GEC was slightly modified in 2018 with the incorporation of a permanent driving ban on clean cars registered before 2012. The present study analyzes the impact of the GEC but framed in its original design.
} 
A). ${ }^{13}$ Yet, it is still difficult to anticipate the effectiveness of the PPDA when it comes to other airborne pollutants such as $\mathrm{PM}_{2.5}$ or $\mathrm{NO}_{X}$, potentially due to the rapid urban growth that the city experienced during these years (Romero et al., 1999).

Figure 1 plots the hourly station-average concentrations of these pollutants during winter days without environmental episodes, before episodes, and with episodes. As observed in Figure 1, hourly pollution concentrations peak twice a day: early in the morning, and late in the evening. Middle-hand panels, however, show higher readings during days preceding an episode in combination with a high dispersion, mostly for $\mathrm{CO}$ (panel c) and $\mathrm{NO}_{X}$ (panel d). Right-hand panels show high persistence of these conditions on days with episodes, although with a visible drop late at night.

\section{[INSERT FIGURE 1 ABOUT HERE]}

\subsection{Air Quality Warnings}

The issuance of environmental episodes is based on a pollution forecasting system of Santiago's particulate matter concentrations used by the Ministry of Environment (Ministerio de Medio Ambiente - MMA) since 2000. This daily forecast, based on a prediction model called the Cassmassi model, takes place every winter day at 8pm, generating a 24-hour moving average prediction of $\mathrm{PM}_{10}$ and $\mathrm{PM}_{2.5}$ concentrations for the following day (Perez, 2008; Salini, 2009). ${ }^{14}$ These expected concentrations correlate with two indexes of Air Quality from Particulates (Índice de Calidad del Aire Referido a Partículas - ICAP) which, inspired by the former US EPA Air Quality Index, were created to easily correlate different levels of $\mathrm{PM}_{10}$ and $\mathrm{PM}_{2.5}$ on the same scale. These indexes (hereafter called $\mathrm{ICAP}_{10}$ and $\mathrm{ICAP}_{2.5}$, respectively), transform measures of particulate matter concentrations into a comparable scale so that the higher the indexes values the greater the particulate concentrations and the potential health concern.

Different thresholds in the air quality indexes lead to a three-tier label system of environmental episodes (alert, pre-emergency, and emergency) issued whenever the indexes exceed the thresholds in at least one of the monitoring stations. ${ }^{15}$ In this case, the Environment

\footnotetext{
${ }^{13}$ Though the evident improvement in Santiago's $\mathrm{PM}_{10}$ concentrations since 1990, their annual average readings are still well above the WHO guideline levels. These specific guidelines for 24-hour mean concentrations are set in $50 \mathrm{\mu g} / \mathrm{m}^{3}$ and $25 \mathrm{\mu g} / \mathrm{m}^{3}$ for heavy and fine particulate matter respectively.

${ }^{14}$ The Cassmassi model is a set of linear equations (one per station) that incorporates particulate matter concentrations and 24-hour forecasts of meteorological conditions and atmospheric stability in the city (Saide et al., 2011). See Appendix B for an example of the equations used in the prediction of 24-hour $\mathrm{PM}_{10}$ concentrations for the Pudahuel station, the unit that generally reports the highest levels of particle concentrations in the city.

${ }^{15}$ Since 1997, the Cassmassi model, and the announcement of episodes, were both uniquely based on the
} 
Superintendent (Superintendencia del Medio Ambiente -SMA) recommends to the Governor of Santiago's Metropolitan Area (Intendente) the issuance of an episode for the following day (starting at midnight). Once this decision is taken, the episode is publicly announced through either evening newscast TV, radio shows, the SMA's official website, newspapers, and smartphone apps, and goes on until early in the morning of the next day (the day with the episode).

Table 2 displays the thresholds for the $\mathrm{PM}_{10^{-}}$and $\mathrm{PM}_{2.5^{-}}$based ICAP values, their 24-hour average particulate matter correlations, and the corresponding episode. Forecasts of good air quality are equivalent to ICAP values below 100, while predictions of regular air quality relate to ICAP values between 100 and 199. The protocol establishes an air quality episode whenever the ICAPs reach the 200-threshold. The mildest episode, an alert, is announced for ICAPs between 200 and 299, equivalent to $195-239 \mu \mathrm{g} / \mathrm{m}^{3} \mathrm{PM}_{10}$ concentrations, and to 80$109 \mu \mathrm{g} / \mathrm{m}^{3} \mathrm{PM}_{2.5}$ concentrations. The 300-threshold leads to an environmental pre-emergency that takes place for ICAPs between 300 and 499, equivalent to $240-329 \mu \mathrm{g} / \mathrm{m}^{3}$ and to 110 $169 \mu \mathrm{g} / \mathrm{m}^{3} \mathrm{PM}_{10}$ and $\mathrm{PM}_{2.5}$ concentrations, respectively. Lastly, the 500-threshold leads to an environmental emergency with ICAPs equivalent to $\mathrm{PM}_{10}$ concentrations $\geq 330 \mu \mathrm{g} / \mathrm{m}^{3}$, or $\mathrm{PM}_{2.5}$ concentrations $\geq 170 \mu \mathrm{g} / \mathrm{m}^{3}$.

\section{[INSERT TABLE 2 ABOUT HERE]}

Despite the policy design considering the $\mathrm{ICAP}_{10}$ and $\mathrm{ICAP}_{2.5}$ as the key variables triggering an episode, previous indications suggest other factors can play a role in this process as well. In particular, this decision might involve experienced air quality forecasters, while in some other cases it might be a political decision (Saide et al., 2011). To the extent that omitted factors can trigger an environmental episode becomes crucial to identify causal effects, as the air quality indexes would be influencing the probability of an episode instead of triggering it. Further details on this distinction are offered in Section 5.

\subsection{Temporary Driving Restrictions}

Air quality episodes trigger several mitigation actions that affect emissions from both mobile and stationary sources. Discharges from stationary sources are addressed with the temporary shutdown of industrial facilities and the prohibition of wood-burning stoves, while temporary driving bans that reinforce the permanent restriction are aimed at targeting

expected concentrations of heavy particulate matter $\left(\mathrm{PM}_{10}\right)$. Currently, and due to the introduction of the ICAP index based on PM2.5 concentrations in 2011, air quality episodes can be announced based on the concentrations of this pollutant as well. In particular, episodes can be issued whenever one of these two indexes exceeds the tolerable ceilings. 
mobile source emissions. In general, the more severe the episode the stricter their actions, as shown in Table 1.

Temporary driving restrictions match the permanent ban by prohibiting the driving of light-duty cars between 7:30am and 9pm. ${ }^{16}$ Unlike their long-term counterpart, however, these temporary restrictions can 1) be placed during any day of the week and, 2) affect both clean and dirty vehicles, that is, with and without green stickers, respectively. Table A1 (Appendix A) displays the historical versions of this policy, along with the number of digits and the type of cars affected. Nowadays, air quality alerts extend the 2-digit permanent restriction on dirty vehicles to Saturdays and Sundays; pre-emergencies add two more digits to the permanent ban on dirty cars and impose a 2-digit restriction on cleans cars, while air quality emergencies trigger an 8-digit restriction on dirty cars and impose a 4-digit restriction on clean cars.

Implementing these driving bans requires planning ahead for a full year which license plate numbers to ban from driving. ${ }^{17}$ Public support for this policy reached $89 \%$, while compliance also is believed to be high. ${ }^{18}$ The national police force task undertakes policy enforcement, boosting visibility and increasing the number of vehicle inspections during days with episodes (Atal, 2009). Penalties for violations include fines between US\$70 and US\$150, and driving license suspensions (de Grange and Troncoso, 2011). ${ }^{19}$

\section{Data}

\subsection{Air Quality Episodes}

Information on air quality episodes comes from the Operative Unit of Traffic Control (Unidad Operativa de Control de Tránsito —UOCT) from 2000 to 2015, for a total of 397 episodes (see Table 3). During this period, air quality alerts were the most common occurrence with 318 episodes, followed by pre-emergencies with 78. Air quality emergencies are a rare event with just one single episode declared since $2000 .^{20}$

\footnotetext{
${ }^{16}$ While temporary driving restrictions are always triggered, they are in effect only during peak hours. Shutdowns of industrial facilities, however, are triggered by the two most critical episodes (pre-emergencies and emergencies), but constitute a 24-hour mandate.

${ }^{17}$ See Table A2 in Appendix A for a 2016 example.

${ }^{18}$ Information from the 2018 National Survey of Environment, available at http://portal.mma.gob.cl. Retrieved on March 27, 2018.

${ }^{19}$ The MMA's 2016 GEC report indicates that 5,578 vehicles were ticketed for driving restriction violations during morning rush hours in 2016. Most of these violations took place during June and July, time where 16 pre-emergencies and 1 emergency were issued. Most of these violations, however, correspond to infringements of the permanent restriction.

${ }^{20}$ In the empirical analysis, emergency episodes will be merged into pre-emergencies.
} 


\section{[INSERT TABLE 3 ABOUT HERE]}

\subsection{Air Pollution and Weather Variables}

Hourly records on pollution come from the National Information System of Air Quality (Sistema de Información de Calidad del Aire - SINCA)'s network of monitoring stations placed in Santiago's metropolitan area. The SINCA network operates with eleven stations spread across the city, which hourly collect measures of air quality and weather conditions. I use records from ten of these stations, which are located in the municipalities affected by driving restrictions. ${ }^{21}$ Later in the paper, I use the eleventh station in a robustness analysis.

From the selected stations, I obtain ambient concentrations of four major pollutants from vehicle emissions from 2000 to 2015: $\mathrm{PM}_{10}, \mathrm{PM}_{2.5}, \mathrm{CO}$, and $\mathrm{NO}_{X}$. Particulate matter concentrations are important to study as their concentrations drive the calling of episodes. Nonetheless, pre-emergency and emergency episodes affect residential and stationary source pollution as well, which threatens identification of the causal effect of driving bans. Hence, the examination of two main tailpipe pollutants from vehicle emissions, $\mathrm{CO}$ and $\mathrm{NO}_{X}$, constitute a better output to isolate the effectiveness of these bans. ${ }^{22}$ Descriptive statistics for these variables are in Table 4 (panel a), while daily average and maximum pollution concentrations by season are displayed in Table 5 for winter days with and without episodes. Average and maximum 24-hour concentrations are substantially lower for all four pollutants during days without episodes. These concentrations show a steady increase during days with episodes, except for $\mathrm{CO}$, which shows a decrease in both average and maximum daily concentrations during the most critical warning, albeit with only one of these episodes included in the sample.

\section{[INSERT TABLE 4 ABOUT HERE]}

\section{[INSERT TABLE 5 ABOUT HERE]}

Data on weather are gathered from several sources from 2003 to 2015. Hourly data on humidity, temperature, and wind speed come from the SINCA stations, while information on daily precipitation comes from the National Water Information System (Sistema Nacional de Información del Agua - SNIA). Combinations of humidity and temperature affect the

\footnotetext{
${ }^{21}$ Daily commuting flows in the area move from suburban belts towards the region's center allowing these stations to read pollution records from most of the daily economic activity taking place in the region. See Figure A1 (Appendix A) for the spatial location of these stations (red dots), and the municipalities affected (shaded area).

${ }^{22}$ The transportation sector is also a primary source of volatile organic compounds (VOCs) emissions. However, lack of data prevents the use of VOCs in this work.
} 
dispersion of pollutants in a similar fashion to winds and precipitations, which carry air contaminants away from the atmosphere. To approximate the effect of inversions, I consider the difference between the city's daily maximum and minimum temperature as a proxy for changes in temperature. This thermal oscillation is positively related to daily average temperatures in the sense that warmer days experience less temperature inversion. Higher thermal oscillations are, therefore, expected to reduce pollution. Descriptive statistics of the weather covariates are displayed in Table 4 (panel b).

\subsection{Urban Flows}

Hourly data on vehicle trips come from the Operative Unit of Traffic Control (Unidad Operativa de Control de Tránsito - UOCT)'s counting stations connected to Santiago's road network from 2004 to 2015. These counting stations are placed underground in the city's main roads, and therefore, are unable to distinguish between public and private transportation, or between light-, medium-, and heavy-duty vehicles. The outcome from these stations, however, represents a useful proxy for light-duty car use whenever unobservable factors affecting this counting occur at random.

Hourly metro trips taken between 2000 and 2015 come from Metro S.A. Santiago's 103$\mathrm{km}$ subway consists of 5 lines that operate continuously from 5:30am to midnight during weekdays, from 6:30am to midnight on Saturdays, and from 8am to midnight on Sundays and holidays. Before 2007, daily ridership on Santiago's metro was 640,000 trips on average. After 2007, however, daily ridership increased drastically to more than 1,750,000 trips due to the ineffective introduction of Santiago's new rapid transit bus, Transantiago. By improving the quality of the city's public transportation, the Transantiago program aimed at persuading drivers to get off the roads. Yet, its inefficient route designs and bus schedules led to opposite results, which translated into higher commuting times and a significant increase in subway use. Despite these initial inefficacies and after more than 10 years of improvements, Transantiago remains in place and in daily use by many riders. For this reason, I also consider data on daily Transantiago ridership between 2007 and 2015, which come from the Ministry of Transportation and Telecommunications (MTT). Table 6 contains the descriptive statistics for these three variables and the different years with data available.

\section{[INSERT TABLE 6 ABOUT HERE]}

To the extent that effective driving restrictions get drivers off the roads and push them towards cleaner forms of transportation suggests that mass-transit systems ridership is ex- 
pected to increase during days with driving bans. ${ }^{23}$ To understand the traffic patterns during days with and without episodes, Table 7 exhibits 24-hour average and maximum trips by transportation mode during winter. Consistent with an effective policy, average vehicle trips decrease for days with air quality episodes. Mass-transit ridership, however, increases only during alerts and decreases during days with pre-emergencies, which could suggest that individuals are responding positively to the official recommendations of avoiding outdoor exposure during days of critical air pollution. In that case, potential increments in daily mass-transit ridership due to effective driving bans would be attenuated by any avoidance behavior in days with severe air quality episodes.

\section{[INSERT TABLE 7 ABOUT HERE]}

\subsection{Indexes of Air Quality from Particulates (ICAPs)}

Station-level daily values for $\mathrm{ICAP}_{10}$ and $\mathrm{ICAP}_{2.5}$ come from the MMA. By definition, the episodes' issuance takes place whenever one of these indexes exceeds the norm in at least one of the monitoring stations, in which case the station with the highest daily reading would be the one driving the process. Hence, I define daily max ICAP values across stations, particularly $\mathrm{ICAP}_{10}$, as the main variable forcing an episode.

The relationship between daily max ICAPs and the announcement of episodes is displayed in Figure 2 for winter 2015, which plots the time-series daily max ICAP for days with and without an episode. Dashed lines depict the different ICAP-thresholds in the episodes' issuance. From the policy design, days preceding an episode are expected to have daily max ICAPs above the 200-threshold in at least one of the two indexes ( $\operatorname{ICAP}_{10}$ or $\left.\mathrm{ICAP}_{2.5}\right)$. Yet, a quick examination of Figure 2 indicates this is not always the case: in 2015, there are days with episodes preceded by days with max ICAPs below the 200-threshold. ${ }^{24}$ This mismatch reflects the discretion embedded in the calling of these warnings, as factors other than the ICAPs can also affect the authorities' decision of announcing these occurrences.

\section{[INSERT FIGURE 2 ABOUT HERE]}

\footnotetext{
${ }^{23}$ Drivers also can substitute towards bicycles or motorcycles, which contributes to airborne pollution as well. Reports on Santiago's vehicle composition, however, rule out this option. During 2001, there were two motorcycles per a hundred of light-duty private vehicles driving in Santiago. In 2015, this number increased to six motorcycles per a hundred of light-duty cars. These increments, however, are identical to the ratios exhibited in other cities in the country, which lack driving restrictions. For more details, see INE (2001) and INE (2015).

${ }^{24}$ The same holds for other years. These graphs are available upon request.
} 


\section{Empirical Strategy}

If short-term driving restrictions effectively curb air pollution and traffic counts, such outcomes should decrease on days with an episode relative to outcomes on days had episodes not been announced. Given that this control is not available for observational data, previous works have tackled this issue either by constructing a control group using days before the policy (the GEC) was established (e.g., Mullins and Bharadwaj (2015)), or by using off-peak hours of days affected with the policy (e.g., Carrillo et al. (2016)). The first option is not a possibility in this study as the goal here is evaluating the role of short-term driving bans on a broad set of air pollutants and traffic counts, for which data are available only since the 2000s. The second approach also is unfeasible given the previous evidence on intertemporal shiftings of driving towards hours unaffected by driving bans, which makes off-peak hours of days with episodes a bad control group.

Given Santiago's policy structure, however, a regression discontinuity that exploits the arbitrariness in the ICAPs' discontinuities that assign an episode (a "treatment"), seems a natural empirical approach to apply in this setting. In particular, a sharp regression discontinuity (SRD) design that considers one of the ICAP variables (e.g., ICAP 10 ) as the variable forcing the treatment assignment would derive unbiased causal estimates of the treatment effect under the identifying assumption that the outcome of interest (i.e., car trips, air pollution), would have changed smoothly around the ICAP threshold in absence of an episode.

To test the previous idea, Figure 3 displays the data-driven plot (Calonico et al., 2015a) of a sharp discontinuity scheme using the two cutoffs that define alerts and pre-emergencies (jointly with emergencies) on the residuals from the augmented local regression of hourly average car trips on weather and fixed effects. ${ }^{25}$ As the jumps in Figure 3 suggest, environmental episodes are slightly curtailing the number of cars on the roads relative to days without episodes. This is consistent with the pattern observed in similar data-driven plots on hourly average pollution in Figure 4; as illustrated, days without episodes exhibit pollution records that are positively correlated with the air quality index. Yet, this correlation loses strength during days with higher index values for which an episode has been announced. Indeed, the jumps in the linear fits at each side of these thresholds suggest that environmental

\footnotetext{
${ }^{25} \mathrm{As}$ local RD designs compare observations in a small neighborhood at each side of a relevant cutoff, controls are generally hard to include because of the reduced number of observations that fit inside this neighborhood. To avoid this challenge, I follow Hausman and Rapson (2018) approach on augmented local linear specifications, in which a local linear approach is fitted on the residuals from the (full) regression of the response variables on weather and seasonality controls. For more details, see Hausman and Rapson (2018). Linear fits at each side of the cutoffs use sample averages of residuals within optimal disjoint bins based on Calonico et al. (2015b).
} 
episodes are sharply reducing airborne concentrations in Santiago. ${ }^{26}$

\section{[INSERT FIGURES 3 AND 4 ABOUT HERE]}

While the policy design establishes the ICAP values as the main variables determining an episode, the authorities' discretion embedded in this process prevents this announcement from being a deterministic function of the ICAPs, which inhibits perfect compliance with the policy. ${ }^{27}$ When the probability of treatment does not jump from 0 to 1 at the relevant cutoffs, the sharp design becomes an impractical option for evaluation as factors other than the running variable may also affect the treatment assignment, leading to inconsistent estimates in Figures 3 and 4.

The air quality indexes, however, still can affect the conditional expectation of assignment to treatment. In this case, causal identification can be tackled by exploiting the discontinuity in the probability of assignment to treatment in a fuzzy regression discontinuity (FRD) design (Imbens and Lemieux, 2008) that uses the discontinuities in the running variable as instruments for the treatment assignment (Angrist and Pischke, 2008). In what follows, I adopt a FRD scheme that resembles an instrumental variable (IV) estimation by exploring two specific designs: a pooled FRD approach aimed at combining the treatment effects of different episodes, and a multi-cutoff FRD setup that exploits the treatment heterogeneity (Cattaneo et al., 2016) using the distinct PPDA thresholds.

\subsection{Pooled Fuzzy Regression Discontinuity Design}

While the ICAP thresholds lead to three types of episodes, the standard in the literature is the score normalization so that a single threshold applies for all units under analysis (i.e. days with episodes (Cattaneo et al., 2016)). In a pooled design, the treatment is defined as having an air quality episode during day $t$, regardless of its type. Formally, let $T_{t}$ be the random variable representing the treatment during day $t$. The probability of issuing an

\footnotetext{
${ }^{26}$ As a balance check, Figure C1 (Appendix C) depicts the data-driven plots of similar linear fits at each side of the thresholds on hourly average wind speed (panel a) and humidity (panel b). As expected, no discontinuities are evident at the thresholds.

${ }^{27}$ This implies there could be days at the right of the relevant thresholds in Figures 3 and 4, for which no episode was issued, or days at the left of these cutoffs that did not have episodes or had a milder episode than expected. See Figure C2 (Appendix C) for the kernel density estimates of the daily air quality indexes $\left(\mathrm{ICAP}_{10}\right.$ and $\mathrm{ICAP}_{2.5}$ ) during days that precede either alert (panel a) or pre-emergency (panel b) episodes. Panel (a) shows that days with alerts have $\operatorname{ICAP}_{10}$ values generally below the 200 -threshold. This situation is slightly similar for days with pre-emergencies, as shown in panel (b). The fact that most of the episodes have been issued with $\mathrm{ICAP}_{10}$ values below their corresponding threshold evidences the fuzzy feature of the discontinuities in this policy.
} 
episode during day $t$ is defined to jump as follows:

$$
P\left(T_{t}=1 \mid \bar{x}_{t-1}\right)= \begin{cases}g_{1}\left(\bar{x}_{t-1}\right) & \text { if } \bar{x}_{t-1} \geq 0 \\ g_{0}\left(\bar{x}_{t-1}\right) & \text { otherwise }\end{cases}
$$

where $g(\cdot)$ is any function with $g_{1}(0)>g_{0}(0)$, and $\bar{x}_{t-1}$ is the running variable defined as the daily max $\operatorname{ICAP}_{10}$ during day $t-1$, normalized as follows: ${ }^{28}$

$$
\bar{x}_{t-1}=I C A P_{10, t-1}-200 .
$$

From equation (2), days with $\bar{x}_{t-1}$ values equal or higher than 0 are more likely to have an episode. I define a flexible first-stage equation of the episodes' announcement on the running variable, $\bar{x}_{t-1}$, as follows:

$$
T_{t}=\alpha_{0}+\alpha_{1} 1\left[\bar{x}_{t-1} \geq 0\right]_{t}+\sum_{j=1}^{p} \gamma_{l j} \bar{x}_{t-1}^{j}+\sum_{j=1}^{p} \gamma_{r j} \bar{x}_{t-1}^{j} \times 1\left[\bar{x}_{t-1} \geq 0\right]_{t}+\mathbf{X}_{\mathbf{h}} \delta+\nu_{t}
$$

where $T_{t}$ is equal to 1 if an episode was announced on day $t$ (=0 otherwise); $1\left[\bar{x}_{t-1} \geq 0\right]_{t}$ is an indicator variable taking 1 for normalized ICAP values equal and above 0 during day $t$ ( $=0$ otherwise); and $\mathbf{X}_{\mathbf{h}}$ is a vector of covariates that include current and 24-hour lags of quartics in humidity, temperature, precipitation, wind speed, and thermal oscillation, and seasonal fixed effects on year, month of the year (month), day of the week (dow), and interactions between weekends and hour of the day. The term $\nu_{t}$ is an error term. I allow the specification of a flexible polynomial fit in equation (3) below and above the discontinuity, where the subscripts $l$ and $r$ identify the coefficients predicting the relationship between the $\operatorname{ICAP}_{10}$ and the treatment below $(l)$ and above $(r)$ the 0 -threshold, respectively, and $p$ indicates the order of the polynomial fit. The magnitude of the discontinuity at the threshold is indicated by the coefficient $\alpha_{1}$. The second-stage equations take the following form:

$$
y_{h}=\beta_{0}+\beta_{1} T_{t}+\sum_{j=1}^{p} \eta_{l j} \bar{x}_{t-1}^{j}+\sum_{j=1}^{p} \eta_{r j}\left[\bar{x}_{t-1}^{j} \times T_{t}\right]+\mathbf{X}_{\mathbf{h}} \zeta+\epsilon_{h}
$$

where $y_{h}$ is the outcome of interest (i.e. log of air pollution, log of traffic volume, log of urban transit flows) during hour $h ; \epsilon_{h}$ is an error term, and coefficients $\eta_{l}$ and $\eta_{r}$ identify a polynomial fit on the outcome variables before $(l)$ and after $(r)$ the treatment, respectively.

\footnotetext{
${ }^{28}$ Since the creation of the GEC, the $\mathrm{ICAP}_{10}$ index was the only metric considered in the issuance of an episode. For this reason, I consider this index as the running variable throughout all the estimations. Nonetheless, and due to the potential influence of $\mathrm{ICAP}_{2.5}$, I use this variable as an additional instrument (additional covariate) all along.
} 
Due to their boundary properties (Hahn et al., 2001), the preferred specification of equations (3) and (4) sets $p=1$ in an augmented local linear estimation as suggested by Hausman and Rapson (2018), using bandwidths at each side of the cutoff defined according to Imbens and Lemieux (2008) and Calonico et al. (2018b). ${ }^{29}$ Assuming that the discontinuity in equation (3) induces the discontinuity in equation (4), the episode impact on the outcome variables, $\beta_{1}$, gives the episode weighted local average treatment effect, weighted by the number of occurrences in each threshold.

\subsection{Multi-Cutoff Fuzzy Regression Discontinuity Design}

Unlike a pooled FRD, a multi-cutoff FRD uses all the information available by allowing the running variable to affect the probability of one or more treatments through several discontinuities (Cattaneo et al., 2016). As pre-emergency and emergency episodes are grouped together, I estimate a multi-cutoff FRD with two discontinuities on the running variable: at the 200-threshold, and at the 300-threshold. I define a generic first-stage multi-cutoff FRD equation as follows:

$$
T_{t}^{A}=\delta_{0}+\delta_{1} 1[\text { Alerts }]_{t}+\sum_{j=1}^{p} \theta_{l j} I C A P_{10, t-1}^{j}+\sum_{j=1}^{p} \theta_{r j} 1[\text { Alerts }]_{t} \times I C A P_{10, t-1}^{j}+\mathbf{X}_{\mathbf{h}} \varphi+v_{t}
$$

where $T_{t}^{A}$ is the response variable taking 1 if an alert episode was announced during day $t$ (=0 otherwise); $1[\text { Alerts }]_{t}$ is an indicator variable taking 1 if $I C A P_{10, t-1} \in[200,299] \quad(=0$ if $\left.I C A P_{10, t-1} \in[0,199]\right) ; \mathbf{X}_{\mathbf{h}}$ is a vector of weather covariates and fixed effects as defined before; and $v_{t}$ is an error term. This specification includes a flexible polynomial fit at each side of the discontinuity, where the subscripts $l$ and $r$ identify the coefficients predicting the relationship between $\operatorname{ICAP}_{10, t-1}$ and the outcomes below and above the first discontinuity, respectively. I define an expression similar to equation (5) for pre-emergencies, where the response variable is defined as $T_{t}^{P}$, and the indicator $1[\text { Alerts }]_{t}$ is replaced with $1[\text { Pre }-e m]_{t}$ that takes 1 if $I C A P_{10, t-1} \geq 300$ (=0 if $\left.I C A P_{10, t-1} \in(200,299]\right)$. For the second-stage

\footnotetext{
${ }^{29}$ In particular, I consider a bandwidth of $h=25$ with $K_{0}=2$ and $K_{1}=2$ number of bins at each side of the cutoff based on Imbens and Lemieux (2008), and optimal bandwidths as defined in Calonico et al. (2018b).
} 
equation:

$$
\begin{aligned}
y_{h}=\lambda_{0}+\lambda_{1} T_{t}^{A} & +\lambda_{2} T_{t}^{P}+\sum_{j=1}^{p} \omega_{l j} I C A P_{10, t-1}^{j} \\
& +\sum_{j=1}^{p} \omega_{m j} I C A P_{10, t-1}^{j} \times T_{t}^{A}+\sum_{j=1}^{p} \omega_{r j} I C A P_{10, t-1}^{j} \times T_{t}^{P}+\mathbf{X}_{\mathbf{h}} \mu+\xi_{h},
\end{aligned}
$$

where the subscripts $l, m$, and $r$, identify the coefficients below, in the middle, and above the two discontinuities, respectively.

In line with the pooled FRD, the preferred specifications of equations (5) and (6) are the linear specifications with $p=1$, and estimated on a small neighborhood around the 200 and 300-thresholds. Aimed at testing for intertemporal shifts in driving, all the estimation equations consider the outcome variable measured during peak (banned) and off-peak hours. Whether drivers substitute their driving towards unrestricted hours, the estimated results should indicate a significant increase in car use during these hours of days with episodes. Changes in car emissions during these hours, however, may not be as sharply reflected in the results due to the different lifetimes of pollutants in the atmosphere (Gibson and Carnovale, 2015; Zhang et al., 2017). Factors such as pollutants' atmospheric chemistry, their formation, and their lifetime in the air, all might affect the pace whereby eventual reductions in traffic flows are reflected in ambient pollution concentrations. Failing to control for these factors could lead to inaccurate conclusions regarding the policy impact on pollution. Because of this possibility, I include the outcome variable lagged 12 hours in all estimation equations where the outcome is pollution. ${ }^{30}$ In addition, I split off-peak hours between early morning (5-6am) and late evening (9pm-0am) across all the estimations.

Because of the time series characteristic of the outcome variables, I estimate the previous equations using a Generalized Method of Moments (IV-GMM) procedure that accounts for serial correlation in the data. This is performed with the Newey-West heteroskedastic- and autocorrelation-consistent HAC weighting matrix (Barlett kernel). Based upon the analysis of partial autocorrelations, I define the HAC weighting matrix to be robust to 24-hour lags in air pollution, to 2-hour lag in vehicle trips, and to 1-hour/1-day lag in mass-transit systems. All the estimation equations use the $\mathrm{ICAP}_{2.5}$ variable as an additional instrument.

\footnotetext{
${ }^{30}$ The analysis of partial autocorrelations on the time series on pollution indicates 24-hour autocorrelations with values equal or higher than 0.5 . Yet, the inclusion of that number of lagged periods as covariates turns the estimations into a very intensive computational task. For the sake of parsimony, I only include 12-hour lags on pollution, although the inclusion of 24-hour lags in the weather covariates should capture any effect lasting for more than 12 hours.
} 


\section{The Effectiveness of Air Quality Warnings and their Temporary Driving Bans}

\subsection{The Overall Effectiveness - Pooled FRD}

Tables 8 and 9 depict the estimated episode impact on hourly average vehicle trips and pollution, respectively, from the pooled FRD estimation for peak and off-peak hours. Tables D1 and D2 (Appendix D) display similar results on hourly maximum car trips and pollution concentrations. ${ }^{31}$

\section{[INSERT TABLE 8 ABOUT HERE]}

The results in Table 8 suggest air quality episodes effectively push cars off the roads. These results are consistent and significantly different from zero through all the different specifications. In particular, the GMM-IV results in Table 8 indicate that an episode reduces hourly average car flows by 6-9 percent during peak hours. Reductions that are small in magnitude are expected when pooling the episodes as air quality alerts, the most common episode, trigger driving bans that only affect dirty vehicles, which constitute a tiny fraction of light-duty vehicles in the city. ${ }^{32}$ The results during off-peak hours, however, indicate a weak reduction for early hours - potentially due to early-bird restricted drivers - and a strong 8 percent reduction during late hours. Even though these restrictions are placed only until 9pm, the city's long commuting hours could maybe explain some of these reductions late at night. In any case, a decrease in car trips during off-peak hours, or even zero effects, all constitute evidence against an intertemporal shift in driving towards unrestricted hours. The results in Table D1 for hourly max flows are consistent with this intuition.

\section{[INSERT TABLE 9 ABOUT HERE]}

The results in Table 9 for the pooled FRD on hourly average pollution indicate reductions in $\mathrm{PM}_{10}, \mathrm{PM}_{2.5}$ and $\mathrm{CO}$ concentrations during peak hours of days with episodes. Findings in panel a) strongly indicate the episodes' announcement reduces hourly average $\mathrm{PM}_{10}$ readings in 1-2 percent. Although small, the consistency of these results through the different

\footnotetext{
${ }^{31}$ In addition, Tables D3 and D4 in the Appendix D contain the results of a global polynomial fitted on these outcome variables.

${ }^{32}$ Table A3 (Appendix A) contains the expected number of light-duty private vehicles in the Santiago's Metropolitan Region affected by this policy. Temporary driving bans during days with alerts are expected to affect a $5.7 \%$ of cars - a number that is close in magnitude to the result in Table 8 . Nevertheless -it is important to note that the results in Table 8 reveal the episodes' impact on car trips, which is not necessarily the same as the number of light-duty private vehicles driving the city.
} 
bandwidths is somewhat an optimistic finding considering the role of this pollutant in the calling of an episode. Panels b) and c) weakly suggest a .8 and a 1 percent reduction in $\mathrm{PM}_{2.5}$ and $\mathrm{CO}$, respectively, while no effects are found for $\mathrm{NO}_{X}$. Considering the potentially complex atmospheric behavior of these pollutants throughout the day, a weak episode impact on their average concentrations might reflect an omitted pollution trend that is not being fully captured by the estimation equations. In any case, the results during early off-peak hours suggest a significant 3-11 percent reduction in airborne concentrations of all the four pollutants - a plausible scenario in the case of early-bird drivers getting off the roads. Either way, this situation exposes the importance of evaluating driving bans using data on traffic flows instead of uniquely relying on air pollution concentrations, as factors other than the policy could be driving the findings on airborne concentrations. Reductions in pollution are evident, however, after examining Table D2 on hourly maximum readings. An episode reduces maximum pollution concentrations of these pollutants in 2-3 percent during peak hours. The results in Table D2 also reveal a positive impact on $\mathrm{PM}_{2.5}$ concentrations, although this effect is not statistically significant across the several bandwidths. All the results

in Tables 8 and 9 pass the Stock-Wright-Yogo rule of thumb on weak instruments (Stock et al., 2002).

\subsection{Heterogeneous Effects - Multi-Cutoff FRD}

Heterogeneous effects of alert and pre-emergency episodes on hourly average (hourly maximum) car flows and pollution concentrations are depicted in Table 10 and 11 (Tables D5 and D6 in Appendix D) for peak and off-peak hours, respectively.

The results for car flows in Table 10 indicate that environmental episodes, through their temporary driving bans, reduce car flows during peak hours of days with alerts and preemergencies. Findings in Table 10 weakly suggest that alert episodes reduce average car trips in 3-6 percent during off-peak hours, while the results during pre-emergencies strongly indicate a 5-15 percent reduction for the same hours. Findings for car use during off-peak hours weakly suggest a 8 percent reduction during early hours of days with pre-emergencies, and a 5-6 percent decrease during late hours of days with alerts.

\section{[INSERT TABLE 10 AROUND HERE]}

Despite the strong results found in Table 10 on the discouragement of car use during preemergencies, these results are smaller than expected (see Table A3). While the scenario in which some of the restricted drivers bypass the restrictions is always an option, an additional possibility is that some unrestricted drivers might be taking advantage of a reduced road 
congestion during days with severe driving restrictions, which would lead to more miles driven (more car trips) by these drivers on days with episodes. Whether this is the case, congestion effects would be outweighing some of the initial reductions in the number of car trips avoided by restricted drivers, leading to smaller causal impacts. Although this is not directly testable, the results in Table D5 on hourly maximum car trips undermine this possibility. Hourly maximum car trips decrease during the most severe episodes, which means less car trips (less congestion) around the most saturated counting stations during days with episodes. Taken together, the results in Table 10 and Table D5 suggest compliance with the policy, notably during days in which the severe driving bans are in place.

\section{[INSERT TABLE 11 ABOUT HERE]}

Results in Table 11 (Table D6) on average (maximum) pollution concentrations offer mixed findings. Estimates of the episodes' impact during peak hours in panels a), b), and c), indicate that alerts reduce hourly average concentrations of $\mathrm{PM}_{10}, \mathrm{PM}_{2.5}$, and $\mathrm{CO}$ by around 1-2 percent. These results are consistent and statistically different from zero for all three specifications. The estimated effects on average $\mathrm{NO}_{X}$ concentrations also are negative, although not statistically significant. When it comes to pre-emergencies, however, the results show no effects or, as in the case of $\mathrm{NO}_{X}$, positive effects. Whether this is because of the ineffectiveness of the policy or because of a misspecification of the pollution estimation equations, the previous results on car flows can offer an answer. Furthermore, a potential atmospheric persistence during days of heavy contamination is in line with the results obtained during off-peak hours in Table 11. Estimates of the alert impact during early off-peak hours all are found negative and significant. These episodes sometimes are preceded by a pre-emergency episode, which in combination with the potential lifetime persistence of these pollutants, make feasible a scenario in which some of these reductions could be reflecting lagged effects from the episodes announced the day before. Similar conclusions regarding the atmospheric persistence of these pollutants can be drawn for the results during late off-peak hours. The severity of the airborne contamination that motivates the announcement of an episode in the first place could dictate a slower pollution dissipation even in the presence of effective mitigation actions. In the next section, an additional differences-in-differences estimation is used to control for these potentially unobserved pollution trends common to these stations and omitted from the current FRD analysis.

\subsection{Evidence from Mass-Transit Systems Ridership}

The previous pooled FRD and multi-cutoff FRD estimations suggest that temporary

driving restrictions, triggered by environmental episodes, effectively reduce the number of 
cars on the roads. Weak evidence suggests these reductions might lead to lower mobile source pollution as well, although they are not conclusive. To get better insights on the actual effectiveness of these short-term driving bans, Table 12 displays findings for the FRD estimations on hourly metro trips, while Table 13 exhibits results on daily trips taken in Santiago's bus rapid transit system Transantiago.

\section{[INSERT TABLE 12 ABOUT HERE]}

Results in panel a) of Table 12 suggest that environmental episodes increase the number of metro trips by roughly 16-28 percent during early off-peak hours (5-6am), a time at which the system runs with excess capacity. These results seem higher than expected given the estimated effect on car trips (see Table 8). One possibility is that this coefficient could be capturing not only new demand (restricted drivers), but an intertemporal shift in ridership by regular users as well. The threat of a crowded service during peak hours of a day with an episode might force current subway users to travel at early non-rush hours as well. In panel b), the results indicate a 7-11 percent increase in the number trips taken during peak hours of days with pre-emergencies. Although no effect is found for peak hours of days with alerts, middle columns in Table 12 suggest a significant increase in the number of rides taken during these days at early hours. Pre-emergencies seem to push some metro rides towards late offpeak hours as well. Overall, the results in Table 12 suggest some drivers are substituting with the metro during days of temporary driving restrictions, and particularly at non-rush hours. Consistently, the results in Table 13 indicate some banned drivers could be switching to the use of Transantiago as well. The results on the multi-cutoff FRD estimator in panel b) suggest a 12 percent increase in bus rapid transit ridership during days with alerts and a 16 percent increase during pre-emergencies. ${ }^{33}$

\section{[INSERT TABLE 13 ABOUT HERE]}

\subsection{Robustness Checks}

\subsubsection{Placebo Cutoffs}

The previous findings are robust to several specifications. First, I run a falsification test using placebo thresholds in the FRD estimation. In order to set these placebo thresholds and considering that days with ICAP values equal to or higher than the first threshold all are expected to receive a treatment (i.e., an episode), I split the baseline sample starting from the

\footnotetext{
${ }^{33}$ Estimates using peak and off-peak hours in Transantiago are unfeasible because of the frequency of data available.
} 
first cutoff to the left, attempting to avoid possible misspecifications due to the imposition of zero jumps at the original thresholds. As the first threshold is at 200, the subsample for the placebo test uses all days in the baseline sample with $\operatorname{ICAP}_{10, t-1}$ values between 0 and 199. To fit the three different placebo cutoffs, $\bar{x}_{t-1}^{*}$, I use the following simplified rule:

$$
\bar{x}_{t-1}^{*}=\left\{\begin{aligned}
{[50,99] } & \rightarrow \text { Alerts } \\
{[100,149] } & \rightarrow \text { Pre-emergencies } \\
{[150,199] } & \rightarrow \text { Emergencies }
\end{aligned}\right.
$$

The results for this placebo test using optimal bandwidths are in Table 14 for the episodes' impact on car, metro and bus trips, and in Table 15 (Table D7, Appendix D) for the impact on average pollution during peak hours (off-peak hours). All the results are derived using the same specifications on the previous FRD equations. The results in Table 14 indicate zero impact of environmental episodes on vehicle trips and mass-transit systems ridership during both peak and off-peak hours, regardless of whether these episodes are pooled (panel a) or not (panel b). Similar results are found for the episodes' impact on hourly average pollution during peak (Table 15) and off-peak (Table D7) hours. Taken together, the results for this falsification test corroborate the validity of the previous findings.

\section{[INSERT TABLE 14 AROUND HERE]}

\section{[INSERT TABLE 15 AROUND HERE]}

\subsubsection{Using a Control Monitoring Station}

In this section, I delve deeper into the effectiveness of environmental episodes on pollution using information on airborne concentrations originated in the SINCA network station that was omitted from the FRD analysis. This station, called Talagante, and labeled before as the eleventh station (see Section 4), is located at $38 \mathrm{~km}$. (23 miles) SE of Santiago's downtown. Talagante is a municipality that belongs to the Talagante province in Santiago's Metropolitan Region, but currently sits outside the GEC plan on environmental episodes. The existence of an "untreated" station that is close enough to the area treated with this policy allows for a difference-in-difference (DID) robustness check on pollution. The DID design considers all the SINCA's monitoring stations that were part of the previous analysis as the "treated" stations during days with episodes, and the Talagante station as the "control" station. Assuming that, conditional on weather covariates and several time fixed effects, station-specific unobservables affecting pollution trends are uncorrelated with the episodes' issuance, the DID estimator should provide a reliable estimation of the episodes' 
impact on pollution concentrations. Additionally, to the extent that atmospheric conditions around Talagante and the rest of Santiago's stations are similar, allows the DID design to remove any lifetime pollution trend common to these stations. ${ }^{34}$

\section{[INSERT TABLE 16 ABOUT HERE]}

Table 16 displays the results for the DID estimation on hourly (peak-hours) average pollution using a Newey-West estimator that is robust to serial autocorrelation. Panel a) contains the average treatment effect on the treated (ATT) stations after pooling the episodes, while panel b) displays the ATT when heterogeneous effects are allowed. All estimations include weather covariates, and year, month, day-of-the-week, and weekend $\times$ hour fixed effects, in addition to station-fixed effects. The difference between columns (1) and (2) is the addition of a quadratic time trend in the latter. The results in panel a) consistently suggest that overall, environmental episodes reduce hourly mobile source pollution in 12-47 percent in the treated stations relative to the average concentration in Talagante. In particular, environmental episodes reduce hourly $\mathrm{PM}_{10}$ average concentrations by 12 percent, $\mathrm{PM}_{2.5}$ by 28 percent, $\mathrm{CO}$ by 21 percent, and $\mathrm{NO}_{X}$ by 47 percent. When the heterogeneity of these episodes is taken into account, the results in panel b) indicate that air quality alerts and pre-emergencies (and emergencies) both curb mobile source pollution, with pre-emergencies curbing these concentrations at a higher proportion. On average, alert episodes reduce $\mathrm{PM}_{10}$ by 9 percent, $\mathrm{PM}_{2.5}$ by 24 percent, $\mathrm{CO}$ by 14 percent, and $\mathrm{NO}_{X}$ by 45 percent. Similarly, pre-emergency episodes curb $\mathrm{PM}_{10}$ concentrations by 24 percent, $\mathrm{PM}_{2.5}$ by 43 percent, $\mathrm{CO}$ by 43 percent, and $\mathrm{NO}_{X}$ by 50 percent. ${ }^{35}$ These findings provide suggestive evidence on the effectiveness of the episodes in curbing pollution concentrations. Moreover, the results in panel a) of Table 16 represent a simple test on the success of their driving restrictions as well, as this episode targets pollution mostly from mobile sources. An additional test on this last point, however, is presented next.

\footnotetext{
${ }^{34}$ Figure C3 (Appendix C) displays an overview of the parallel trends assumption for the treated and control stations for 2011, one of the years in the sample with the highest number of episodes during summer (pre-treatment) and winter periods. Additional plots are available upon request.

${ }^{35}$ The magnitude of these estimates, although high, is in line with those in Mullins and Bharadwaj (2015), who find a 20 percent reduction in $\mathrm{PM}_{10}$. It is important to consider here that, while the DID estimator leads to an ATT effect, the RD specification leads to a local average treatment effect, or LATE. In other words, the RD design gives an average treatment effect for those days at the margin of receiving the treatment, i.e., days with $\mathrm{ICAP}_{10}$ values right around the threshold, and therefore, these two results are not directly comparable. In fact, recent evidence on FRD models suggests that LATE could be a lower bound of average treatment effects in cases with two-sided noncompliance (Huang, 2015).
} 


\subsubsection{Mobile vs. Stationary Source Pollution}

Despite the legitimacy of using car flows and mass-transit systems ridership in evaluating the effectiveness of driving bans, a valid concern is that some of the findings in Tables 9 and 11 on pollution concentrations could be driven by some of the additional abatement actions triggered by the episodes that target stationary sources. A straightforward answer that rules out this concern is based on the results for alerts in Tables 11 and 16. As mentioned before, temporary driving restrictions are embedded in all three different episodes, whilst the shutdown of industrial facilities come into effect only during the most severe episodes of pre-emergencies and emergencies (see Table 1). Hence, the results in Table 11 (corroborated later in Table 16) on the impacts of alerts cannot be attributable to the contemporaneous suspension of these facilities.

In addition to triggering driving bans, however, alert episodes trigger the prohibition of burning wood and biomass for residential heating, which are an important source of particulate matter as well. To tease out the effect of the driving bans from this additional prohibition, I run a FRD analysis using only the information on airborne concentrations that come from a monitoring station, called Parque O'Higgins, that is the nearest to Santiago's downtown. As in any other city, Santiago's downtown houses a high percentage of government buildings and also constitutes the core of commercial activity in the city, minimizing the likelihood of observing industrial facilities or residential homes near this station. Thus, pollution records captured by this station should reflect pollution emissions mostly from mobile sources.

\section{[INSERT TABLE 17 ABOUT HERE]}

Table 17 contains the FRD results for the estimated episodes impact during peak hours on hourly pollution concentrations in Parque O'Higgins, using optimal bandwidths. The results indicate no effects on air pollution during days with alerts, an expected result considering that this episode increases the number of restricted cars in the city but only during weekends. For pre-emergencies, instead, the results indicate a strong negative effect, particularly on $\mathrm{PM}_{2.5}$, $\mathrm{CO}$, and $\mathrm{NO}_{X}$. Significant reductions in airborne concentrations of these pollutants during pre-emergencies in Santiago's downtown suggest short-term driving bans, when triggered by these air quality warnings, effectively curtail pollution.

\subsection{Potential Threats to Identification}

One concern regarding the validity of the previous results is that factors omitted from the analysis could bias the estimated impact of driving bans. For instance, drivers could an- 
ticipate future episodes and decide to drive more the day before, biasing the local estimated impact towards zero. Several factors make this option implausible. First, in order to anticipate a future episode, drivers should perceive air pollution concentrations in concordance with objective readings, something that has been dismissed in the literature (Berezansky et al., 2010). Second, and even if objective and subjective indicators were aligned in the heads of Santiago's drivers, they would have to distinguish between air pollution levels that lead to an episode - and the type of episode - and those that do not. Finally, and from the calendar of restrictions in Table A2, individuals would have to be familiar with the calendar of restrictions in order to truly anticipate and change their behavior over the threat of being banned from driving the next day. In any case, and in the unlikely scenario that these conditions are all met, the estimates in this work would represent a lower bound of the true effect.

The empirical approach carried out in this work relies on the identifying assumption that the outcome of interest (i.e., car trips, air pollution), would have changed smoothly around the ICAP threshold in absence of an episode. Yet, and because of the similarities between the FRD approach and instrumental variables estimation, a fair concern could lie on the validity of the exclusion restriction when estimating the FRD. As explained in Section 5, ICAPs are used as instruments of the episode announcement, and therefore, they are required to satisfy both the relevance and the exclusion restriction. While the policy design illustrates itself the relevance of the instruments, compliance with the exclusion condition could be less clear. To clarify this point, it is important to consider that ICAPs on day $t-1$ are the instruments for the episodes on day $t$. A violation of the exclusion restriction would imply that, after controlling for a rich set of fixed effects, climatic variables, and lagged values of pollution, today's ICAPs would have an effect on tomorrow's pollution through mechanisms other than the episodes' announcement. One valid argument could be a longlasting persistence of pollution - for more than a day - in the atmosphere, which might be the case of $\mathrm{PM}_{2.5}$ (Pérez et al., 2000). In this case, and because of the design of the air quality indexes, the long-lasting persistence of pollution would likely violate the exclusion restriction in the $\mathrm{PM}_{2.5}$ regression leading to inconsistent estimates. Though there could be correlation between particulate matter and $\mathrm{CO}$ and $\mathrm{NO}_{X}$ as well, there are no a priori reasons to expect that this correlation will prevail after including the set of covariates in the estimation equations. At the same time, it is even more unlikely that ICAPs will affect car flows or mass-transit ridership through mechanisms other than the episodes. ${ }^{36}$ This shows

\footnotetext{
${ }^{36}$ One possibility here is that today's economic activity could affect today's car flows and mass-transit ridership as well as future pollution, a relationship that should be captured by the rich set of fixed effects included in the estimation.
} 
the importance of evaluating this type of policy on outcomes other than airborne pollution concentrations.

\section{Conclusions}

Driving restrictions are a common regulatory mechanism used by many governments to reduce mobile source pollution and traffic congestion. Empirical evidence on how these restrictions affect the number of cars in circulation, and so their effects on pollution, is not yet conclusive. In this study, I provide evidence that driving bans, when issued on a temporary basis and in conjunction with air quality warnings, represent an efficient mechanism to curb emissions from mobile sources. I test this idea using evidence from Santiago's shortterm, license-plate based driving restrictions. Triggered by environmental episodes, these restrictions are issued whenever the authorities foresee critical levels of air pollution. I explore the causal impact of these temporary bans with data on mobile source pollution, car trips and mass-transit systems ridership, in a fuzzy regression discontinuity design that uses the city's air quality index as the forcing variable.

Results on the overall impact of these driving bans show a 1-2 percent reduction in mobile source pollution, and a 6-9 percent reduction in car trips during peak hours. In addition, the results indicate an increase in mass-transit ridership, particularly during hours at which the systems run with excess capacity. Findings also reveal a reduction in car trips during offpeak hours, which rejects the idea of an intertemporal substitution of driving towards hours unaffected by the policy. Results on the heterogeneous impact of these episodes corroborate these findings. Car trips are curtailed mostly during the most severe episodes, although at a smaller rate than expected, which suggests that some unaffected drivers might be taking advantage of a reduced road congestion during restricted days. Mass-transit systems ridership, however, show significant increases mostly during off-peak hours, implying that some drivers are switching towards alternative modes of transportations mainly at non-rush hours. Pollution exhibits a slight increase late at night, although additional evidence suggests these surges could be explained by the high persistence of these pollutants in the atmosphere during days with critical airborne contamination.

The empirical exercise in this paper documents that Santiago's mechanism of temporary banning cars from driving is an effective policy for an immediate action to counteract pollution from mobile sources. While banning drivers from the roads can be quite costly (Blackman et al., 2018), this policy certainly derives some benefits from a reduced airborne pollution exposure during days with episodes. Miller and Ruiz-Tagle (2019) estimate that a $10 \mu \mathrm{g} / \mathrm{m}^{3}$ reduction in $\mathrm{PM}_{10}$ concentrations yields 19.9 fewer all-cause infant deaths per 
100,000 infants annually in Santiago. Average $\mathrm{PM}_{10}$ concentrations in our dataset are 85.04 $\mu \mathrm{g} / \mathrm{m}^{3}$ so that a $1-2 \%$ decrease due to driving bans yields a $0.85-1.7 \mu \mathrm{g} / \mathrm{m}^{3}$ reduction in $\mathrm{PM}_{10}$ concentrations per episode. Considering that 397 episodes were announced from 2000 to 2015, and assuming a linear relationship between pollution and health, back-of-the-envelope calculations indicate that the impact of this policy on heavy particulate matter concentrations has yielded approximately 672-1,344 fewer all-cause infant deaths per 100,000 infants in Santiago. Using Parada-Contzen et al. (2013)'s estimates of the value of a statistical life in Chile, this mortality benefit is valued at US\$3.1-6.2 billion. A more thorough cost-benefit analysis of this policy should consider the benefits not only from an improved local air quality but also from a reduced car congestion.

Multiple factors can make this policy effective in Santiago relative to similar designs in other cities. Santiago's temporary driving bans affect dirty and clean cars differently. This distinction has been found to incentivize adoption of lower-emitting vehicles in Santiago (Barahona et al., 2018) in a fashion similar to other successful driving restrictions designs such as Germany's LEZ (Wolff, 2014). At the same time, short-term driving bans —as opposed to long-term restrictions - might induce different behavioral responses on affected drivers. Santiago's policy restricts drivers with a less-than-one probability, which might mitigate some of the incentives to purchase a second car. Furthermore, the fact that these restrictions are triggered by air quality warnings increases awareness regarding air quality conditions as well, which might trigger different reactions on affected (and unaffected) drivers. The existence of mass-transit systems over a wide extent of the city also helps to safeguard compliance with the policy as affected drivers face alternative modes of transportations during restricted days. Finally, it is also possible the success of Santiago's driving bans could be reflecting the role of enforcement and cultural habits of the local population. However, the results found in this study regarding the use of Santiago's Metro and bus rapid transit, suggest that the existence of uncrowded mass-transit systems might be a key aspect in securing the effectiveness of temporary driving bans.

\section{References}

Angrist, J. D. and Pischke, J.-S. (2008). Mostly harmless econometrics: An empiricist's companion. Princeton university press.

Atal, R. (2009). Efectos de las medidas de gestión de episodios críticos en la calidad del aire en santiago, chile. Instituto de Economía, Pontificia Universidad Católica de Chile, Santiago. 
Barahona, N., Gallego, F., Montero, J.-P., et al. (2018). Vintage-specific driving restrictions. Review of Economic Studies.

Berezansky, B., Portnov, B., and Barzilai, B. (2010). Objective vs. perceived air pollution as a factor of housing pricing: A case study of the greater haifa metropolitan area. Journal of Real Estate Literature, 18(1):99-122.

Blackman, A., Alpízar, F., Carlsson, F., and Planter, M. R. (2018). A contingent valuation approach to estimating regulatory costs: Mexico's day without driving program. Journal of the Association of Environmental and Resource Economists, 5(3):607-641.

Bonilla, J. A. (2016). The More Stringent, the Better? Rationing Car Use in Bogotá with Moderate and Drastic Restrictions. The World Bank Economic Review, pages lhw053-25.

Calonico, S., Cattaneo, M. D., and Farrell, M. H. (2018a). On the effect of bias estimation on coverage accuracy in nonparametric inference. Journal of the American Statistical Association, 113(522):767-779.

Calonico, S., Cattaneo, M. D., and Farrell, M. H. (2018b). Optimal bandwidth choice for robust bias corrected inference in regression discontinuity designs. arXiv preprint arXiv:1809.00236.

Calonico, S., Cattaneo, M. D., Farrell, M. H., and Titiunik, R. (2017). rdrobust: Software for regression-discontinuity designs. The Stata Journal, 17(2):372-404.

Calonico, S., Cattaneo, M. D., and Titiunik, R. (2014). Robust nonparametric confidence intervals for regression-discontinuity designs. Econometrica, 82(6):2295-2326.

Calonico, S., Cattaneo, M. D., and Titiunik, R. (2015a). Optimal data-driven regression discontinuity plots. Journal of the American Statistical Association, 110(512):1753-1769.

Calonico, S., Cattaneo, M. D., and Titiunik, R. (2015b). Optimal Data-Driven Regression Discontinuity Plots. Journal of the American Statistical Association, 110(512):1753-1769.

Cantillo, V. and De Dios Ortúzar, J. (2014). Restricting the use of cars by license plate numbers: A misguided urban transport policy. DYNA, 81(188):75-82.

Carrillo, P. E., Malik, A. S., and Yoo, Y. (2016). Driving restrictions that work? quito's pico y placa program. Canadian Journal of Economics/Revue Canadienne d'Économique, 49(4):1536-1568. 
Cattaneo, M. D., Titiunik, R., Vazquez-Bare, G., and Keele, L. (2016). Interpreting Regression Discontinuity Designs with Multiple Cutoffs. The Journal of Politics, 78(4):12291248.

Chang, T., Graff Zivin, J., Gross, T., and Neidell, M. (2016). Particulate Pollution and the Productivity of Pear Packers. American Economic Journal: Economic Policy, 8(3):141-69.

Chay, K. Y. and Greenstone, M. (2003). The impact of air pollution on infant mortality: evidence from geographic variation in pollution shocks induced by a recession. The quarterly journal of economics, 118(3):1121-1167.

Chen, Y., Jin, G. Z., Kumar, N., and Shi, G. (2013). The promise of Beijing: Evaluating the impact of the 2008 Olympic Games on air quality. Journal of Environmental Economics and Management, 66(3):424-443.

Crocker, T. D. and Horst, R. L. (1981). Hours of Work, Labor Productivity, and Environmental Conditions: A Case Study. The Review of Economics and Statistics, 63(3):361.

Currie, J., Hanushek, E. A., Kahn, E. M., Neidell, M., and Rivkin, S. G. (2009). Does Pollution Increase School Absences? . Review of Economics and Statistics, 91(4):682-694.

Currie, J. and Neidell, M. (2005). Air pollution and infant health: what can we learn from california's recent experience? The Quarterly Journal of Economics, 120(3):1003-1030.

Davis, L. W. (2008). The Effect of Driving Restrictions on Air Quality in Mexico City. The Journal of Political Economy, 116(1):38-81.

de Grange, L. and Troncoso, R. (2011). Impacts of vehicle restrictions on urban transport flows The case of Santiago, Chile. Transport Policy, 18(6):862-869.

Eskeland, G. S. and Feyzioglu, T. (1997). Rationing can backfire: the "day without a car" in Mexico City. The World Bank Economic Review, pages 383-408.

Gallego, F., Montero, J.-P., and Salas, C. (2013). The Effect of Transport Policies on Car Use: Evidence from Latin American Cities. Journal of Public Economics, 107:47-62.

Gibson, M. and Carnovale, M. (2015). The effects of road pricing on driver behavior and air pollution. Journal of Urban Economics, 89:62-73.

Greenstone, M. and Hanna, R. (2014). Environmental Regulations, Air and Water Pollution, and Infant Mortality in India. The American Economic Review, 104(10):3038-3072. 
Greenstone, M. and Jack, B. K. (2015). Envirodevonomics: A Research Agenda for an Emerging Field. Journal of Economic Literature, 53(1):5-42.

Hahn, J., Todd, P., and Van der Klaauw, W. (2001). Identification and estimation of treatment effects with a regression-discontinuity design. Econometrica, 69(1):201-209.

Hanna, R. and Oliva, P. (2015). The effect of pollution on labor supply: Evidence from a natural experiment in Mexico City. Journal of Public Economics, 122:68-79.

Hausman, C. and Rapson, D. S. (2018). Regression discontinuity in time: Considerations for empirical applications. Annual Review of Resource Economics, 10:533-552.

Hausman, J. A., Ostro, B. D., and Wise, D. A. (1984). Air Pollution and Lost Work. National Bureau of Economic Research Cambridge.

Huang, C. (2015). Bounds on treatment effects of encouragement experiments and implications for fuzzy regression discontinuity analysis. Unpublished Manuscript.

Imbens, G. W. and Lemieux, T. (2008). Regression discontinuity designs: A guide to practice. Journal of econometrics, 142(2):615-635.

INE (2001). Parque de Vehículos En Circulación 2001. INE, Santiago.

INE (2015). Parque de Vehículos En Circulación 2015. INE, Santiago.

Knittel, C. R., Miller, D. L., and Sanders, N. J. (2016). Caution, Drivers! Children Present: Traffic, Pollution, and Infant Health. Review of Economics and Statistics, 98(2):350-366.

Lichter, A., Pestel, N., and Sommer, E. (2017). Productivity effects of air pollution: Evidence from professional soccer. Labour Economics, 48:54-66.

Miller, S. and Ruiz-Tagle, J. C. (2019). Ambient air pollution and infant mortality in emerging economies: Evidence from santiago, chile. Unpublished Manuscript.

Morales, R. G. (2006). Contaminación atmosférica urbana: Episodios críticos de contaminación ambiental en la ciudad de Santiago. Editorial Universitaria.

Mullins, J. and Bharadwaj, P. (2015). Effects of Short-Term Measures to Curb Air Pollution: Evidence from Santiago, Chile. American Journal of Agricultural Economics, 97(4):11071134.

Neidell, M. J. (2004). Air pollution, health, and socio-economic status: the effect of outdoor air quality on childhood asthma. Journal of health economics, 23(6):1209-1236. 
OECD (2005). OECD Environmental Performance Reviews: Chile 2005. OECD Publishing.

Ostro, B. D. (1983). The effects of air pollution on work loss and morbidity. Journal of Environmental Economics and Management, 10(4):371-382.

Parada-Contzen, M., Riquelme-Won, A., and Vasquez-Lavin, F. (2013). The value of a statistical life in chile. Empirical Economics, 45(3):1073-1087.

Perez, P. (2008). Air Quality Forecasting in a Large City. WIT Transactions on Ecology and the Environment, 116(116):21-28.

Pérez, P., Trier, A., and Reyes, J. (2000). Prediction of PM 2.5 Concentrations Several Hours in Advance using Neural Networks in Santiago, Chile. Atmospheric Environment, 34(8):1189-1196.

Romero, H., Ihl, M., Rivera, A., Zalazar, P., and Azocar, P. (1999). Rapid urban growth, land-use changes and air pollution in Santiago, Chile. Atmospheric Environment, 33(2425):4039-4047.

Saide, P. E., Carmichael, G. R., Spak, S. N., Gallardo, L., Osses, A. E., Mena-Carrasco, M. A., and Pagowski, M. (2011). Forecasting urban PM10 and PM2.5 pollution episodes in very stable nocturnal conditions and complex terrain using WRF-Chem CO tracer model. Atmospheric Environment, 45(16):2769-2780.

Salas, C. H. (2010). Evaluating Public Policies with High Frequency Data: Evidence for Driving Restrictions in Mexico City Revisited. Documentos de Trabajo (Instituto de Economía PUC), (374):1.

Salini, G. A. (2009). Desarrollo de un modelo para pronosticar concentraciones extremas de $\mathrm{pm}_{2.5}$ en santiago. Universidad de Santiago de Chile, Santiago.

Stafford, T. M. (2015). Indoor air quality and academic performance. Journal of Environmental Economics and Management, 70:34-50.

Stock, J. H., Wright, J. H., and Yogo, M. (2002). A Survey of Weak Instruments and Weak Identification in Generalized Method of Moments. Journal of Business $\&$ Economic Statistics, 20(4):518-529.

Troncoso, R., de Grange, L., and Cifuentes, L. A. (2012). Effects of environmental alerts and pre-emergencies on pollutant concentrations in Santiago, Chile. Atmospheric Environment, 61:550-557. 
United Nations Environment Programme (2002). Global Environment Outlook 3: Past, Present and Future Perspectives. GEO report series. Earthscan.

Viard, V. B. and Fu, S. (2015). The effect of Beijing's driving restrictions on pollution and economic activity. Journal of Public Economics, 125:98-115.

Wolff, H. (2014). Keep your clunker in the suburb: low-emissions zones and adoption of green vehicles. The Economic Journal, 124(578):F481-F512.

World Health Organization (2006). World Health Organization Air Quality Guidelines. Global Update 2005. World Health Organization.

World Health Organization (2014). Ambient (Outdoor) Air Pollution in Cities Database. Data retrieved from the World Health Organization Ambient Air Pollution in Cities Database 2014, http://www.who.int/phe/health_topics/outdoorair/ databases/cities-2014/en/.

Zhang, W., Lawell, C. Y. C. L., and Umanskaya, V. I. (2017). The Effects of License PlateBased Driving Restrictions on Air Quality: Theory and Empirical Evidence. Journal of Environmental Economics and Management, 82:181-220.

Zivin, J. G. and Neidell, M. (2012). The Impact of Pollution on Worker Productivity. The American Economic Review, 102(7):3652-3673. 


\section{Figures and Tables}

Table 1: 2015 Protocols in Environmental Episodes

\begin{tabular}{ll}
\hline \hline Episode & Protocols \\
\hline Baseline & - Permanent driving restrictions on $40 \%$ (weekdays) of dirty vehicles \\
\hline & $\begin{array}{l}\text { - Temporary driving restriction on } 20 \% \text { (weekends) of dirty vehicles } \\
\text { Alert }\end{array}$ \\
& $\begin{array}{l}\text { ing } \\
\end{array}$ \\
\hline
\end{tabular}

- Temporary driving restriction on $60 \%$ (all days) of dirty vehicles

- Temporary driving restriction on 20\% (all days) of clean vehicles

Pre-emergency

- Temporary suspension of stationary emissions sources responsable for $30 \%$ of total stationary emissions of particulate matter. This is equivalent to the shutdown of 750 facilities.

- Elementary and high-school physical education classes and community sports are suspended by the Ministry of Education

- Prohibition in the use of wood and other biomass for residential heating

- Temporary driving restriction on $80 \%$ (all days) of dirty vehicles

- Temporary driving restriction on $40 \%$ (all days) of clean vehicles

Emergency

- Temporary suspension of stationary emissions sources responsable for $50 \%$ of total stationary emissions of particulate matter. This is equivalent to the shutdown of 2,461 facilities.

- Recommendation by the Ministry of Education of classes cancellations in elementary schools and high-schools

- Prohibition in the use of wood and other biomass for residential heating

Notes: Adapted from Mullins and Bharadwaj (2015). 
Figure 1: Hourly Average Pollution by Type of Day

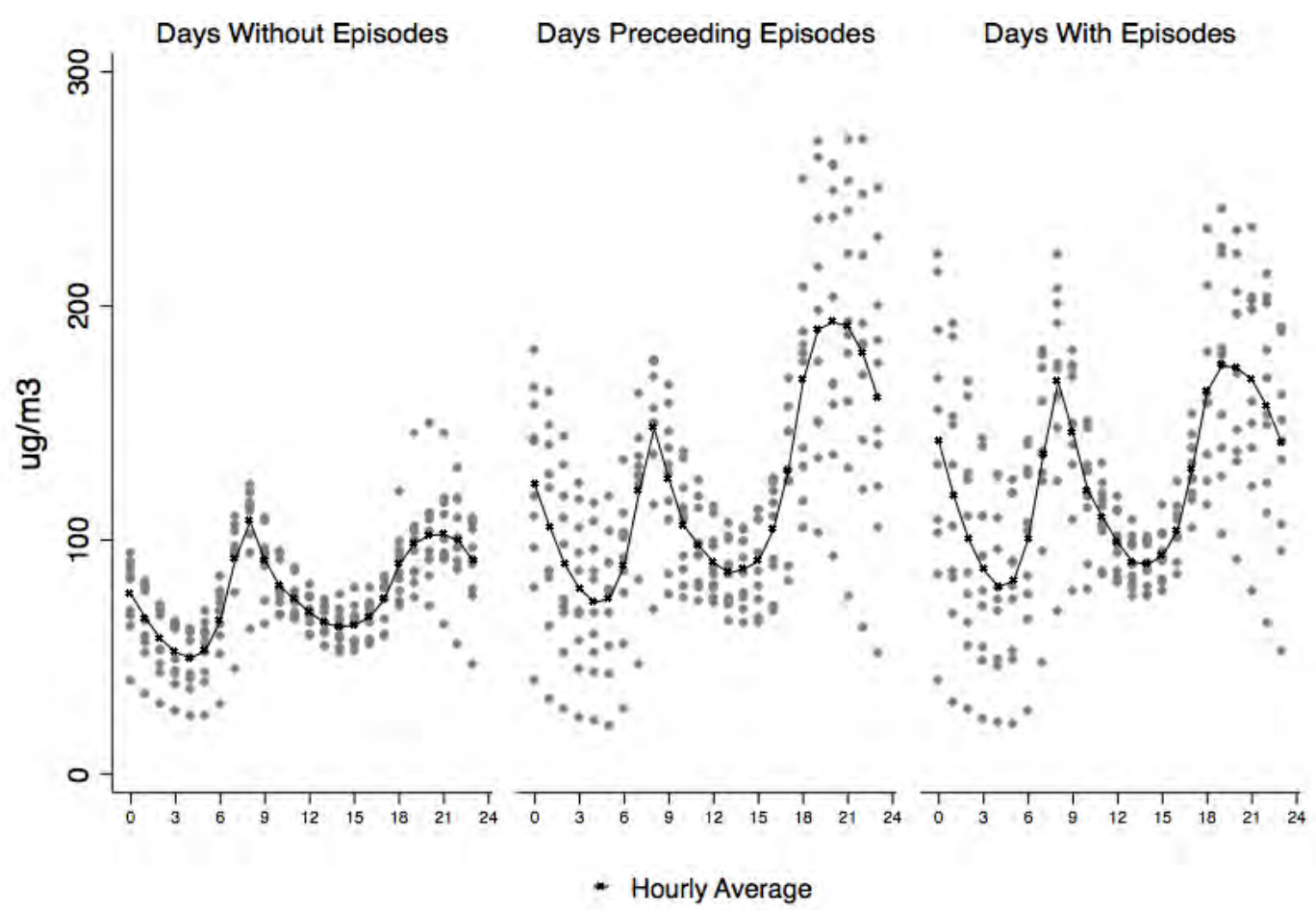

(a) $\mathrm{PM}_{10}$

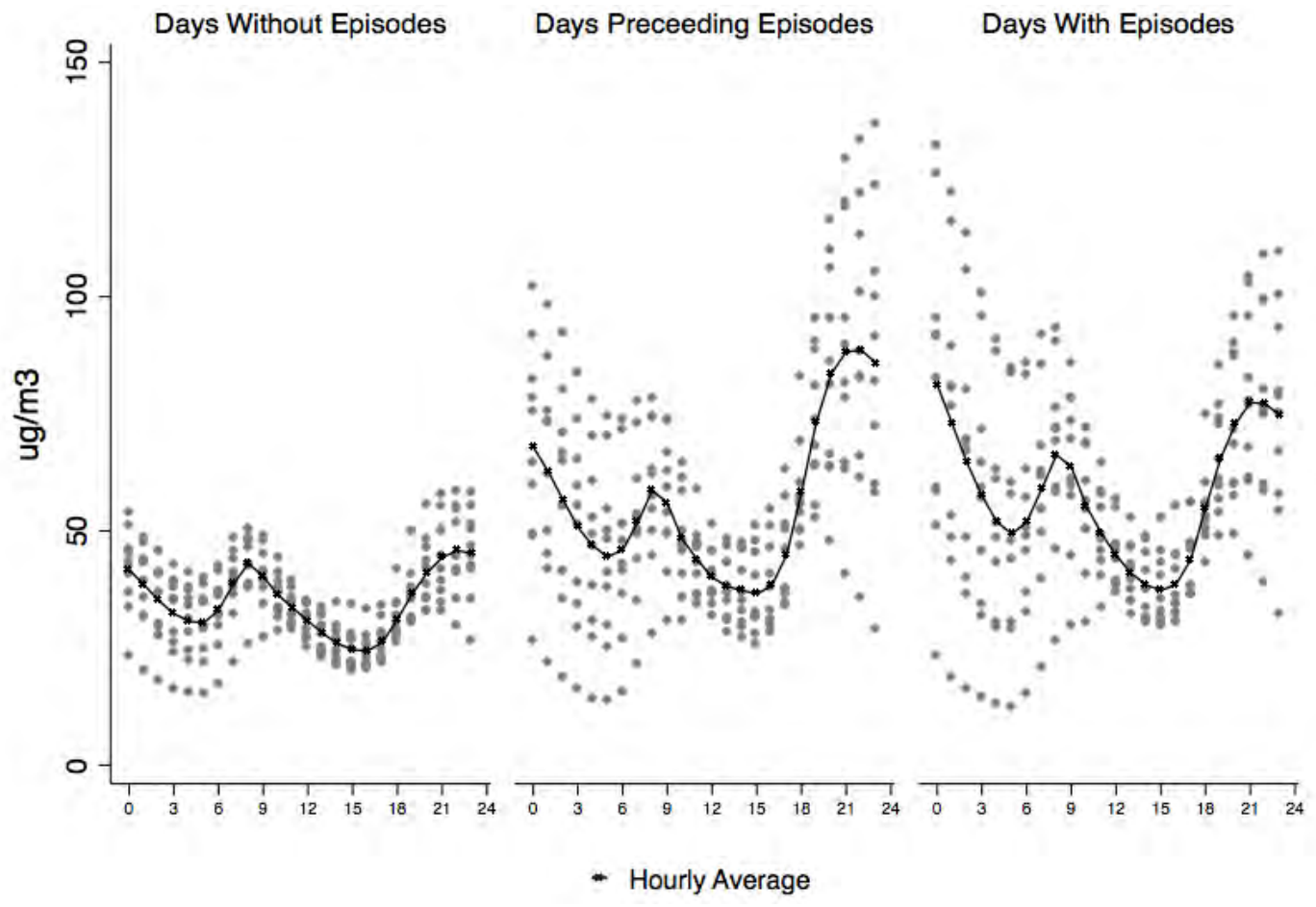

(b) $\mathrm{PM}_{2.5}$ 
Figure 1: Hourly Average Pollution by Type of Day (continued)

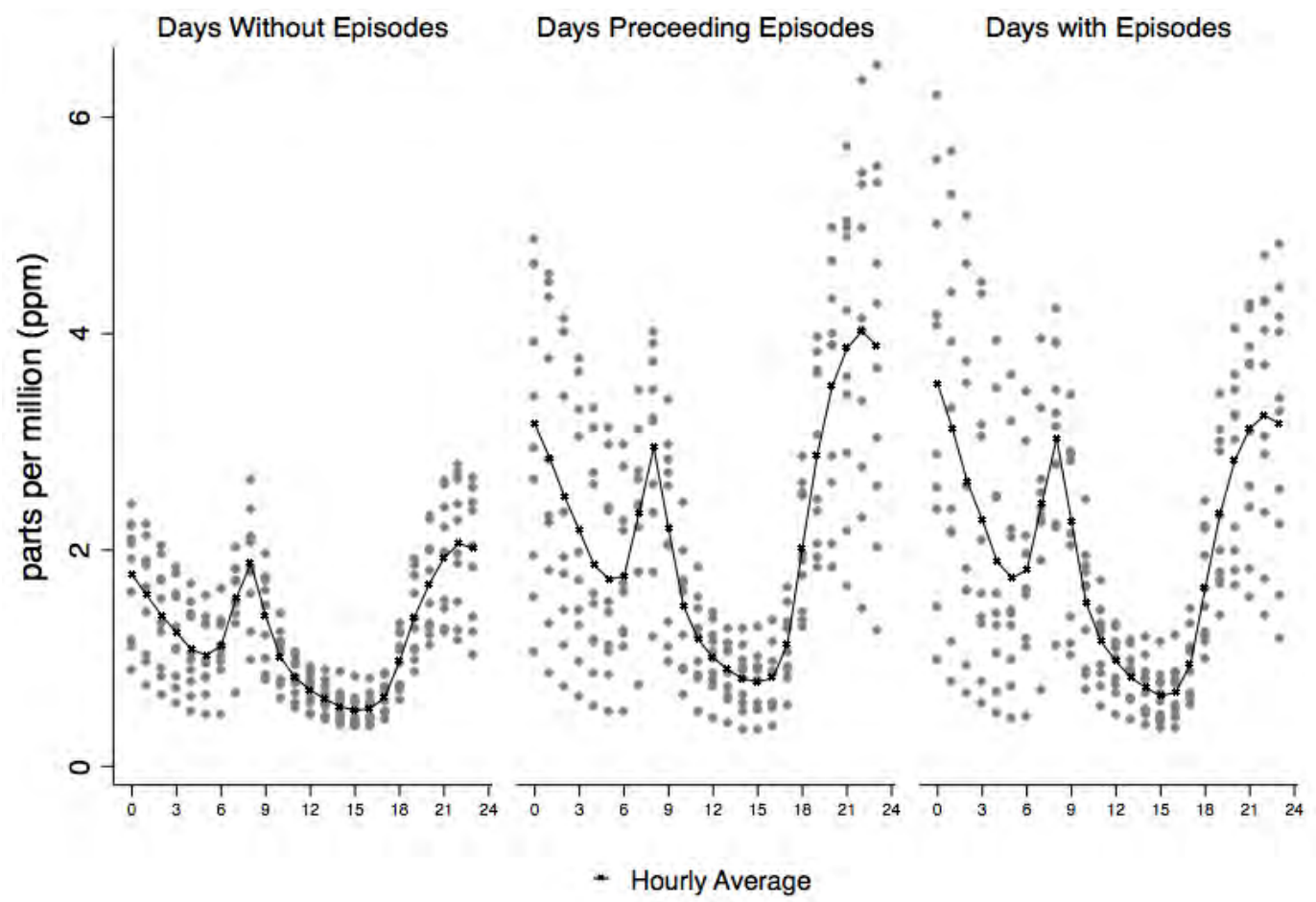

(c) $\mathrm{CO}$

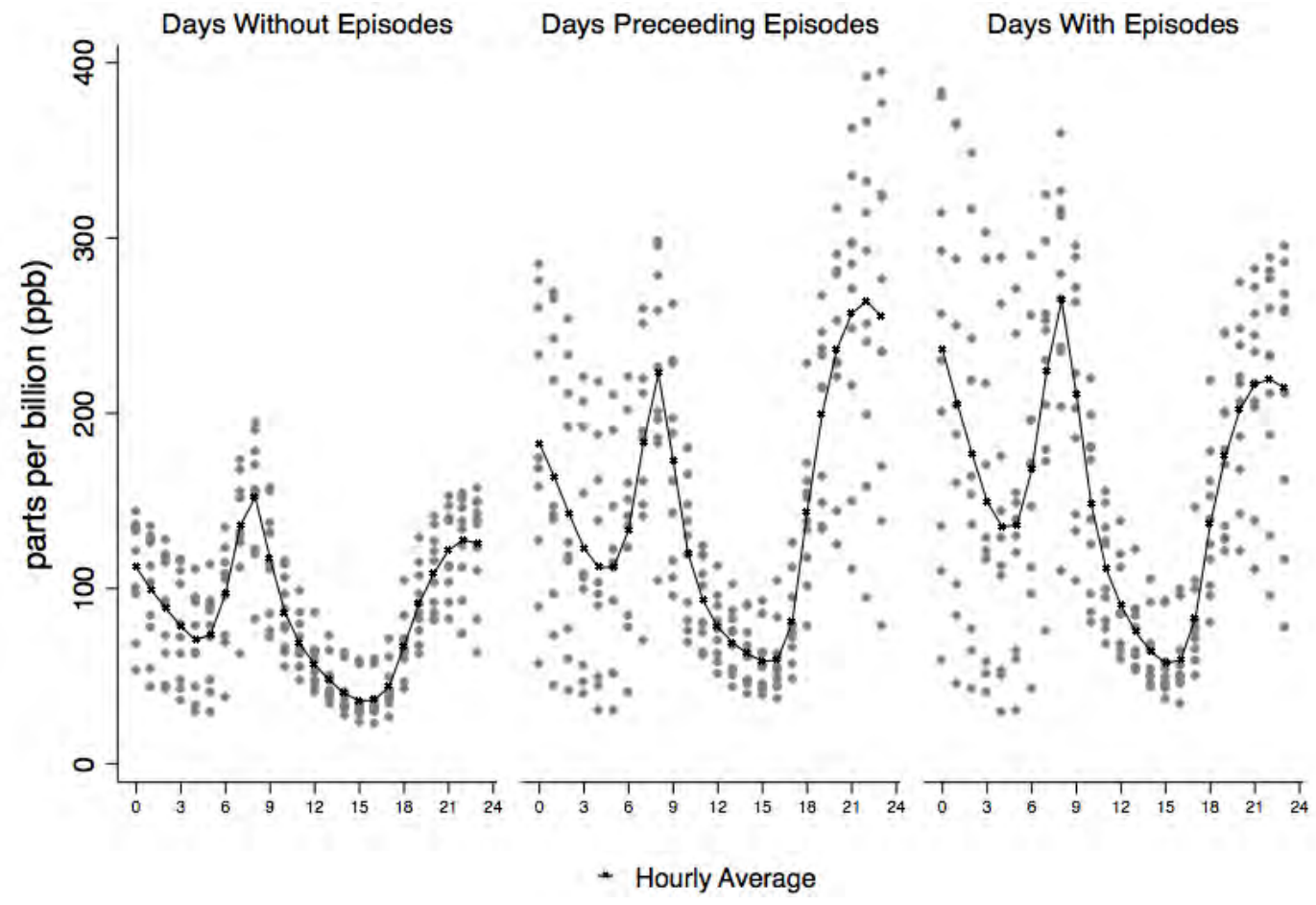

(d) $\mathrm{NO}_{X}$

Notes: Observations are station-hour during winter. Line represents the hourly average across stations. Days with episodes include all three different types of episode. Winter goes from April 1st through August 31st. 
Table 2: Indexes of Air Quality from Particulates (ICAPs)

\begin{tabular}{ccccc}
\hline \hline Values & $\begin{array}{c}\text { 24-hour } \mathrm{PM}_{10} \\
\text { Concentration }\left(\mu \mathrm{g} / \mathrm{m}^{3}\right)\end{array}$ & $\begin{array}{c}\text { 24-hour } \mathrm{PM}_{2.5} \\
\text { Concentration }\left(\mu \mathrm{g} / \mathrm{m}^{3}\right)\end{array}$ & $\begin{array}{c}\text { Air Quality } \\
\text { Condition }\end{array}$ & $\begin{array}{c}\text { Environmental } \\
\text { Episode }\end{array}$ \\
\hline $0-99$ & $\leq 149$ & $\leq 49$ & Good & - \\
$100-199$ & $150-194$ & $50-79$ & Regular & - \\
$200-299$ & $195-239$ & $80-109$ & Bad & Alert \\
$300-399$ & $240-284$ & $110-139$ & Critical & Pre-emergency \\
$400-499$ & $285-329$ & $140-169$ & Dangerous & Pre-emergency \\
+500 & $\geq 330$ & $\geq 170$ & Exceeding & Emergency \\
\hline
\end{tabular}

Notes: Adapted from Morales (2006).

Table 3: Historical Issuance of Environmental Episodes. 2000-2015

\begin{tabular}{ccccc}
\hline \hline \multirow{2}{*}{ Year } & \multicolumn{4}{c}{ Environmental Episodes } \\
\cline { 2 - 5 } & Alerts & Pre-emergencies & Emergencies & Total \\
\hline 2000 & 27 & 11 & 0 & 38 \\
2001 & 21 & 4 & 0 & 25 \\
2002 & 22 & 11 & 0 & 33 \\
2003 & 21 & 5 & 0 & 26 \\
2004 & 13 & 2 & 0 & 15 \\
2005 & 7 & 2 & 0 & 9 \\
2006 & 21 & 3 & 0 & 24 \\
2007 & 27 & 4 & 0 & 31 \\
2008 & 21 & 8 & 0 & 29 \\
2009 & 23 & 0 & 0 & 23 \\
2010 & 7 & 2 & 0 & 9 \\
2011 & 19 & 7 & 0 & 26 \\
2012 & 23 & 2 & 0 & 25 \\
2013 & 6 & 0 & 0 & 6 \\
2014 & 22 & 1 & 0 & 23 \\
2015 & 38 & 16 & 1 & 55 \\
\hline Total & 318 & 78 & 1 & 397 \\
\hline
\end{tabular}

Notes: Data from the Unidad Operativa de Control de Tránsito (UOCT). 
Table 4: Descriptive Statistics on Pollution and Weather Variables.

\begin{tabular}{lrrrrrr}
\hline \hline Variables & Obs. & Mean & Std. Dev. & Min & Max & Years \\
\hline Panel A: Pollutants & & & & & & \\
$\mathrm{PM}_{10}$ & 467,012 & 85.04 & 65.38 & 0 & 945 & $2000-2015$ \\
$\mathrm{PM}_{2.5}$ & 401,296 & 40.22 & 31.08 & 0 & 645 & $2000-2015$ \\
$\mathrm{CO}$ & 513,765 & 1.39 & 1.57 & 0 & 47.25 & $2000-2015$ \\
$\mathrm{NO}_{X}$ & 347,622 & 100.89 & 103.69 & 0 & 1,374 & $2000-2015$ \\
& & & & & & \\
Panel B: Weather Variables & & & & & & \\
Humidity (\%) & 400,265 & 65.94 & 21.53 & 0 & 105 & $2003-2015$ \\
Wind Speed $(\mathrm{m} / \mathrm{s})$ & 401,719 & 1.07 & 0.79 & 0 & 17.3 & $2003-2015$ \\
Temperature $\left({ }^{\circ} \mathrm{C}\right)$ & 412,885 & 11.65 & 6.29 & -33.22 & 39.77 & $2003-2015$ \\
Thermal Oscillation $\left({ }^{\circ} \mathrm{C}\right)$ & 1,884 & 11.27 & 4.84 & 1.42 & 24.85 & $2003-2015$ \\
Precipitation (mm) & 2,448 & 1.69 & 6.58 & 0 & 118.74 & $2003-2015$ \\
\hline
\end{tabular}

Notes: Using winter only. Panel A: Observations are station-hour. Particulate matter is in micrograms per cubic meter, $\mathrm{CO}$ is in parts per millions, and $\mathrm{NO}_{X}$ is in parts per billions. Panel B: Observations are station-hour for humidity, wind speed, and temperature; and days for thermal oscillation and precipitation. 
Table 5: Pollution Concentrations During Days with Episodes

\begin{tabular}{llrr}
\hline \hline Pollutant & Type of Episode & 24-Hour Average & 24-Hour Maximum \\
\hline \multirow{3}{*}{$\mathrm{PM}_{10}$} & Without Episodes & 78.7 & 149.5 \\
\cline { 2 - 4 } & Alerts & 120.3 & 216.1 \\
& Pre-emergencies & 129.9 & 228.3 \\
& Emergencies & 148.1 & 238.1 \\
\hline \multirow{3}{*}{$\mathrm{PM}_{2.5}$} & Without Episodes & 38.1 & 68.7 \\
\cline { 2 - 4 } & Alerts & 57.3 & 98.0 \\
& Pre-emergencies & 62.4 & 108.6 \\
& Emergencies & 79.9 & 92.8 \\
\hline \multirow{3}{*}{$\mathrm{CO}^{*}$} & Without Episodes & 1.29 & 3.03 \\
\cline { 2 - 4 } & Alerts & 2.08 & 4.61 \\
& Pre-emergencies & 2.34 & 5.33 \\
& Emergencies & 2.15 & 4.59 \\
\hline \multirow{2}{*}{$\mathrm{NO}_{X}$} & Without Episodes & 90.5 & 210.5 \\
\cline { 2 - 4 } & Alerts & 151.2 & 327.4 \\
& Pre-emergencies & 159.1 & 347.7 \\
\hline
\end{tabular}

Notes: Data from the UOCT and SINCA. Particulate matter is in micrograms per cubic meter, CO is in parts per millions, and $\mathrm{NO}_{X}$ is in parts per billions. 
Table 6: Descriptive Statistics on Urban Traffic Flows

\begin{tabular}{lrrrrrr}
\hline \hline Trips & Obs. & Mean & Std. Dev. & Min & Max & Years \\
\hline Vehicles & $1,442,526$ & 688.79 & 697.55 & 0 & 4,635 & $2004-2015$ \\
Metro & 48,960 & $66,011.11$ & $58,768.99$ & 0 & 282,664 & $2000-2015$ \\
Transantiago & 1,377 & $2,974,280.00$ & $956,229.10$ & 688,569 & $4,468,663$ & $2007-2015$ \\
\hline
\end{tabular}

Notes: Using winter only. Observations are station-hours for vehicle flows; hours for metro ridership; and days for Transantiago trips.

Table 7: Urban Flows During Episodes

\begin{tabular}{|c|c|c|c|}
\hline Urban Flow & Type of Episode & 24-Hour Average & 24-Hour Maximum \\
\hline \multirow{4}{*}{ Vehicle Trips } & Without Episodes & 682 & 2,946 \\
\hline & Alerts & 680 & 2,863 \\
\hline & Pre-emergencies & 651 & 2,674 \\
\hline & Emergencies & 618 & 2,516 \\
\hline \multirow{4}{*}{ Metro Trips } & Without Episodes & 65,662 & 133,099 \\
\hline & Alerts & 69,113 & 139,633 \\
\hline & Pre-emergencies & 61,846 & 124,843 \\
\hline & Emergencies & 120,603 & 265,590 \\
\hline \multirow{4}{*}{ Transantiago Trips } & Without Episodes & 123,919 & 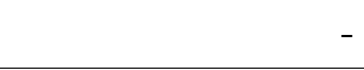 \\
\hline & Alerts & 125,262 & - \\
\hline & Pre-emergencies & 117,648 & . \\
\hline & Emergencies & 137,549 & - \\
\hline
\end{tabular}

Notes: 24-hour average vehicle trips are obtained by averaging across stations and hours. 24-hour averages for buses are obtained by dividing daily totals in 24 . 
Figure 2: Daily Maximum $\mathrm{ICAP}_{10}$ and $\mathrm{ICAP}_{2.5}$ during Winter 2015

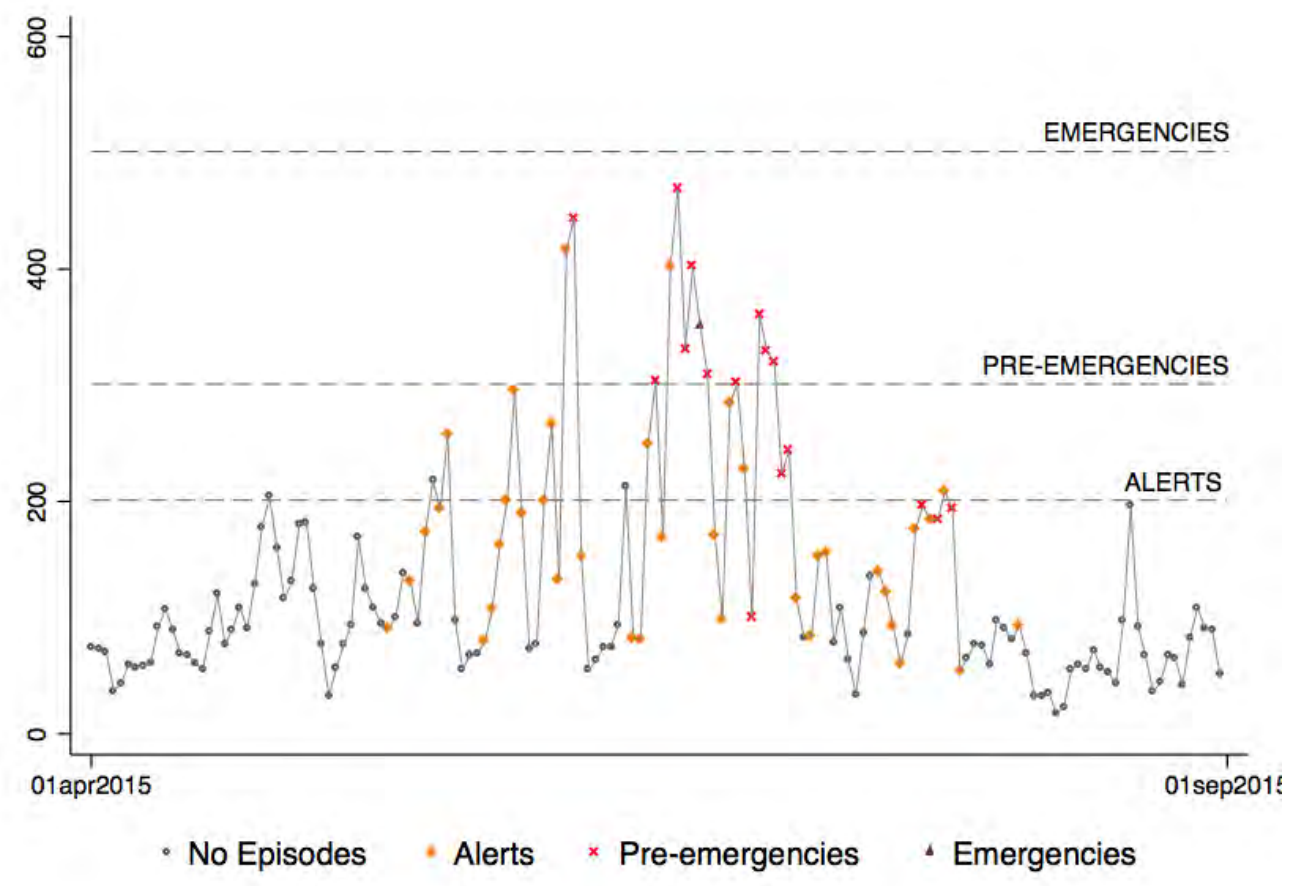

(a) ICAP based on $\mathrm{PM}_{10}$

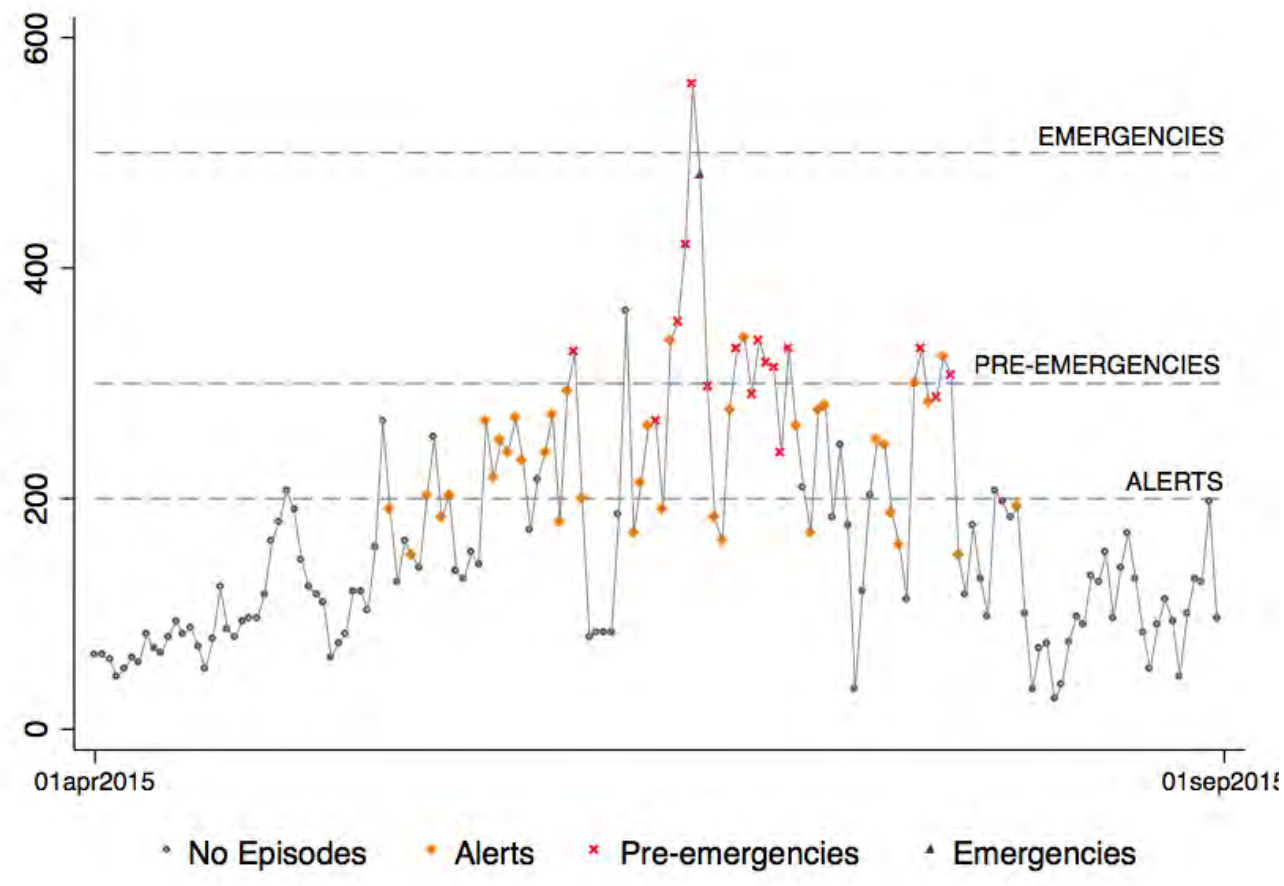

(b) ICAP based on $\mathrm{PM}_{2.5}$

Notes: Using daily maximum ICAP. 
Figure 3: Discontinuity Plot on Hourly Average Vehicle Trips

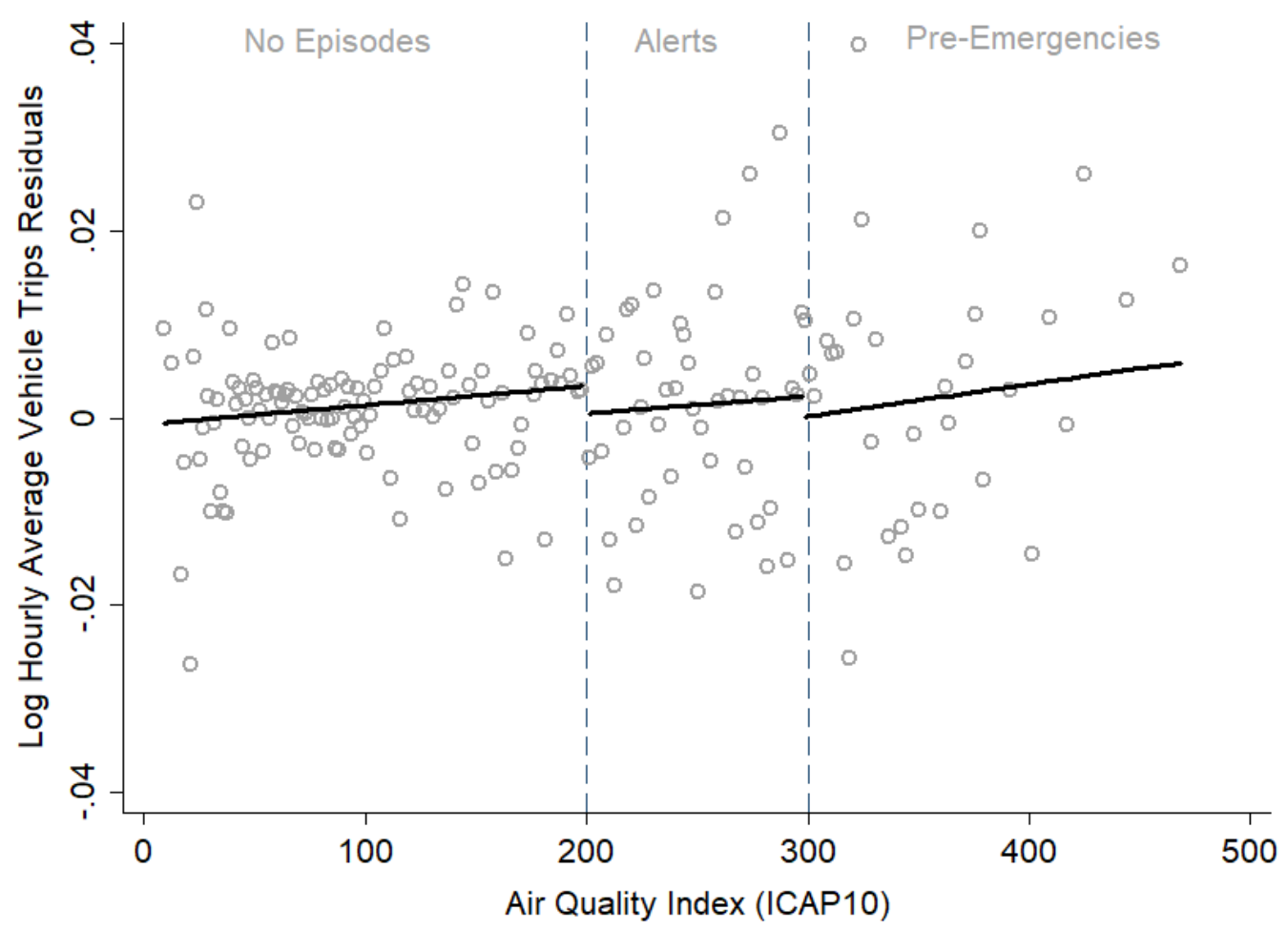

Notes: Linear fit during winter days using $\operatorname{ICAP}_{10, t-1}$ as the running variable. The outcome variable are residuals from the regressions of hourly average vehicle trips (in logs) on weather variables (current and 24-hour lags of quartics in precipitation, humidity, temperature, wind speed, and thermal oscillation), and year, month, dow, and hour $\times$ weekend fixed effects. The linear fit uses binned sample means at each side of the cutoffs following the mimicking variance evenly-spaced method using spacing estimators (see Calonico et al. (2015a) for more details). 


\section{Figure 4: Discontinuity Plot on Hourly Average Pollution Concentrations}

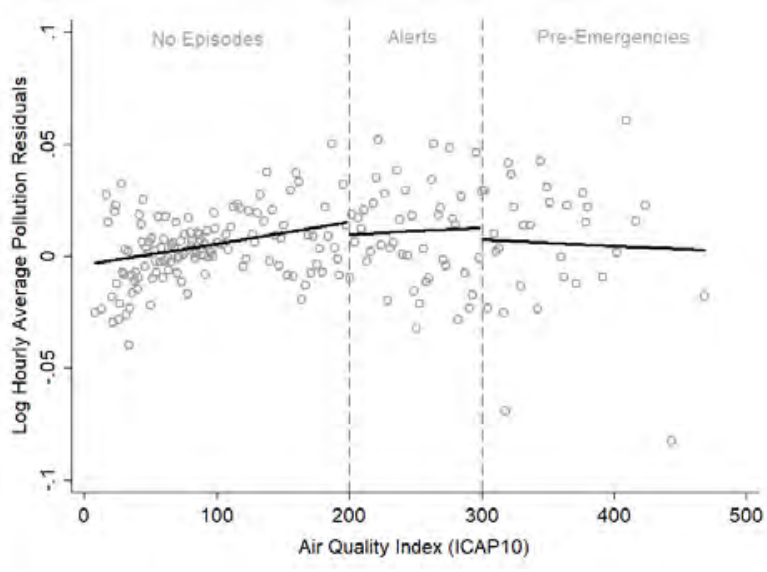

(a) $\mathrm{PM}_{10}$

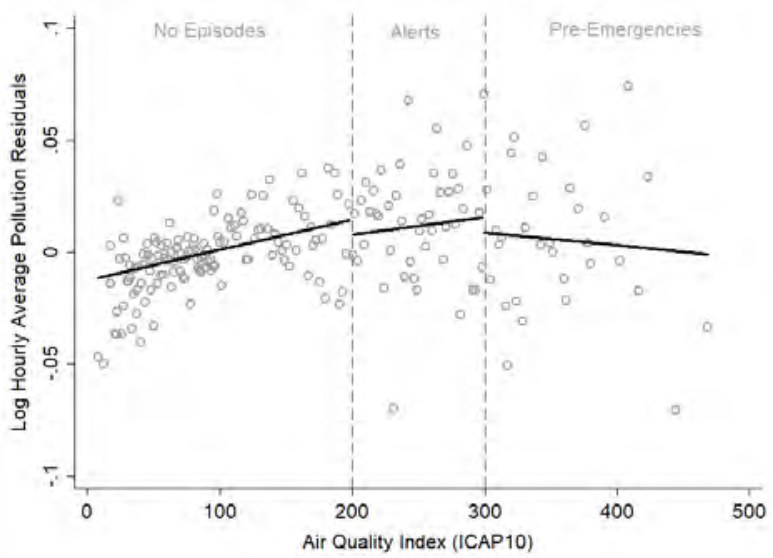

(c) $\mathrm{CO}$

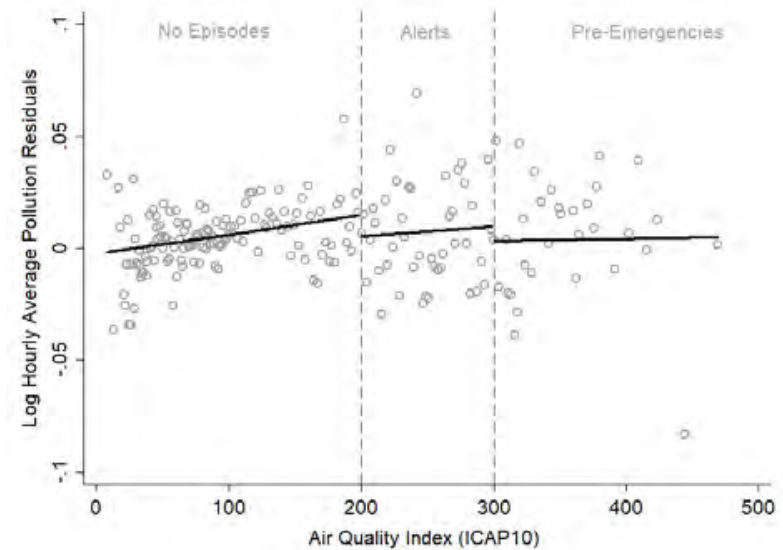

(b) $\mathrm{PM}_{25}$

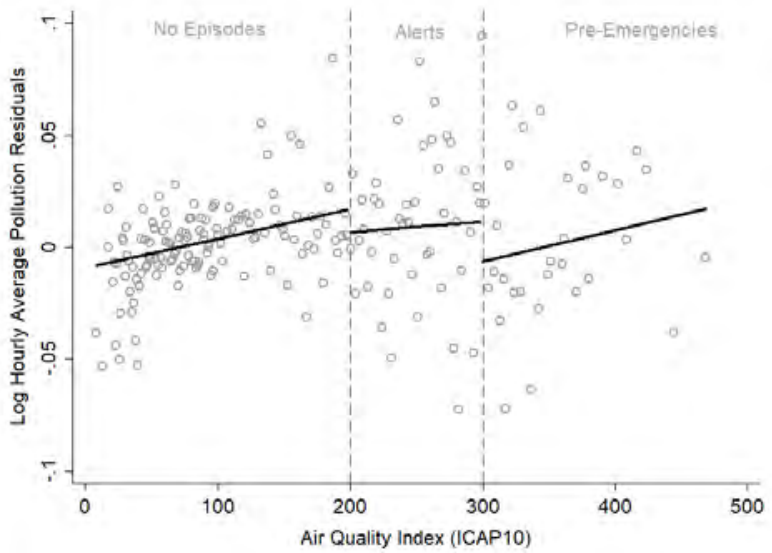

(d) $\mathrm{NO}_{X}$

Notes: Linear fit during winter days using $\operatorname{ICAP}_{10, t-1}$ as the running variable. Outcome variables are residuals from the regressions of hourly average pollution (in logs) on weather variables (current and 24-hour lags of quartics in precipitation, humidity, temperature, wind speed, and thermal oscillation), and year, month, dow, and hour $\times$ weekend fixed effects. All estimations include 12-hour lags of pollution. The linear fit uses binned sample means at each side of the cutoffs following the mimicking variance evenly-spaced method using spacing estimators (see Calonico et al. (2015a) for more details). 
Table 8: Episodes Impact on Hourly Average Vehicle Trips

\begin{tabular}{|c|c|c|c|c|c|c|c|c|c|}
\hline \multirow{2}{*}{ Episode/Bandwidth } & \multicolumn{3}{|c|}{ Peak Hours } & \multicolumn{3}{|c|}{ Early Off-Peak Hours } & \multicolumn{3}{|c|}{ Late Off-Peak Hours } \\
\hline & $k=50$ & $k=25$ & Optimal & $k=50$ & $k=25$ & Optimal & $k=50$ & $k=25$ & Optimal \\
\hline 1[Episode] & $\begin{array}{c}-0.098^{* * *} \\
(0.016)\end{array}$ & $\begin{array}{c}-0.061^{* * *} \\
(0.017)\end{array}$ & $\begin{array}{c}-0.093^{* * *} \\
(0.017)\end{array}$ & $\begin{array}{l}-0.026 \\
(0.037)\end{array}$ & $\begin{array}{l}-0.032 \\
(0.044)\end{array}$ & $\begin{array}{c}-0.084^{* *} \\
(0.043)\end{array}$ & $\begin{array}{c}-0.082^{* *} \\
(0.026)\end{array}$ & $\begin{array}{c}-0.082^{* *} \\
(0.028)\end{array}$ & $\begin{array}{c}-0.078^{* *} \\
(0.028)\end{array}$ \\
\hline $\mathrm{N}$ & 4,897 & 2,610 & 3,398 & 5,119 & 2,728 & 3,552 & 5,119 & 2,728 & 3,552 \\
\hline
\end{tabular}

Notes: Local linear GMM-IV estimations of the residuals from the (full) regressions of hourly average vehicle trips (in logs) using $\operatorname{ICAP}_{10, t-1}$ as the running variable and $\operatorname{ICAP}_{2.5, t-1}$ as an additional instrument. All regressions include current and 24-hour lags of quartics in humidity, temperature, wind speed, precipitation, and thermal oscillation, and dummies for year, month, dow, and hour $\times$ weekend. Optimal bandwidth estimated using a common MSE-optimal bandwidth selector based on Calonico et al. (2014), Calonico et al. (2017), and Calonico et al. (2018a). Standard errors robust to heteroskedasticity and to 2-hour serial correlation in parentheses. Significance levels: ${ }^{*} p<0.10,{ }^{* *} p<0.05,{ }^{* * *} p<0.001$.

Table 9: Episodes Impact on Hourly Average Pollution

\begin{tabular}{|c|c|c|c|c|c|c|c|c|c|}
\hline \multirow{2}{*}{ Episode/Bandwidth } & \multicolumn{3}{|c|}{ Peak Hours } & \multicolumn{3}{|c|}{ Early Off-Peak Hours } & \multicolumn{3}{|c|}{ Late Off-Peak Hours } \\
\hline & $k=50$ & $k=25$ & Optimal & $k=50$ & $k=25$ & Optimal & $k=50$ & $k=25$ & Optimal \\
\hline \multicolumn{10}{|l|}{ Panel a) $\mathrm{PM}_{10}$ : } \\
\hline 1[Episode] & $\begin{array}{c}-0.014^{* *} \\
(0.005)\end{array}$ & $\begin{array}{c}-0.018^{* * *} \\
(0.005)\end{array}$ & $\begin{array}{c}-0.014^{* *} \\
(0.005)\end{array}$ & $\begin{array}{c}-0.064^{* * *} \\
(0.012)\end{array}$ & $\begin{array}{c}-0.059^{* * *} \\
(0.013)\end{array}$ & $\begin{array}{c}-0.096^{* * *} \\
(0.013)\end{array}$ & $\begin{array}{c}0.015 \\
(0.010)\end{array}$ & $\begin{array}{c}0.020 \\
(0.012)\end{array}$ & $\begin{array}{c}0.015 \\
(0.010)\end{array}$ \\
\hline $\mathrm{N}$ & 5,227 & 2,770 & 12,323 & 5,454 & 2,890 & 12,858 & 5,454 & 2,890 & 12,858 \\
\hline \multicolumn{10}{|l|}{ Panel b) $\mathrm{PM}_{25}$ : } \\
\hline $1[$ Episode] & $\begin{array}{c}-0.008^{*} \\
(0.005)\end{array}$ & $\begin{array}{l}-0.008^{*} \\
(0.005)\end{array}$ & $\begin{array}{l}-0.002 \\
(0.005)\end{array}$ & $\begin{array}{c}-0.028^{* *} \\
(0.010)\end{array}$ & $\begin{array}{c}-0.050^{* * *} \\
(0.011)\end{array}$ & $\begin{array}{c}-0.047^{* * *} \\
(0.012)\end{array}$ & $\begin{array}{l}0.020^{* *} \\
(0.009)\end{array}$ & $\begin{array}{c}0.038^{* * *} \\
(0.011)\end{array}$ & $\begin{array}{c}0.014 \\
(0.009)\end{array}$ \\
\hline $\mathrm{N}$ & 5,227 & 2,770 & 15,139 & 5,454 & 2,890 & 15,796 & 5,454 & 2,890 & 15,796 \\
\hline \multicolumn{10}{|l|}{ Panel c) CO: } \\
\hline 1[Episode] & $\begin{array}{c}-0.015^{* *} \\
(0.005)\end{array}$ & $\begin{array}{c}-0.014^{* *} \\
(0.006)\end{array}$ & $\begin{array}{l}-0.008 \\
(0.005)\end{array}$ & $\begin{array}{c}-0.052^{* * *} \\
(0.014)\end{array}$ & $\begin{array}{c}-0.045^{* * *} \\
(0.013)\end{array}$ & $\begin{array}{c}-0.068^{* * *} \\
(0.013)\end{array}$ & $\begin{array}{c}0.002 \\
(0.011)\end{array}$ & $\begin{array}{c}0.008 \\
(0.013)\end{array}$ & $\begin{array}{c}0.011 \\
(0.011)\end{array}$ \\
\hline $\mathrm{N}$ & 5,227 & 2,770 & 9,873 & 5,454 & 2,890 & 10,302 & 5,454 & 2,890 & 10,302 \\
\hline \multicolumn{10}{|l|}{ Panel d) $\mathrm{NO}_{X}$ : } \\
\hline 1[Episode] & $\begin{array}{l}-0.005 \\
(0.006)\end{array}$ & $\begin{array}{l}-0.009 \\
(0.007)\end{array}$ & $\begin{array}{c}0.009 \\
(0.006)\end{array}$ & $\begin{array}{c}-0.052^{* * *} \\
(0.014)\end{array}$ & $\begin{array}{c}-0.045^{* * *} \\
(0.013)\end{array}$ & $\begin{array}{c}-0.116^{* * *} \\
(0.017)\end{array}$ & $\begin{array}{l}-0.006 \\
(0.015)\end{array}$ & $\begin{array}{c}-0.009 \\
(0.018)\end{array}$ & $\begin{array}{c}0.005 \\
(0.013)\end{array}$ \\
\hline $\mathrm{N}$ & 5,227 & 2,770 & 9,528 & 5,454 & 2,890 & 9,942 & 5,454 & 2,890 & 9,942 \\
\hline
\end{tabular}

Notes: Local linear GMM-IV estimations of the residuals from the (full) regressions of hourly average pollution concentrations (in logs) using $\operatorname{ICAP}_{10, t-1}$ as the running variable and $\operatorname{ICAP}_{2.5, t-1}$ as an additional instrument. All estimations include 12-hour lags of pollution. Weather variables include current and 24-hour lags of quartics in humidity, temperature, wind speed, precipitation, and thermal oscillation, and dummies for year, month, dow, and hour $\times$ weekend. Optimal bandwidth estimated using a common MSE-optimal bandwidth selector based on Calonico et al. (2014), Calonico et al. (2017), and Calonico et al. (2018a). Standard errors robust to heteroskedasticity and to 24 -hour serial correlation in parentheses. Significance levels: ${ }^{*} p<0.10,{ }^{* *} p<0.05$, ${ }^{* * *} p<0.001$. 
Table 10: Alerts and Pre-emergencies Impact on Hourly Vehicle Trips

\begin{tabular}{|c|c|c|c|c|c|c|c|c|c|}
\hline \multirow{2}{*}{ Episode/Bandwidth } & \multicolumn{3}{|c|}{ Peak Hours } & \multicolumn{3}{|c|}{ Early Off-Peak Hours } & \multicolumn{3}{|c|}{ Late Off-Peak Hours } \\
\hline & $k=50$ & $k=25$ & Optimal & $k=50$ & $k=25$ & Optimal & $k=50$ & $k=25$ & Optimal \\
\hline 1 [Alerts] & $\begin{array}{c}-0.056^{* * *} \\
(0.014)\end{array}$ & $\begin{array}{c}-0.027^{* *} \\
(0.013)\end{array}$ & $\begin{array}{c}0.005 \\
(0.014)\end{array}$ & $\begin{array}{c}0.042 \\
(0.032)\end{array}$ & $\begin{array}{c}0.009 \\
(0.033)\end{array}$ & $\begin{array}{c}0.003 \\
(0.038)\end{array}$ & $\begin{array}{c}-0.055^{* *} \\
(0.022)\end{array}$ & $\begin{array}{c}-0.047^{* *} \\
(0.023)\end{array}$ & $\begin{array}{l}-0.026 \\
(0.024)\end{array}$ \\
\hline $\mathrm{N}$ & 4,897 & 2,610 & 1,564 & 5,119 & 2,728 & 1,634 & 5,119 & 2,728 & 1,634 \\
\hline $1[$ Pre-emergencies] & $\begin{array}{c}-0.052^{* *} \\
(0.022)\end{array}$ & $\begin{array}{c}-0.099^{* * *} \\
(0.022)\end{array}$ & $\begin{array}{c}-0.145^{* * *} \\
(0.012)\end{array}$ & $\begin{array}{l}-0.035 \\
(0.059)\end{array}$ & $\begin{array}{l}-0.014 \\
(0.067)\end{array}$ & $\begin{array}{c}-0.075^{*} \\
(0.039)\end{array}$ & $\begin{array}{l}-0.015 \\
(0.045)\end{array}$ & $\begin{array}{l}-0.011 \\
(0.042)\end{array}$ & $\begin{array}{c}0.002 \\
(0.042)\end{array}$ \\
\hline $\mathrm{N}$ & 1,917 & 945 & 352 & 2,003 & 988 & 368 & 2,003 & 988 & 368 \\
\hline
\end{tabular}

Notes: Local linear GMM-IV estimations of the residuals from the (full) regressions of hourly average vehicle trips (in logs) using $\operatorname{ICAP}_{10, t-1}$ as the running variable and $\mathrm{ICAP}_{2.5, t-1}$ as an additional instrument. All regressions include current and 24-hour lags of quartics in humidity, temperature, wind speed, precipitation, and thermal oscillation, and dummies for year, month, dow, and hour $\times$ weekend. Optimal bandwidth estimated using a common MSE-optimal bandwidth selector based on Calonico et al. (2014), Calonico et al. (2017), and Calonico et al. (2018a). Standard errors robust to heteroskedasticity and to 2-hour serial correlation in parentheses. Significance levels: ${ }^{*} p<0.10,{ }^{* *} p<0.05,{ }^{* * *} p<0.001$. 
Table 11: Alerts and Pre-emergencies Impact on Hourly Pollution

\begin{tabular}{|c|c|c|c|c|c|c|c|c|c|}
\hline \multirow{2}{*}{ Episode/Bandwidth } & \multicolumn{3}{|c|}{ Peak Hours } & \multicolumn{3}{|c|}{ Early Off-Peak Hours } & \multicolumn{3}{|c|}{ Late Off-Peak Hours } \\
\hline & $k=50$ & $k=25$ & Optimal & $k=50$ & $k=25$ & Optimal & $k=50$ & $k=25$ & Optimal \\
\hline \multicolumn{10}{|l|}{ Panel a) $\mathrm{PM}_{10}$ : } \\
\hline 1 [Alerts] & $\begin{array}{c}-0.014^{* *} \\
(0.006)\end{array}$ & $\begin{array}{c}-0.019^{* *} \\
(0.006)\end{array}$ & $\begin{array}{c}-0.023^{* * *} \\
(0.006)\end{array}$ & $\begin{array}{c}-0.076^{* * *} \\
(0.014)\end{array}$ & $\begin{array}{c}-0.067^{* * *} \\
(0.014)\end{array}$ & $\begin{array}{c}-0.073^{* * *} \\
(0.016)\end{array}$ & $\begin{array}{l}0.020^{*} \\
(0.012)\end{array}$ & $\begin{array}{c}0.021 \\
(0.014)\end{array}$ & $\begin{array}{l}0.029^{* *} \\
(0.014)\end{array}$ \\
\hline $\mathrm{N}$ & 5,227 & 2,770 & 3,341 & 5,454 & 2,890 & 3,486 & 5,454 & 2,890 & 3,486 \\
\hline 1 [Pre-emergencies] & $\begin{array}{l}0.016^{*} \\
(0.009)\end{array}$ & $\begin{array}{c}0.003 \\
(0.006)\end{array}$ & $\begin{array}{c}0.003 \\
(0.006)\end{array}$ & $\begin{array}{c}-0.108^{* * *} \\
(0.025)\end{array}$ & $\begin{array}{c}-0.101^{* * *} \\
(0.015)\end{array}$ & $\begin{array}{c}-0.101^{* * *} \\
(0.015)\end{array}$ & $\begin{array}{l}0.048^{* *} \\
(0.023)\end{array}$ & $\begin{array}{c}0.003 \\
(0.017)\end{array}$ & $\begin{array}{c}0.003 \\
(0.017)\end{array}$ \\
\hline $\mathrm{N}$ & 2,013 & 989 & 989 & 2,100 & 1,032 & 1,032 & 2,100 & 1,032 & 1032 \\
\hline \multicolumn{10}{|l|}{ Panel b) $\mathrm{PM}_{25}$ : } \\
\hline 1 [Alerts] & -0.009 & $-0.011^{*}$ & $-0.016^{* *}$ & $-0.035^{* *}$ & $-0.065^{* * *}$ & $-0.059^{* * *}$ & $0.022^{* *}$ & $0.037^{* *}$ & $0.029^{* *}$ \\
\hline $\mathrm{N}$ & $\begin{array}{c}5,227 \\
(0.006)\end{array}$ & $\begin{array}{c}2,770 \\
(0.006)\end{array}$ & $\begin{array}{c}3,433 \\
(0.006)\end{array}$ & $\begin{array}{c}5,454 \\
(0.012)\end{array}$ & $\begin{array}{c}2,890 \\
(0.012)\end{array}$ & $\begin{array}{c}3,582 \\
(0.013)\end{array}$ & $\begin{array}{c}5,454 \\
(0.011)\end{array}$ & $\begin{array}{c}2,890 \\
(0.012)\end{array}$ & $\begin{array}{c}3,582 \\
(0.012)\end{array}$ \\
\hline 1[Pre-emergencies] & $\begin{array}{c}0.007 \\
(0.009)\end{array}$ & $\begin{array}{c}-0.0004 \\
(0.006)\end{array}$ & $\begin{array}{c}-0.0004 \\
(0.006)\end{array}$ & $\begin{array}{c}-0.103^{* * *} \\
(0.025)\end{array}$ & $\begin{array}{c}-0.076^{* * *} \\
(0.015)\end{array}$ & $\begin{array}{c}-0.076^{* * *} \\
(0.015)\end{array}$ & $\begin{array}{c}0.032 \\
(0.021)\end{array}$ & $\begin{array}{c}-0.016 \\
(0.013)\end{array}$ & $\begin{array}{l}-0.016 \\
(0.013)\end{array}$ \\
\hline $\mathrm{N}$ & 2,013 & 989 & 989 & 2,100 & 1,032 & 1,032 & 2,100 & 1,032 & 1,032 \\
\hline \multicolumn{10}{|l|}{ Panel c) CO: } \\
\hline 1 [Alerts] & $\begin{array}{c}-0.015^{* *} \\
(0.006)\end{array}$ & $\begin{array}{l}-0.013^{*} \\
(0.007)\end{array}$ & $\begin{array}{c}-0.018^{* *} \\
(0.006)\end{array}$ & $\begin{array}{c}-0.061^{* * *} \\
(0.016)\end{array}$ & $\begin{array}{c}-0.053^{* * *} \\
(0.014)\end{array}$ & $\begin{array}{c}-0.050^{* * *} \\
(0.014)\end{array}$ & $\begin{array}{c}0.004 \\
(0.013)\end{array}$ & $\begin{array}{c}0.008 \\
(0.015)\end{array}$ & $\begin{array}{c}0.011 \\
(0.014)\end{array}$ \\
\hline $\mathrm{N}$ & 5,227 & 2,770 & 2,467 & 5,454 & 2,890 & 2,574 & 5,454 & 2,890 & 2,574 \\
\hline $1[$ Pre-emergencies $]$ & $\begin{array}{c}0.031^{* * *} \\
(0.00829)\end{array}$ & $\begin{array}{c}0.006 \\
(0.006)\end{array}$ & $\begin{array}{c}0.009 \\
(0.006)\end{array}$ & $\begin{array}{c}-0.062^{* *} \\
(0.021)\end{array}$ & $\begin{array}{c}-0.041^{* *} \\
(0.013)\end{array}$ & $\begin{array}{c}-0.046^{* * *} \\
(0.014)\end{array}$ & $\begin{array}{l}0.060^{* *} \\
(0.022)\end{array}$ & $\begin{array}{c}0.074^{* * *} \\
(0.017)\end{array}$ & $\begin{array}{l}0.055^{* *} \\
(0.017)\end{array}$ \\
\hline $\mathrm{N}$ & 2,013 & 989 & 1,104 & 2,100 & 1,032 & 1,152 & 2,100 & 1,032 & 1,152 \\
\hline \multicolumn{10}{|l|}{ Panel d) $\mathrm{NO}_{X}$ : } \\
\hline 1 [Alerts] & $\begin{array}{l}-0.008 \\
(0.007)\end{array}$ & $\begin{array}{c}-0.009 \\
(0.008)\end{array}$ & $\begin{array}{l}-0.012 \\
(0.008)\end{array}$ & $\begin{array}{c}-0.110^{* * *} \\
(0.020)\end{array}$ & $\begin{array}{c}-0.085^{* * *} \\
(0.019)\end{array}$ & $\begin{array}{c}-0.112^{* * *} \\
(0.022)\end{array}$ & $\begin{array}{l}-0.004 \\
(0.017)\end{array}$ & $\begin{array}{c}-0.009 \\
(0.021)\end{array}$ & $\begin{array}{l}-0.002 \\
(0.021)\end{array}$ \\
\hline $\mathrm{N}$ & 5,227 & 2,770 & 3,115 & 5,454 & 2,890 & 3,250 & 5,454 & 2,890 & 3,250 \\
\hline $1[$ Pre-emergencies $]$ & $\begin{array}{c}0.041^{* * *} \\
(0.010)\end{array}$ & $\begin{array}{l}0.021^{* *} \\
(0.007)\end{array}$ & $\begin{array}{l}0.022^{* *} \\
(0.007)\end{array}$ & $\begin{array}{c}-0.120^{* * *} \\
(0.032)\end{array}$ & $\begin{array}{c}-0.097^{* * *} \\
(0.019)\end{array}$ & $\begin{array}{c}-0.085^{* * *} \\
(0.018)\end{array}$ & $\begin{array}{l}0.066^{* *} \\
(0.032)\end{array}$ & $\begin{array}{c}0.038^{*} \\
(0.023)\end{array}$ & $\begin{array}{c}0.064^{* * *} \\
(0.018)\end{array}$ \\
\hline $\mathrm{N}$ & 2,013 & 989 & 736 & 2,100 & 1,032 & 768 & 2,100 & 1,032 & 768 \\
\hline
\end{tabular}

Notes: Local linear GMM-IV estimations of the residuals from the (full) regressions of hourly average pollution concentrations (in logs) using $\operatorname{ICAP}_{10, t-1}$ as the running variable and $\operatorname{ICAP}_{2.5, t-1}$ as an additional instrument. All estimations include 12-hour lags of pollution. Weather variables include current and 24-hour lags of quartics in humidity, temperature, wind speed, precipitation, and thermal oscillation, and dummies for year, month, dow, and hour $\times$ weekend. Optimal bandwidth estimated using a common MSE-optimal bandwidth selector based on Calonico et al. (2014), Calonico et al. (2017), and Calonico et al. (2018a). Standard errors robust to heteroskedasticity and to 24 -hour serial correlation in parentheses. Significance levels: ${ }^{*} p<0.10,{ }^{* *} p<0.05$, ${ }^{* * *} p<0.001$. 
Table 12: Episodes Impact on Hourly Metro Trips

\begin{tabular}{|c|c|c|c|c|c|c|c|c|c|}
\hline \multirow{2}{*}{ Episode/Bandwidth } & \multicolumn{3}{|c|}{ Peak Hours } & \multicolumn{3}{|c|}{ Early Off-Peak Hours } & \multicolumn{3}{|c|}{ Late Off-Peak Hours } \\
\hline & $k=50$ & $k=25$ & Optimal & $k=50$ & $k=25$ & Optimal & $k=50$ & $k=25$ & Optimal \\
\hline \multicolumn{10}{|c|}{ Panel a) Pooling Episodes: } \\
\hline \multirow[t]{2}{*}{1 [Episodes] } & -0.024 & -0.006 & -0.020 & $0.155^{* *}$ & $0.235^{* * *}$ & $0.275^{*}$ & 0.002 & $0.050^{*}$ & -0.012 \\
\hline & $(0.017)$ & $(0.018)$ & $(0.027)$ & $(0.071)$ & $(0.060)$ & $(0.142)$ & $(0.028)$ & $(0.030)$ & $(0.039)$ \\
\hline $\mathrm{N}$ & 4,081 & 2174 & 2688 & 4308 & 2295 & 2837 & 4308 & 2295 & 2837 \\
\hline \multicolumn{10}{|c|}{ Panel b) Heterogeneous Episodes: } \\
\hline \multirow[t]{2}{*}{$1[$ Alerts $]$} & -0.023 & 0.010 & -0.023 & $0.250^{* *}$ & $0.302^{* * *}$ & $0.364^{* * *}$ & -0.026 & 0.043 & 0.0005 \\
\hline & $(0.019)$ & $(0.020)$ & $(0.019)$ & $(0.083)$ & $(0.071)$ & $(0.069)$ & $(0.035)$ & $(0.037)$ & $(0.033)$ \\
\hline $\mathrm{N}$ & 4,081 & 2,174 & 1,523 & 4,308 & 2,295 & 1,608 & 4,308 & 2,295 & 1,608 \\
\hline \multirow[t]{2}{*}{1 [Pre-emergencies] } & -0.040 & $0.067^{* *}$ & $0.105^{* * *}$ & 0.017 & -0.133 & 0.150 & $0.140^{* *}$ & $0.133^{* *}$ & $0.153^{* *}$ \\
\hline & $(0.026)$ & $(0.026)$ & $(0.031)$ & (0.098) & $(0.104)$ & (0.103) & $(0.059)$ & $(0.056)$ & $(0.050)$ \\
\hline $\mathrm{N}$ & 1,571 & 775 & 683 & 1,658 & 818 & 721 & 1,658 & 818 & 721 \\
\hline
\end{tabular}

Notes: Local linear GMM-IV estimations of the residuals from the (full) regressions of hourly metro trips (in logs) using $\mathrm{ICAP}_{10, t-1}$ as the running variable and $\mathrm{ICAP}_{2.5, t-1}$ as an additional instrument. All regressions include current and 24-hour lags of quartics in humidity, temperature, wind speed, precipitation, and thermal oscillation, and dummies for year, month, dow, and hour $\times$ weekend. Optimal bandwidth estimated using a common MSEoptimal bandwidth selector based on Calonico et al. (2014), Calonico et al. (2017), and Calonico et al. (2018a). Standard errors robust to heteroskedasticity and to 1-hour serial correlation in parentheses. Significance levels: ${ }^{*} p<0.10,{ }^{* *} p<0.05,{ }^{* * *} p<0.001$.

Table 13: Episodes Impact on Daily Bus (Transantiago) Trips

\begin{tabular}{|c|c|c|c|}
\hline \multirow{2}{*}{ Episode/Bandwidth } & \multicolumn{3}{|c|}{ Daily Flows } \\
\hline & $k=50$ & $k=25$ & Optimal \\
\hline \multicolumn{4}{|c|}{ Panel a) Pooling Episodes: } \\
\hline 1[Episodes] & $\begin{array}{l}0.058^{*} \\
(0.032)\end{array}$ & $\begin{array}{c}0.019 \\
(0.039)\end{array}$ & $\begin{array}{c}0.035 \\
(0.034)\end{array}$ \\
\hline $\mathrm{N}$ & 175 & 98 & 148 \\
\hline \multicolumn{4}{|c|}{ Panel b) Heterogeneous Episodes: } \\
\hline 1 [Alerts] & $\begin{array}{l}0.118^{* *} \\
(0.042)\end{array}$ & $\begin{array}{c}0.065 \\
(0.051)\end{array}$ & $\begin{array}{l}0.121^{* *} \\
(0.047)\end{array}$ \\
\hline $\mathrm{N}$ & 175 & 98 & 67 \\
\hline $1[$ Pre-emergencies] & $\begin{array}{l}0.154^{*} \\
(0.085)\end{array}$ & $\begin{array}{l}0.279^{* *} \\
(0.100)\end{array}$ & $\begin{array}{l}0.159^{*} \\
(0.090)\end{array}$ \\
\hline $\mathrm{N}$ & 72 & 36 & 69 \\
\hline
\end{tabular}

Notes: Local linear GMM-IV estimations of the residuals from the (full) regressions of daily bus trips (in logs) using $\operatorname{ICAP}_{10, t-1}$ as the running variable and $\operatorname{ICAP}_{2.5, t-1}$ as an additional instrument. All regressions include current and 1-day lags of quartics in humidity, temperature, wind speed, precipitation, and thermal oscillation, and dummies for year, month, and dow. Optimal bandwidth estimated using a common MSEoptimal bandwidth selector based on Calonico et al. (2014), Calonico et al. (2017), and Calonico et al. (2018a). Standard errors robust to heteroskedasticity and to 1-day serial correlation in parentheses. Significance levels: ${ }^{*} p<0.10,{ }^{* *} p<0.05,{ }^{* * *} p<0.001$. 
Table 14: Episodes Impact on Traffic Flows Using False Cutoffs

\begin{tabular}{|c|c|c|c|c|c|c|c|}
\hline & \multicolumn{3}{|c|}{ Vehicle Trips } & \multicolumn{3}{|c|}{ Metro Trips } & \multirow{2}{*}{$\begin{array}{c}\text { Bus Trips } \\
\text { Daily } \\
\text { Average }\end{array}$} \\
\hline & $\begin{array}{l}\text { Peak } \\
\text { Hours }\end{array}$ & $\begin{array}{c}\text { Off-Peak } \\
\text { Early Hours }\end{array}$ & $\begin{array}{c}\text { Off-Peak } \\
\text { Late Hours }\end{array}$ & $\begin{array}{l}\text { Peak } \\
\text { Hours }\end{array}$ & $\begin{array}{c}\text { Off-Peak } \\
\text { Early Hours }\end{array}$ & $\begin{array}{c}\text { Off-Peak } \\
\text { Late Hours }\end{array}$ & \\
\hline \multicolumn{8}{|c|}{ Panel a) Pooling Episodes: } \\
\hline $1[$ Episodes $]$ & $\begin{array}{l}-1.059 \\
(0.957)\end{array}$ & $\begin{array}{l}-0.819 \\
(0.971)\end{array}$ & $\begin{array}{l}-0.917 \\
(0.979)\end{array}$ & $\begin{array}{c}0.049 \\
(0.730)\end{array}$ & $\begin{array}{c}6.519 \\
(6.196)\end{array}$ & $\begin{array}{c}3.621 \\
(3.407)\end{array}$ & $\begin{array}{c}2.076 \\
(1.727)\end{array}$ \\
\hline $\mathrm{N}$ & 28,762 & 30,069 & 30,069 & 22,770 & 24,035 & 24,035 & 1,112 \\
\hline \multicolumn{8}{|c|}{ Panel b) Heterogeneous Episodes: } \\
\hline $1[$ Alerts $]$ & $\begin{array}{l}-2.976 \\
(2.388)\end{array}$ & $\begin{array}{c}-9.215 \\
(10.210)\end{array}$ & $\begin{array}{l}-4.610 \\
(6.212)\end{array}$ & $\begin{array}{l}-2.154 \\
(4.642)\end{array}$ & $\begin{array}{l}-22.43 \\
(22.99)\end{array}$ & $\begin{array}{l}-0.667 \\
(9.686)\end{array}$ & $\begin{array}{c}1.958 \\
(1.551)\end{array}$ \\
\hline $\mathrm{N}$ & 20,741 & 21,683 & 21,683 & 22,837 & 24,108 & 24,108 & 1,543 \\
\hline $1[$ Pre-emergencies $]$ & $\begin{array}{c}1.222 \\
(0.758)\end{array}$ & $\begin{array}{c}2.989 \\
(3.164)\end{array}$ & $\begin{array}{l}-0.333 \\
(1.648)\end{array}$ & $\begin{array}{c}3.847 \\
(3.366)\end{array}$ & $\begin{array}{l}-1.378 \\
(5.016)\end{array}$ & $\begin{array}{c}9.036 \\
(9.865)\end{array}$ & $\begin{array}{l}-1.851 \\
(1.984)\end{array}$ \\
\hline $\mathrm{N}$ & 14,159 & 14,797 & 14,797 & 5,982 & 6,314 & 6,314 & 356 \\
\hline
\end{tabular}

Notes: Local linear GMM-IV estimations of the residuals from the (full) regressions of hourly average vehicle trips (in logs) using optimal bandwidths. Standard errors robust to heteroskedasticity and to 2-hour serial correlation in parentheses. Significance levels: ${ }^{*} p<0.10,{ }^{* *} p<0.05,{ }^{* * *} p<0.001$.

Table 15: Episodes Impact on Hourly Average Pollution Using False Cutoffs

\begin{tabular}{|c|c|c|c|c|}
\hline & $\mathrm{PM}_{10}$ & $\mathrm{PM}_{2.5}$ & $\mathrm{CO}$ & $\mathrm{NO}_{X}$ \\
\hline \multicolumn{5}{|c|}{ Panel a) Pooling Episodes: } \\
\hline 1[Episodes] & $\begin{array}{l}-0.068 \\
(0.177)\end{array}$ & $\begin{array}{c}0.081 \\
(0.207)\end{array}$ & $\begin{array}{c}0.027 \\
(0.206)\end{array}$ & $\begin{array}{c}0.276 \\
(0.274)\end{array}$ \\
\hline $\mathrm{N}$ & 24,643 & 29,157 & 35,549 & 35,549 \\
\hline \multicolumn{5}{|c|}{ Panel b) Heterogeneous Episodes: } \\
\hline 1 [Alerts] & $\begin{array}{c}0.105 \\
(0.214)\end{array}$ & $\begin{array}{c}0.006 \\
(0.210)\end{array}$ & $\begin{array}{c}0.093 \\
(0.237)\end{array}$ & $\begin{array}{c}0.389 \\
(0.338)\end{array}$ \\
\hline $\mathrm{N}$ & 29,174 & 29,157 & 35,549 & 35,549 \\
\hline $1[$ Pre-emergencies $]$ & $\begin{array}{c}0.255 \\
(0.190)\end{array}$ & $\begin{array}{c}0.301 \\
(0.202)\end{array}$ & $\begin{array}{c}0.265 \\
(0.176)\end{array}$ & $\begin{array}{c}0.625 \\
(0.401)\end{array}$ \\
\hline $\mathrm{N}$ & 8,606 & 8,606 & 9,020 & 14,172 \\
\hline
\end{tabular}

Notes: Local linear GMM-IV estimations of the residuals from the (full) regressions of peak hourly pollution concentrations (in logs) using optimal bandwidths. Standard errors robust to heteroskedasticity and to 24-hour serial correlation in parentheses. Significance levels: ${ }^{*} p<0.10,{ }^{* *} p<0.05,{ }^{* * *} p<0.001$. 
Table 16: DID Estimation Using Talagante as a Control Station

\begin{tabular}{lcccccccc}
\hline \hline & \multicolumn{2}{c}{$\mathrm{PM}_{10}$} & \multicolumn{2}{c}{$\mathrm{PM}_{2.5}$} & \multicolumn{2}{c}{$\mathrm{CO}$} & $\mathrm{NO}_{X}$ \\
\cline { 2 - 9 } & $(1)$ & $(2)$ & $(1)$ & $(2)$ & $(1)$ & $(2)$ & $(1)$ & $(2)$ \\
\hline Panel a) Pooling Episodes: & & & & & & & & \\
1[Treated] $\times$ [Episodes] & $-0.120^{* *}$ & $-0.119^{* *}$ & $-0.285^{* * *}$ & $-0.286^{* * *}$ & $-0.215^{* * *}$ & $-0.213^{* * *}$ & $-0.470^{* * *}$ & $-0.472^{* * *}$ \\
& $(0.044)$ & $(0.043)$ & $(0.048)$ & $(0.047)$ & $(0.052)$ & $(0.052)$ & $(0.059)$ & $(0.059)$ \\
$\mathrm{N}$ & 384,125 & 384,125 & 414,300 & 414,300 & 414,480 & 414,480 & 381,100 & 381,100 \\
Panel b) Heterogeneous Episodes: & & & & & & & & \\
1 [Treated] $\times 1$ [Alerts] & $-0.092^{*}$ & $-0.091^{*}$ & $-0.244^{* * *}$ & $-0.245^{* * *}$ & $-0.144^{* *}$ & $-0.142^{* *}$ & $-0.447^{* * *}$ & $-0.449^{* * *}$ \\
& $(0.049)$ & $(0.049)$ & $(0.053)$ & $(0.053)$ & $(0.058)$ & $(0.058)$ & $(0.063)$ & $(0.063)$ \\
1 [Treated] $\times 1$ [Pre-emergencies] $]$ & $-0.224^{* *}$ & $-0.222^{* *}$ & $-0.425^{* * *}$ & $-0.426^{* * *}$ & $-0.439^{* * *}$ & $-0.436^{* * *}$ & $-0.501^{* *}$ & $-0.503^{* *}$ \\
& $(0.093)$ & $(0.093)$ & $(0.099)$ & $(0.098)$ & $(0.110)$ & $(0.110)$ & $(0.153)$ & $(0.153)$ \\
N & 383,068 & 383,068 & 412,956 & 412,956 & 413,291 & 413,291 & 380,291 & 380,291 \\
Polynomial Time Trend & - & $t^{2}$ & - & $t^{2}$ & - & $t^{2}$ & - & $t^{2}$ \\
\hline
\end{tabular}

Notes: Newey-West estimations during peak hours using current and 24-hour lags of quartics in humidity, temperature, wind speed, precipitation, and thermal oscillation; fixed effects for year, month, dow, and hour $\times$ weekend; and stations fixed effects. Standard errors robust to 24-hour serial correlation. Significance levels: ${ }^{*} p<0.10,{ }^{* *} p<0.05,{ }^{* * *} p<0.001$

Table 17: FRD Using Santiago's Nearest Downtown Station Parque O'Higgins

\begin{tabular}{lcccc}
\hline \hline Pollutant & $\mathrm{PM}_{10}$ & $\mathrm{PM}_{2.5}$ & $\mathrm{CO}$ & $\mathrm{NO}_{X}$ \\
\hline 1[Alerts] & 0.021 & 0.025 & -0.036 & -0.004 \\
& $(0.028)$ & $(0.024)$ & $(0.029)$ & $(0.032)$ \\
$\mathrm{N}$ & 3,395 & 3,127 & 2,597 & 1,405 \\
1 [Pre-emergencies] & -0.079 & $-0.097^{*}$ & $-0.160^{* *}$ & $-0.150^{*}$ \\
& $(0.0608)$ & $(0.0546)$ & $(0.0612)$ & $(0.0865)$ \\
$\mathrm{N}$ & 905 & 720 & 1,340 & 390 \\
\hline
\end{tabular}

Notes: Local linear GMM estimations of the residuals from the (full) regressions of hourly (peak hours) pollution concentrations (in logs) using optimal bandwidths. Standard errors robust to heteroskedasticity and to 24 -hour serial correlation in parentheses. Significance levels: ${ }^{*} p<0.10,{ }^{* *} p<0.05,{ }^{* * *} p<0.001$. 


\section{A. Supplemental Material}

Figure A1: Spatial Location of Santiago's Monitoring Stations

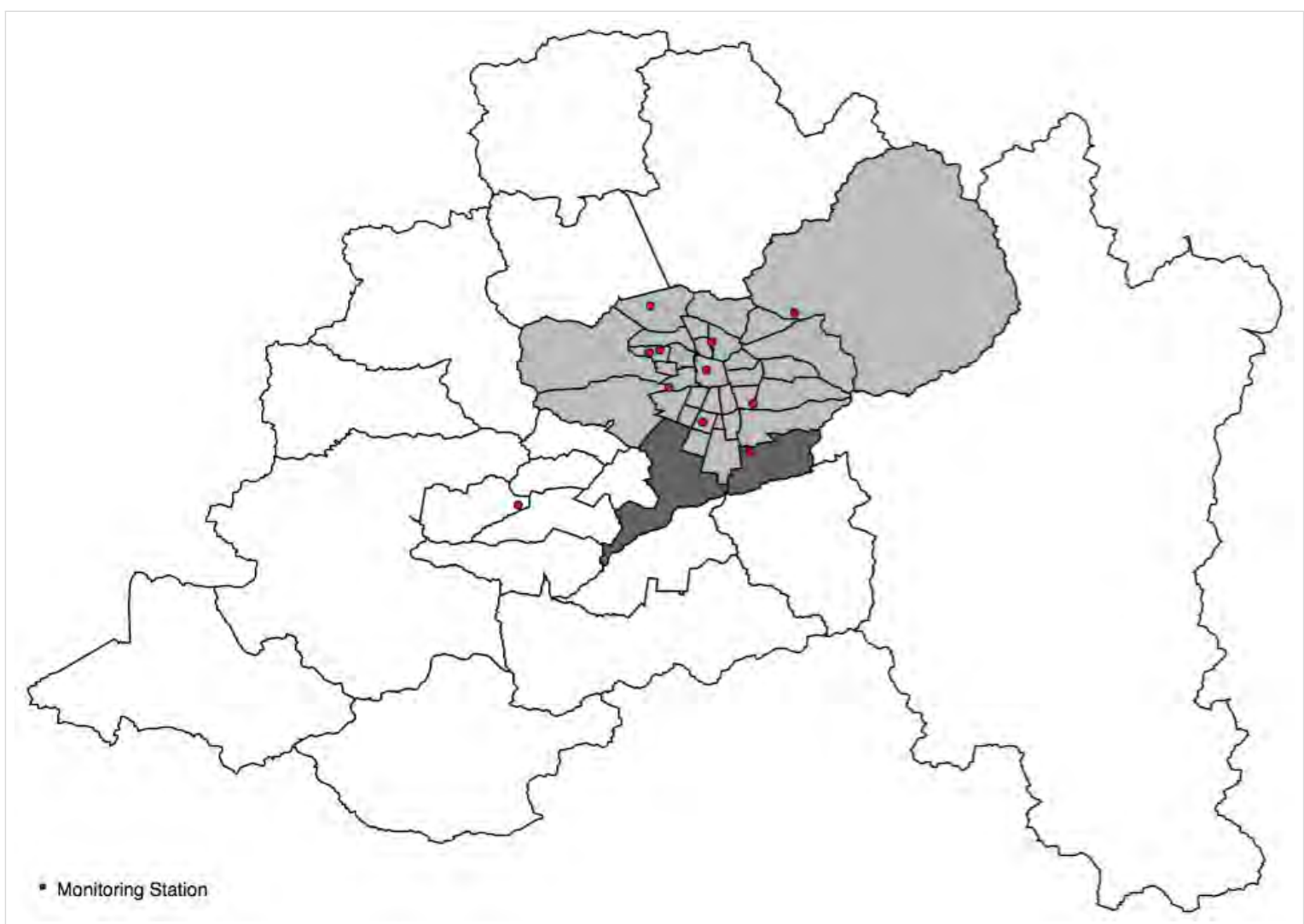

Notes: Areas affected by driving restrictions in color. Only one monitoring station is outside this range - the Talagante station. Borders represent municipalities' limits. 
Figure A2: Daily Average Pollutant Concentrations



(a) $\mathrm{PM}_{10}$

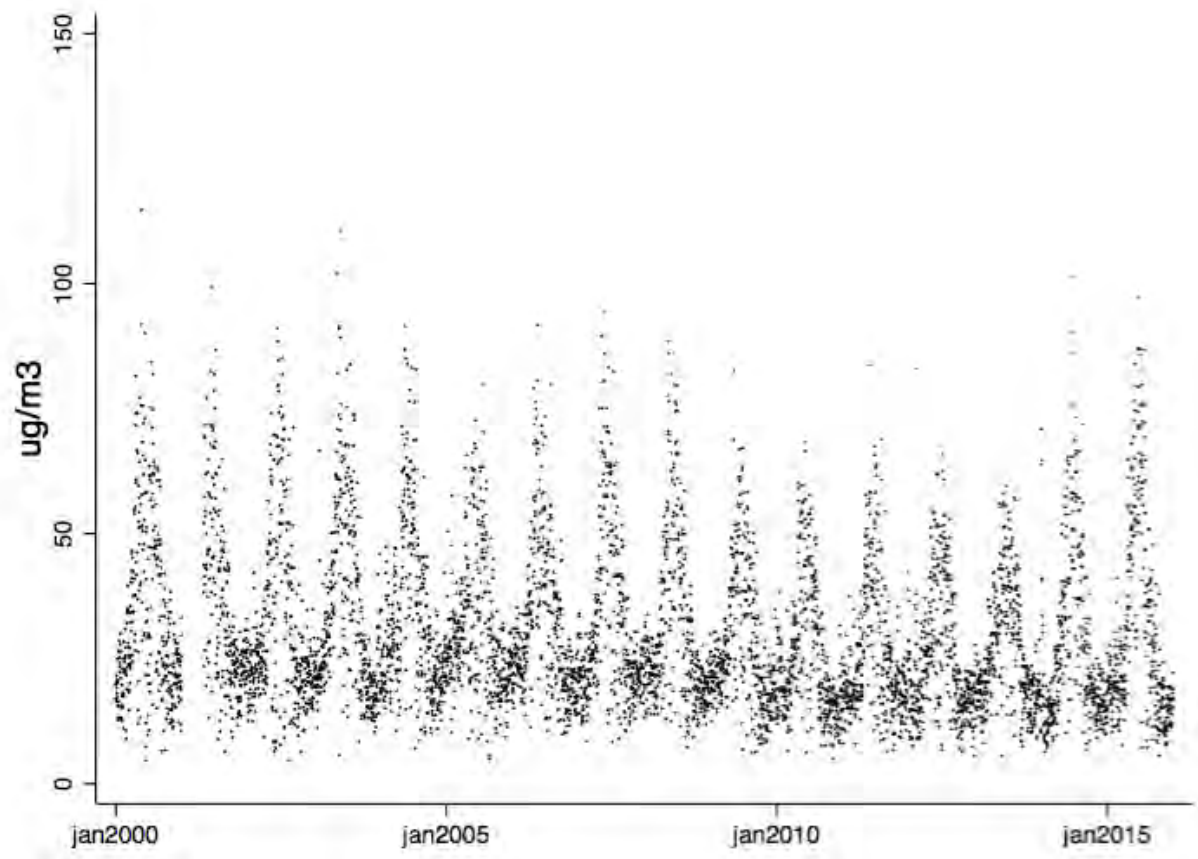

(b) $\mathrm{PM}_{2.5}$ 
Figure A2: Daily Average Pollutant Concentrations (continued)

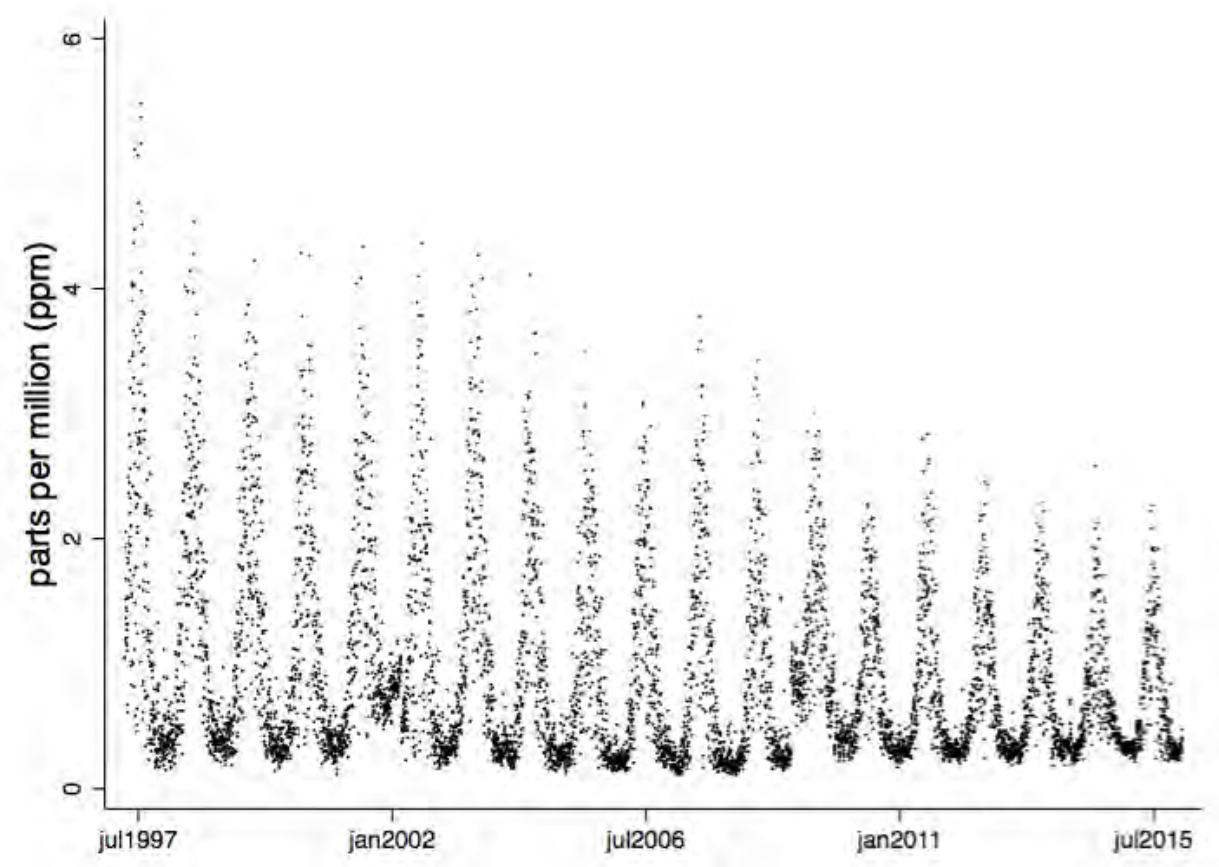

(c) $\mathrm{CO}$

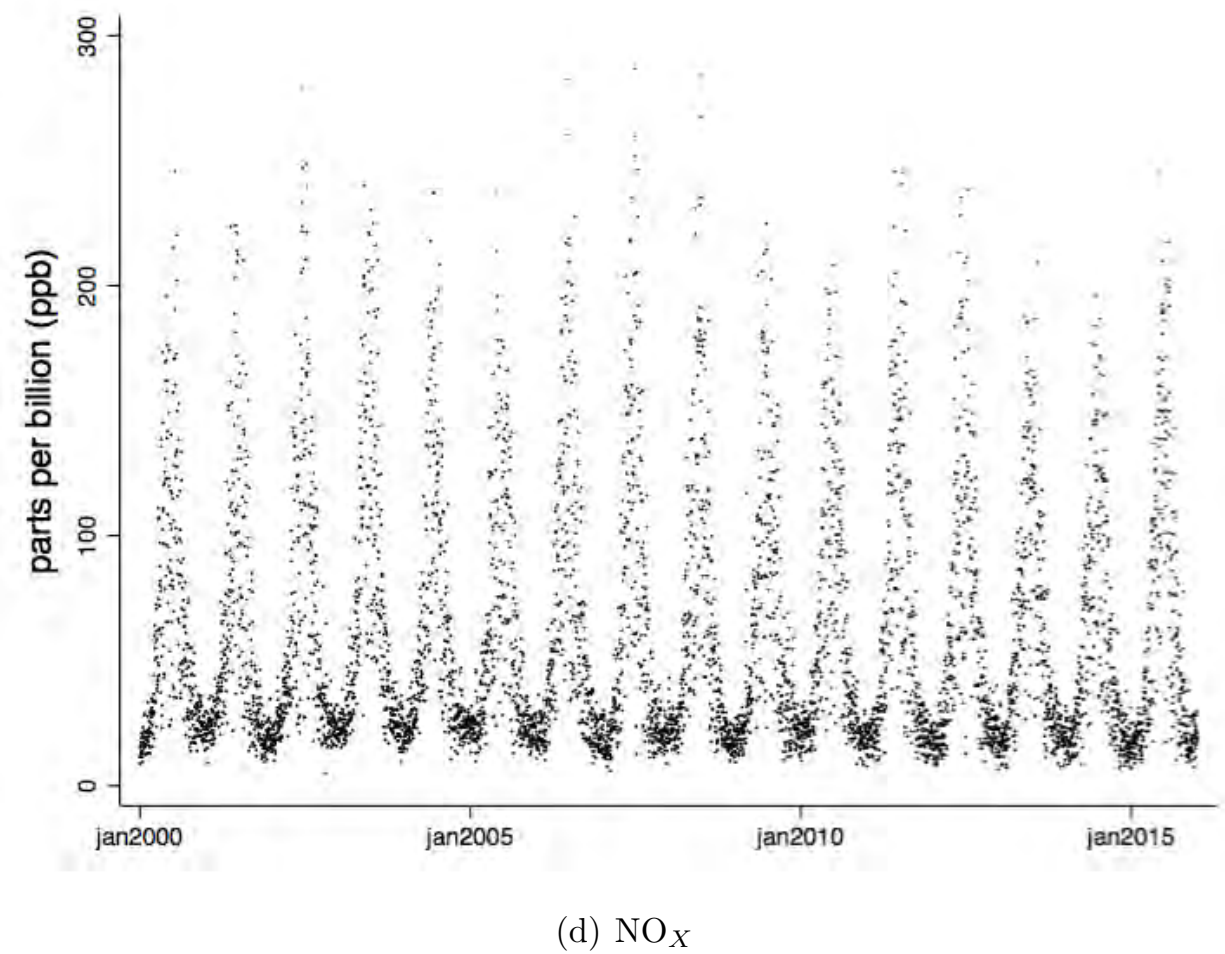


Table A1: Number of License Plate Digits Restricted by Permanent and Temporary Driving Restrictions. 1990-2015

\begin{tabular}{|c|c|c|c|c|c|c|}
\hline \multirow{2}{*}{ Stage } & \multirow{2}{*}{$\begin{array}{c}\text { Type of } \\
\text { Light Vehicle }\end{array}$} & \multirow{2}{*}{$\begin{array}{c}\text { Day of } \\
\text { the Week }\end{array}$} & \multirow{2}{*}{$\begin{array}{l}\text { Permanent } \\
\text { Restriction }\end{array}$} & \multicolumn{3}{|c|}{ Temporary Restrictions } \\
\hline & & & & Alert & Pre-emergency & Emergency \\
\hline \multirow{4}{*}{ 1990-1996 } & \multirow{2}{*}{ Dirty } & Weekdays & 2 & - & - & - \\
\hline & & Weekends & 0 & - & - & - \\
\hline & \multirow{2}{*}{ Clean } & Weekdays & 0 & - & - & - \\
\hline & & Weekends & 0 & - & - & - \\
\hline \multirow{4}{*}{ 1997-2000 } & \multirow{2}{*}{ Dirty } & Weekdays & 2 & 4 & 6 & 8 \\
\hline & & Weekends & 0 & 2 & 4 & 6 \\
\hline & \multirow{2}{*}{ Clean } & Weekdays & 0 & 0 & 0 & 0 \\
\hline & & Weekends & 0 & 0 & 0 & 0 \\
\hline \multirow{4}{*}{ 2001-2007 } & \multirow{2}{*}{ Dirty } & Weekdays & 2 & 4 & 6 & 8 \\
\hline & & Weekends & 0 & 2 & 4 & 6 \\
\hline & \multirow{2}{*}{ Clean } & Weekdays & 0 & 0 & 2 & 4 \\
\hline & & Weekends & 0 & 0 & 2 & 4 \\
\hline \multirow{4}{*}{ 2008-2015 } & \multirow{2}{*}{ Dirty } & Weekdays & 4 & 4 & 6 & 8 \\
\hline & & Weekends & 0 & 2 & 6 & 8 \\
\hline & \multirow{2}{*}{ Clean } & Weekdays & 0 & 0 & 2 & 4 \\
\hline & & Weekends & 0 & 0 & 2 & 4 \\
\hline
\end{tabular}

Notes: Permanent and temporary driving restrictions are in place only between 7:30am to 9:00pm and from April 1st to August 31st. Temporary driving restrictions show the total number of digits restricted during days with environmental episodes (i.e. number of digits restricted under the permanent restriction plus additional digits). Dirty $=$ Vehicles without a green sticker. Clean $=$ Vehicles with a green sticker . 
Table A2: 2016 Calendar of Driving Restrictions for Santiago

\begin{tabular}{ccc}
\hline \hline Type of Restriction & Day/Episode & Digits Affected \\
\hline \multirow{4}{*}{ Permanent Restriction } & Monday & $3-4-5-6$ \\
& Tuesday & $7-8-9-0$ \\
& Wednesday & $1-2-3-4$ \\
& Thursday & $5-6-7-8$ \\
& Friday & $9-0-1-2$ \\
\hline \multirow{5}{*}{ Temporary Restrictions } & First Episode & $0-1$ \\
& Second Episode & $2-3$ \\
& Fhird Episode & $4-5$ \\
& Fourth Episode & $6-7$ \\
& Fifth Episode & $8-9$ \\
\hline
\end{tabular}

Notes: Permanent restrictions affect dirty vehicles only. 
Table A3: Expected Percentage of Light-Duty Private Cars Affected by Restrictions Over 2001-2015.

\begin{tabular}{|c|c|c|c|c|c|c|c|c|}
\hline \multirow{3}{*}{ Years } & \multirow{2}{*}{\multicolumn{2}{|c|}{ Permanent Restriction }} & \multicolumn{6}{|c|}{ Temporary Restrictions } \\
\hline & & & \multicolumn{2}{|c|}{ Alerts } & \multicolumn{2}{|c|}{ Pre-emergencies } & \multicolumn{2}{|c|}{ Emergencies } \\
\hline & Clean Cars & Dirty Cars & Clean Cars & Dirty Cars & Clean Cars & Dirty Cars & Clean Cars & Dirty Cars \\
\hline 2001 & - & 8.83 & - & 26.49 & 22.34 & 44.15 & 44.68 & 61.82 \\
\hline 2002 & - & 8.22 & - & 24.65 & 23.57 & 41.08 & 47.14 & 57.51 \\
\hline 2003 & - & 7.68 & - & 23.03 & 24.64 & 38.39 & 49.29 & 53.75 \\
\hline 2004 & - & 6.89 & - & 20.68 & 26.21 & 34.47 & 52.43 & 48.25 \\
\hline 2005 & - & 5.94 & - & 17.82 & 28.12 & 29.71 & 56.24 & 41.59 \\
\hline 2006 & - & 7.03 & - & 21.08 & 25.94 & 35.14 & 51.89 & 49.19 \\
\hline 2007 & - & 3.10 & - & 9.30 & 33.80 & 15.51 & 67.59 & 21.71 \\
\hline 2008 & - & 4.82 & - & 7.24 & 35.18 & 14.47 & 70.35 & 19.30 \\
\hline 2009 & - & 3.81 & - & 5.72 & 36.19 & 11.43 & 72.38 & 15.24 \\
\hline 2010 & - & 2.51 & - & 3.76 & 37.49 & 7.52 & 74.99 & 10.02 \\
\hline 2011 & - & 1.99 & - & 2.99 & 38.01 & 5.97 & 76.02 & 7.96 \\
\hline 2012 & - & 1.60 & - & 2.40 & 38.40 & 4.80 & 76.80 & 6.40 \\
\hline 2013 & - & 1.32 & - & 1.98 & 38.68 & 3.96 & 77.36 & 5.28 \\
\hline 2014 & - & 1.07 & - & 1.60 & 38.93 & 3.20 & 77.87 & 4.26 \\
\hline 2015 & - & 0.87 & - & 1.30 & 39.13 & 2.61 & 78.26 & 3.48 \\
\hline Average & \multicolumn{2}{|c|}{2.19} & \multicolumn{2}{|c|}{5.67} & \multicolumn{2}{|c|}{25.97} & \multicolumn{2}{|c|}{45.97} \\
\hline
\end{tabular}

Notes: Considering estrictions placed during both weekdays and weekends. Calculations are based on the number of clean and dirty light-duty private cars registered in Santiago's Metropolitan Area, retrieved from the Annual Reports on Road Vehicles (Anuario del Parque Vehicular de Vehículos en Circulación) available at http://ine.cl. 


\section{B. Example of the Cassmassi Forecast Model}

The following equation describes the weights used by the Cassmassi model to forecast $\mathrm{PM}_{10}$ concentrations in the Pudahuel station:

$$
y_{t+1}=39.4 \nu_{t}+0.33 y_{t}+2.06 x_{t}+0.21 h_{t}-21.7
$$

where $y_{t+1}$ is the expected 24-hour moving average of $\mathrm{PM}_{10}$ on day $t+1 ; \nu_{t}$ is the forecasted atmospheric stability on day $t$ taking discrete values from 1 to $5 ; y_{t}$ is the 24-hour moving average of $\mathrm{PM}_{10}$ measured on day $t$ at 10:00am (local time); $x_{t}$ is the temperature $\left({ }^{\circ} \mathrm{C}\right)$ of the $925 h P a$ level registered in the weather station Santo Domingo (located at $80 \mathrm{~km}$ west of Santiago) at 12:00pm UTC on day $t$, and $h_{t}$ is 24 -hour change in height measured at 500 level registered in Santo Domingo on day $t$ at 12:00pm UTC. The inclusion of $x_{t}$ and $h_{t}$ as part of the equations in the Cassmassi model are intended to control for the strength of thermal inversions in Santiago (Perez, 2008). 


\section{Additional Plots}

Figure C1: Discontinuity Plot on Hourly Average Weather

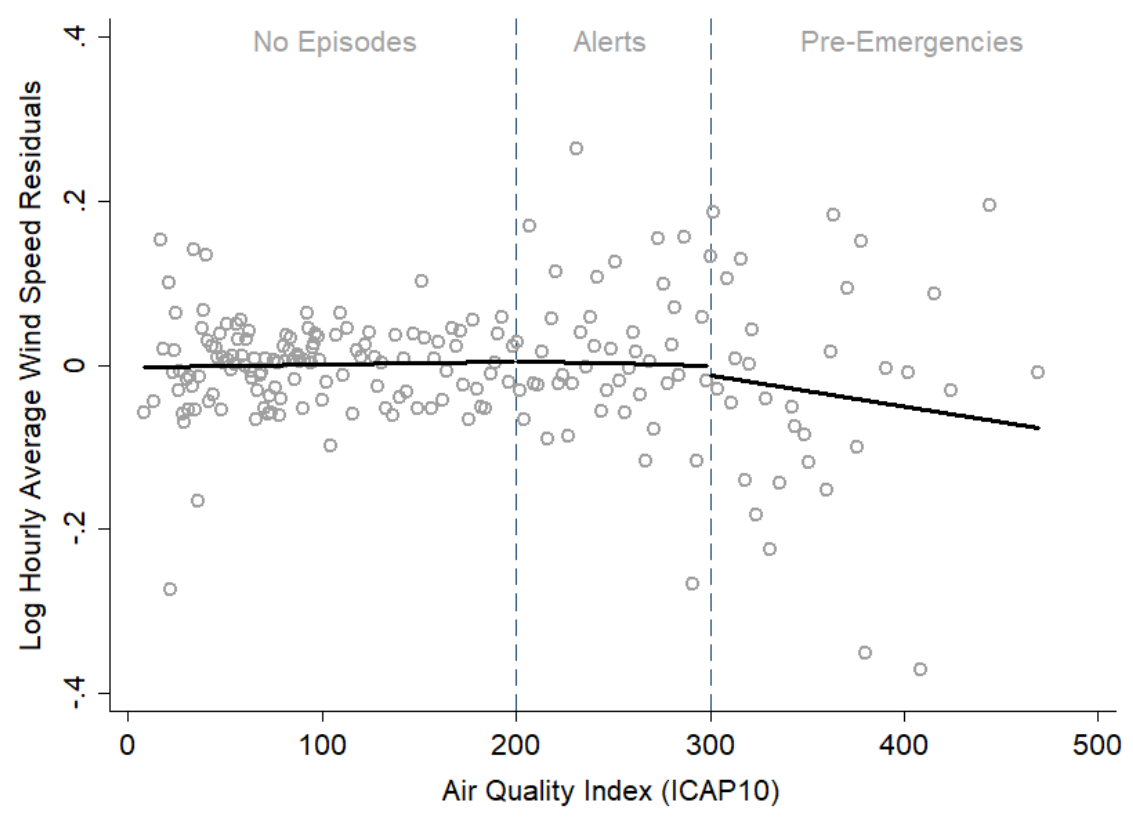

(a) Wind Speed

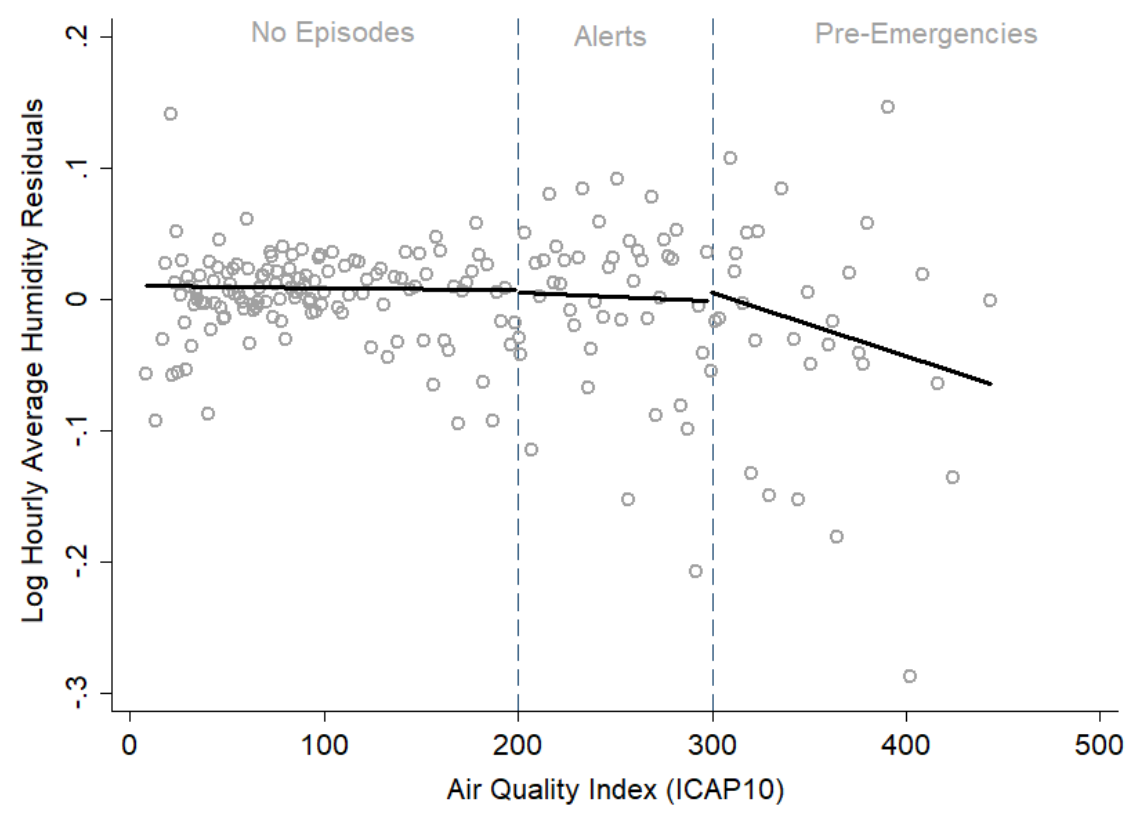

(b) Humidity

Notes: Linear fit during winter days using $\operatorname{ICAP}_{10, t-1}$ as the running variable. The linear fit uses binned sample means at each side of the cutoffs following the mimicking variance evenly-spaced method using spacing estimators (see Calonico et al. (2015a) for more details). 
Figure C2: Air Quality Index Densities During Episodes

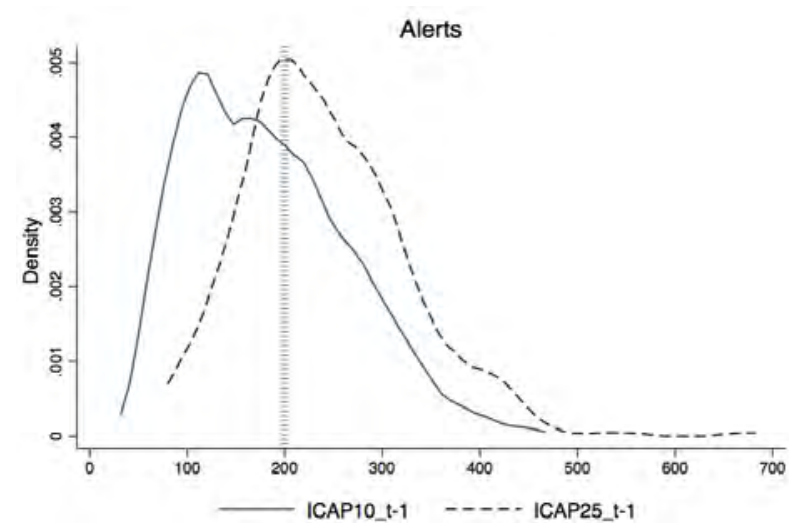

(a) Alerts



(b) Pre-emergencies

Notes: Densities of the daily max air quality indexes during day $t-1$. Using an Epanechnikov kernel, with a 22.88 and a 26.52 bandwidth for alerts and pre-emergencies, respectively. 
Figure C3: Overview of the Parallel Trends Assumption
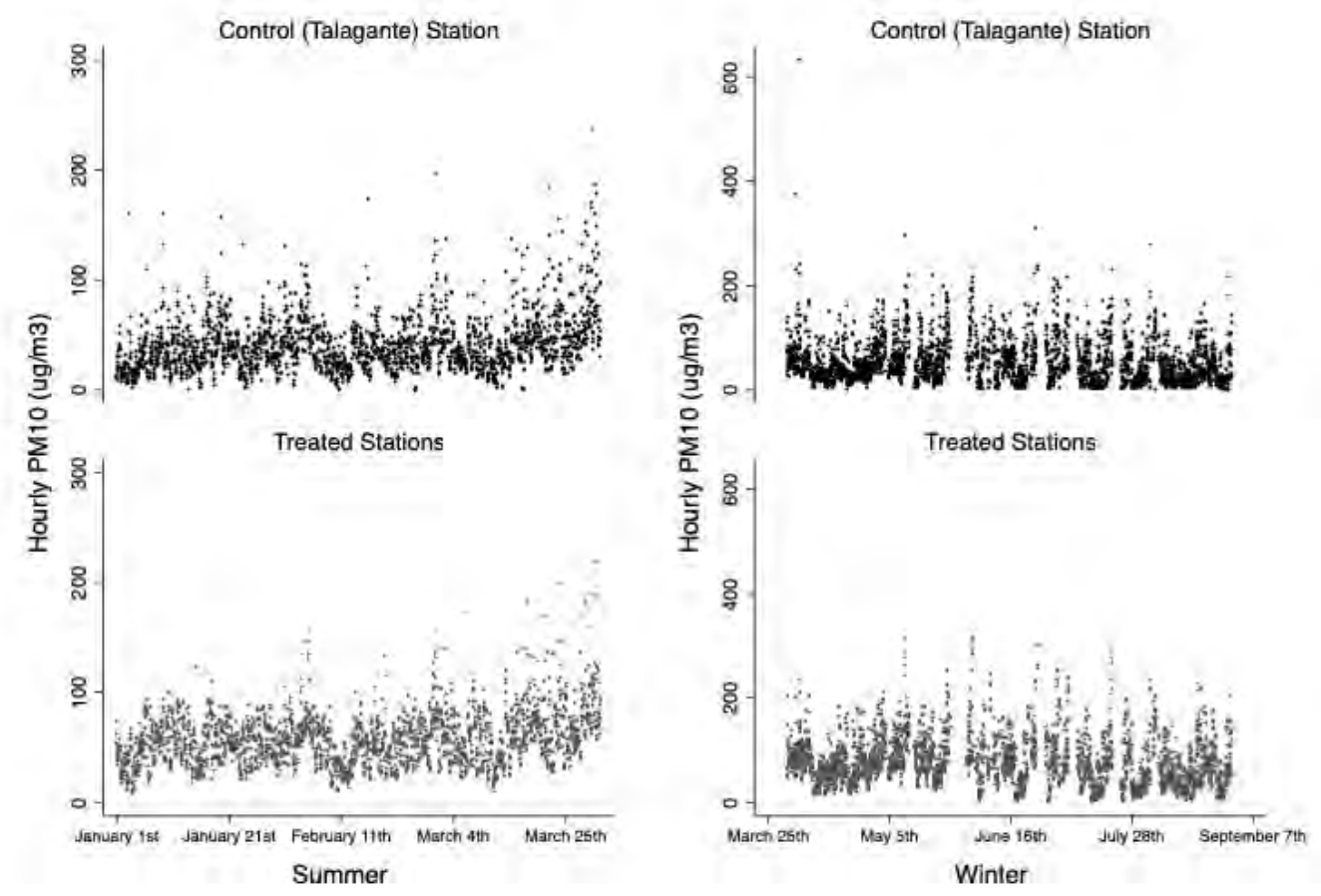

(a) $\mathrm{PM}_{10}$
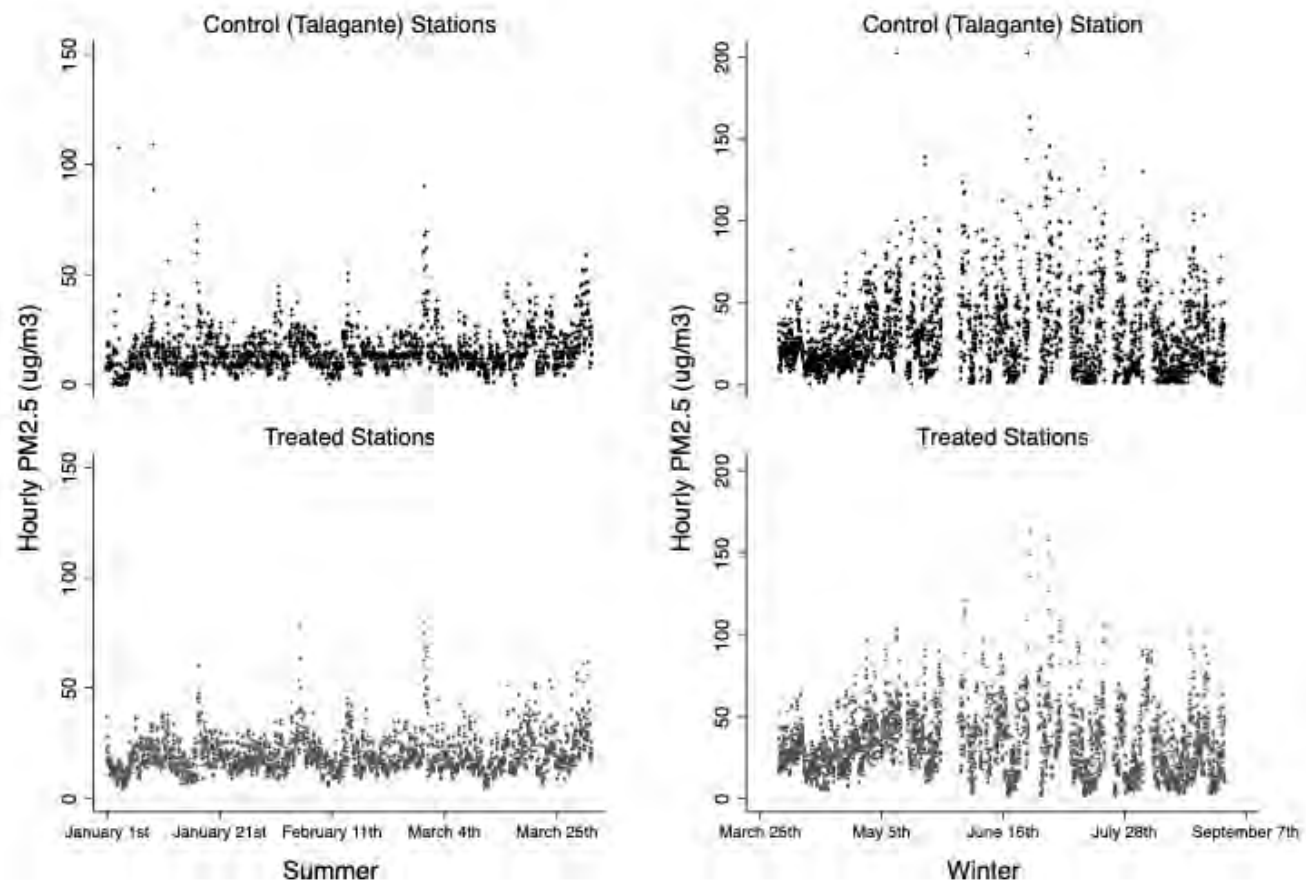

(b) $\mathrm{PM}_{2.5}$ 
Figure C3: Overview of the Parallel Trends Assumption (continued)
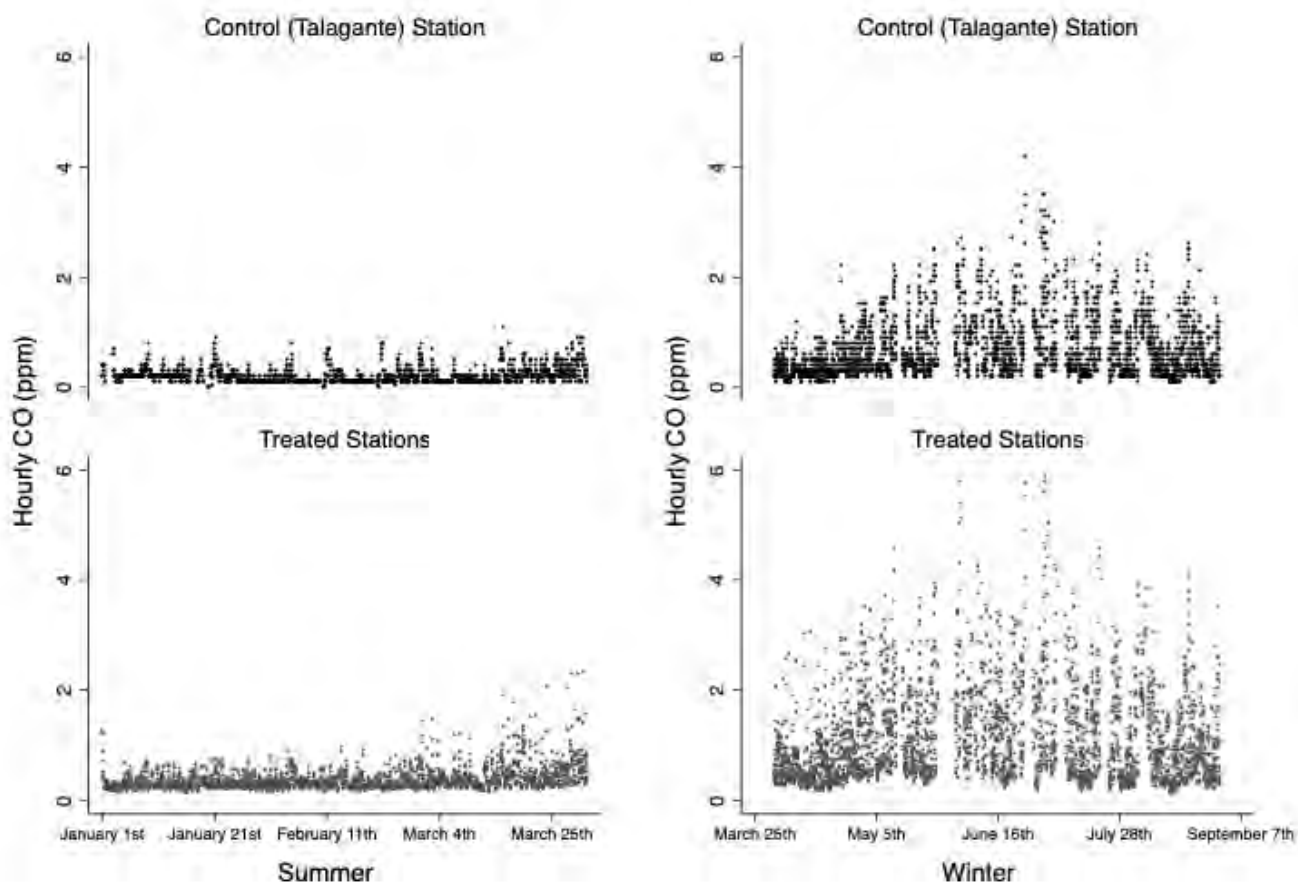

(c) $\mathrm{CO}$
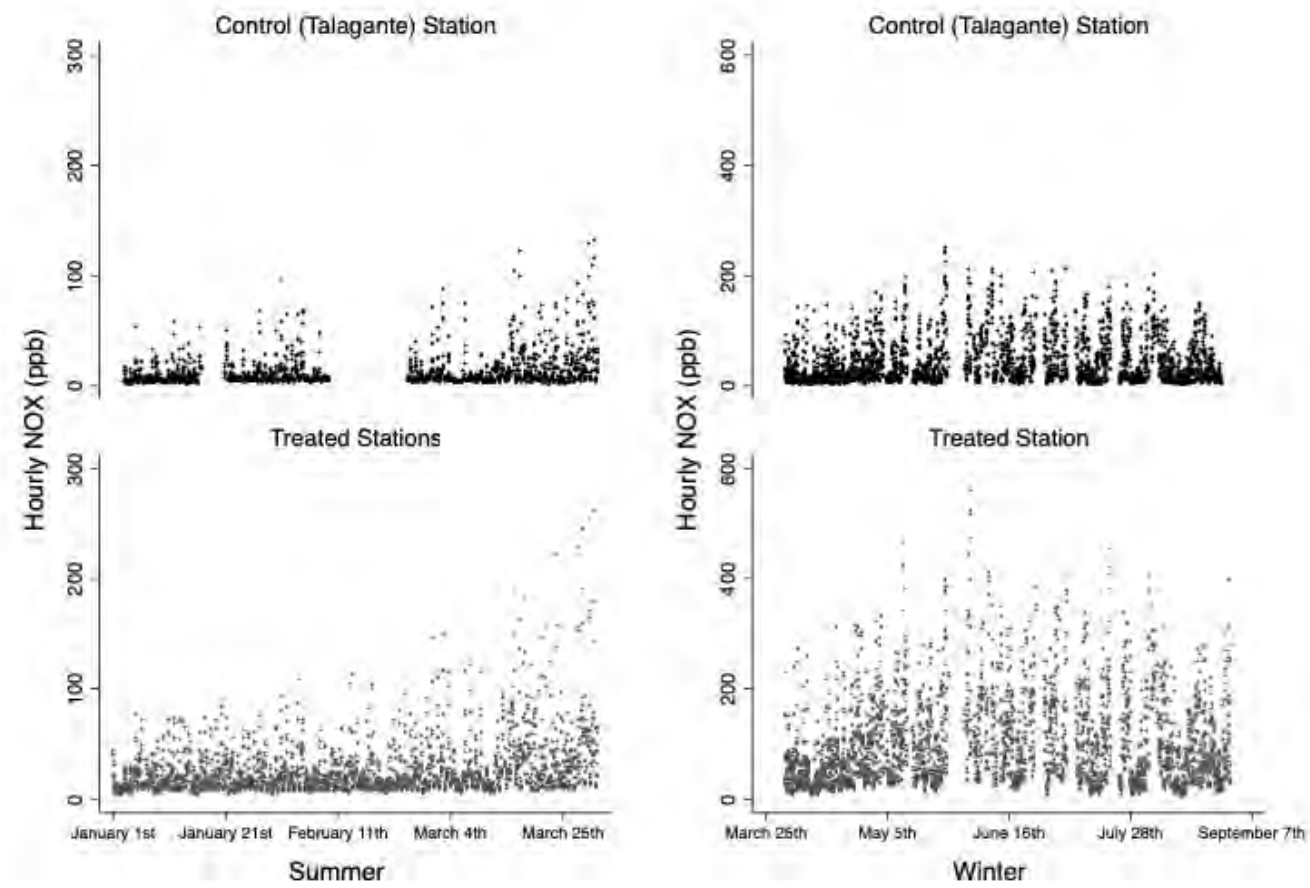

(d) $\mathrm{NO}_{X}$

Notes: Observations are hours during 2011. Plots in panels a), b), and d) use a different y-axis scale for summer and winter. 


\section{Additional Estimations}

Table D1: Episodes Impact on Hourly Max Vehicle Trips

\begin{tabular}{lccccccccccc}
\hline \hline & \multicolumn{3}{c}{ Peak Hours } & & \multicolumn{3}{c}{ Early Off-Peak Hours } & & \multicolumn{3}{c}{ Late Off-Peak Hours } \\
\cline { 2 - 3 } Bandwidth & $k=50$ & $k=25$ & Optimal & & $k=50$ & $k=25$ & Optimal & & $k=50$ & $k=25$ & Optimal \\
\hline 1[Episodes] & $-0.054^{* *}$ & -0.025 & $-0.051^{* * *}$ & & 0.010 & 0.042 & 0.027 & & -0.029 & $-0.069^{*}$ & $-0.050^{* *}$ \\
& $(0.019)$ & $(0.021)$ & $(0.015)$ & & $(0.045)$ & $(0.056)$ & $(0.034)$ & & $(0.029)$ & $(0.035)$ & $(0.023)$ \\
$\mathrm{N}$ & 4,897 & 2,610 & 9,751 & & 5,119 & 2,728 & 10,193 & & 5,119 & 2,728 & 10,193 \\
\hline
\end{tabular}

Notes: Local linear GMM-IV estimations of the residuals from the (full) regressions of hourly max vehicle trips (in logs) using $\mathrm{ICAP}_{10, t-1}$ as the running variable and $\mathrm{ICAP}_{2.5, t-1}$ as an additional instrument. All regressions include current and 24-hour lags of quartics in humidity, temperature, wind speed, precipitation, and thermal oscillation, and dummies for year, month, dow, and hour $\times$ weekend. Standard errors robust to heteroskedasticity and to 2-hour serial correlation in parentheses. Significance levels: ${ }^{*} p<0.10,{ }^{* *} p<0.05,{ }^{* * *} p<0.001$.

Table D2: Episodes Impact on Hourly Max Pollution

\begin{tabular}{|c|c|c|c|c|c|c|c|c|c|}
\hline \multirow[b]{2}{*}{ Bandwidth } & \multicolumn{3}{|c|}{ Peak Hours } & \multicolumn{3}{|c|}{ Early Off-Peak Hours } & \multicolumn{3}{|c|}{ Late Off-Peak Hours } \\
\hline & $k=50$ & $k=25$ & Optimal & $k=50$ & $k=25$ & Optimal & $k=50$ & $k=25$ & Optimal \\
\hline \multicolumn{10}{|c|}{ Panel a) $\mathrm{PM}_{10}$ : } \\
\hline 1[Episodes] & $\begin{array}{c}-0.029^{* * *} \\
(0.007)\end{array}$ & $\begin{array}{c}-0.022^{* *} \\
(0.008)\end{array}$ & $\begin{array}{c}-0.019^{* *} \\
(0.007)\end{array}$ & $\begin{array}{c}-0.050^{* *} \\
(0.017)\end{array}$ & $\begin{array}{c}-0.049^{* *} \\
(0.016)\end{array}$ & $\begin{array}{c}-0.086^{* * *} \\
(0.016)\end{array}$ & $\begin{array}{l}-0.002 \\
(0.014)\end{array}$ & $\begin{array}{l}-0.007 \\
(0.015)\end{array}$ & $\begin{array}{l}-0.012 \\
(0.014)\end{array}$ \\
\hline $\mathrm{N}$ & 5,227 & 2,770 & 11,603 & 5,454 & 2,890 & 12,107 & 5,454 & 2,890 & 12,107 \\
\hline \multicolumn{10}{|c|}{ Panel b) $\mathrm{PM}_{25}$ : } \\
\hline 1[Episodes] & $\begin{array}{c}-0.022^{* *} \\
(0.008)\end{array}$ & $\begin{array}{c}-0.020^{* *} \\
(0.008)\end{array}$ & $\begin{array}{c}-0.012^{*} \\
(0.007)\end{array}$ & $\begin{array}{c}0.008 \\
(0.014)\end{array}$ & $\begin{array}{l}-0.007 \\
(0.015)\end{array}$ & $\begin{array}{l}-0.013 \\
(0.015)\end{array}$ & $\begin{array}{c}0.009 \\
(0.014)\end{array}$ & $\begin{array}{l}0.046^{* *} \\
(0.015)\end{array}$ & $\begin{array}{c}0.013 \\
(0.013)\end{array}$ \\
\hline $\mathrm{N}$ & 5,227 & 2,770 & 10,402 & 5,454 & 2,890 & 10,854 & 5,454 & 2,890 & 10,854 \\
\hline \multicolumn{10}{|l|}{ Panel c) CO: } \\
\hline 1[Episodes] & $\begin{array}{c}-0.031^{* * *} \\
(0.007)\end{array}$ & $\begin{array}{c}-0.027^{* * *} \\
(0.008)\end{array}$ & $\begin{array}{c}-0.021^{* *} \\
(0.007)\end{array}$ & $\begin{array}{c}-0.027^{*} \\
(0.016)\end{array}$ & $\begin{array}{c}-0.039^{* *} \\
(0.015)\end{array}$ & $\begin{array}{c}-0.036^{* *} \\
(0.015)\end{array}$ & $\begin{array}{l}-0.009 \\
(0.015)\end{array}$ & $\begin{array}{c}0.002 \\
(0.017)\end{array}$ & $\begin{array}{c}0.0001 \\
(0.014)\end{array}$ \\
\hline $\mathrm{N}$ & 5,227 & 2,770 & 8,792 & 5,454 & 2,890 & 9,174 & 5,454 & 2,890 & 9,174 \\
\hline \multicolumn{10}{|c|}{ Panel d) $\mathrm{NO}_{X}$ : } \\
\hline 1[Episodes] & $\begin{array}{c}-0.018^{* *} \\
(0.008)\end{array}$ & $\begin{array}{c}-0.018^{* *} \\
(0.009)\end{array}$ & $\begin{array}{l}-0.007 \\
(0.008)\end{array}$ & $\begin{array}{c}-0.078^{* * *} \\
(0.021)\end{array}$ & $\begin{array}{c}-0.073^{* * *} \\
(0.020)\end{array}$ & $\begin{array}{c}-0.124^{* * *} \\
(0.020)\end{array}$ & $\begin{array}{c}-0.044^{* *} \\
(0.017)\end{array}$ & $\begin{array}{c}-0.053^{* *} \\
(0.022)\end{array}$ & $\begin{array}{l}-0.014 \\
(0.017)\end{array}$ \\
\hline $\mathrm{N}$ & 5,227 & 2,770 & 10,402 & 5,454 & 2,890 & 10,854 & 5,454 & 2,890 & 10,854 \\
\hline
\end{tabular}

Notes: Local linear GMM-IV estimations of the residuals from the (full) regressions of hourly max pollution concentrations (in logs) using $\mathrm{ICAP}_{10, t-1}$ as the running variable and $\mathrm{ICAP}_{2.5, t-1}$ as an additional instrument. All estimations include 12-hour lags of pollution. Weather variables include current and 24-hour lags of quartics in humidity, temperature, wind speed, precipitation, and thermal oscillation, and dummies for year, month, dow, and hour $\times$ weekend. Standard errors robust to heteroskedasticity and to 24-hour serial correlation in parentheses. Significance levels: ${ }^{*} p<0.10,{ }^{* *} p<0.05,{ }^{* * *} p<0.001$. 
Table D3: Episodes Impact on Hourly Average Vehicle Trips - Global Polynomial Approach

\begin{tabular}{|c|c|c|c|c|c|c|c|c|c|}
\hline & \multicolumn{3}{|c|}{ Peak Hours } & \multicolumn{3}{|c|}{ Early Off-Peak Hours } & \multicolumn{3}{|c|}{ Late Off-Peak Hours } \\
\hline & $(1)$ & $(2)$ & $(3)$ & $(1)$ & $(2)$ & $(3)$ & $(1)$ & $(2)$ & $(3)$ \\
\hline 1[Episodes] & $\begin{array}{c}-0.014^{* *} \\
(0.005)\end{array}$ & $\begin{array}{c}-0.307^{* * *} \\
(0.089)\end{array}$ & $\begin{array}{c}-0.536^{* * *} \\
(0.135)\end{array}$ & $\begin{array}{c}0.004 \\
(0.014)\end{array}$ & $\begin{array}{c}-2.493^{* *} \\
(0.934)\end{array}$ & $\begin{array}{c}-3.981^{* *} \\
(1.613)\end{array}$ & $\begin{array}{l}-0.001 \\
(0.008)\end{array}$ & $\begin{array}{c}-1.478^{* *} \\
(0.498)\end{array}$ & $\begin{array}{c}-2.258^{* *} \\
(0.770)\end{array}$ \\
\hline $\mathrm{N}$ & 91752 & 91752 & 91752 & 95913 & 95913 & 95913 & 95913 & 95913 & 95913 \\
\hline Estimation & OLS & IV & IV & OLS & IV & IV & OLS & IV & IV \\
\hline Funct. Form & Linear & Linear & Quad & Linear & Linear & Quad & Linear & Linear & Quad \\
\hline
\end{tabular}

Notes: GMM-IV estimations using $\operatorname{ICAP}_{10, t-1}$ as the running variable and $\operatorname{ICAP}_{2.5, t-1}$ as an additional instrument. All regressions include current and 24-hour lags of quartics in humidity, temperature, wind speed, precipitation, and thermal oscillation, and dummies for year, month, dow, and hour $\times$ weekend. Standard errors robust to heteroskedasticity and to 2 -hour serial correlation in parentheses. Significance levels: ${ }^{*} p<0.10$, ${ }^{* *} p<0.05,{ }^{* * *} p<0.001$.

Table D4: Episodes Impact on Hourly Average Pollution - Global Polynomial Approach

\begin{tabular}{|c|c|c|c|c|c|c|c|c|c|}
\hline & \multicolumn{3}{|c|}{ Peak Hours } & \multicolumn{3}{|c|}{ Early Off-Peak Hours } & \multicolumn{3}{|c|}{ Late Off-Peak Hours } \\
\hline & (1) & (2) & (3) & (1) & (2) & (3) & (1) & $(2)$ & $(3)$ \\
\hline \multicolumn{10}{|c|}{ Panel a) $\mathrm{PM}_{10}$ : } \\
\hline 1[Episodes] & $\begin{array}{l}-0.001 \\
(0.004)\end{array}$ & $\begin{array}{l}-0.039 \\
(0.050)\end{array}$ & $\begin{array}{l}-0.077 \\
(0.076)\end{array}$ & $\begin{array}{c}-0.041^{* * *} \\
(0.007)\end{array}$ & $\begin{array}{l}-0.207 \\
(0.346)\end{array}$ & $\begin{array}{c}-0.400 \\
(0.543)\end{array}$ & $\begin{array}{l}-0.010 \\
(0.007)\end{array}$ & $\begin{array}{l}-0.121 \\
(0.203)\end{array}$ & $\begin{array}{c}-0.248 \\
(0.326)\end{array}$ \\
\hline $\mathrm{N}$ & 99,965 & 99,965 & 99,965 & 104,308 & 104,308 & 104,308 & 104,308 & 104,308 & 104,308 \\
\hline \multicolumn{10}{|l|}{ Panel b) $\mathrm{PM}_{25}$ : } \\
\hline 1[Episodes] & $\begin{array}{c}0.001 \\
(0.004)\end{array}$ & $\begin{array}{c}0.009 \\
(0.050)\end{array}$ & $\begin{array}{l}-0.033 \\
(0.079)\end{array}$ & $\begin{array}{c}-0.036^{* * *} \\
(0.007)\end{array}$ & $\begin{array}{c}0.122 \\
(0.349)\end{array}$ & $\begin{array}{l}-0.026 \\
(0.547)\end{array}$ & $\begin{array}{c}-0.011^{*} \\
(0.006)\end{array}$ & $\begin{array}{c}0.074 \\
(0.207)\end{array}$ & $\begin{array}{c}-0.016 \\
(0.336)\end{array}$ \\
\hline $\mathrm{N}$ & 99,914 & 99,914 & 99,914 & 104,255 & 104,255 & 104,255 & 104,255 & 104,255 & 104,255 \\
\hline \multicolumn{10}{|l|}{ Panel c) CO: } \\
\hline 1[Episodes] & $\begin{array}{l}-0.005 \\
(0.004)\end{array}$ & $\begin{array}{c}0.018 \\
(0.046)\end{array}$ & $\begin{array}{l}-0.016 \\
(0.066)\end{array}$ & $\begin{array}{c}-0.023^{* *} \\
(0.007)\end{array}$ & $\begin{array}{c}0.046 \\
(0.316)\end{array}$ & $\begin{array}{l}-0.185 \\
(0.479)\end{array}$ & $\begin{array}{c}-0.015^{* *} \\
(0.006)\end{array}$ & $\begin{array}{c}0.028 \\
(0.197)\end{array}$ & $\begin{array}{c}-0.114 \\
(0.292)\end{array}$ \\
\hline $\mathrm{N}$ & 99,989 & 99,989 & 99,989 & 104,333 & 104,333 & 104,333 & 104,333 & 104,333 & 104,333 \\
\hline \multicolumn{10}{|l|}{ Panel d) $\mathrm{NO}_{X}$ : } \\
\hline 1[Episodes] & $\begin{array}{l}-0.002 \\
(0.004)\end{array}$ & $\begin{array}{r}-0.0001 \\
(0.057)\end{array}$ & $\begin{array}{c}0.012 \\
(0.084)\end{array}$ & $\begin{array}{c}-0.062^{* * *} \\
(0.009)\end{array}$ & $\begin{array}{l}-0.053 \\
(0.390)\end{array}$ & $\begin{array}{c}0.048 \\
(0.618)\end{array}$ & $\begin{array}{l}-0.010 \\
(0.008)\end{array}$ & $\begin{array}{l}-0.031 \\
(0.238)\end{array}$ & $\begin{array}{c}0.029 \\
(0.369)\end{array}$ \\
\hline $\mathrm{N}$ & 99,951 & 99,951 & 99,951 & 104,293 & 104,293 & 104,293 & 104,293 & 104,293 & 104,293 \\
\hline Estimation & OLS & IV & IV & OLS & IV & IV & OLS & IV & IV \\
\hline Funct. Form & Linear & Linear & Quad & Linear & Linear & Quad & Linear & Linear & Quad \\
\hline
\end{tabular}

Notes: GMM-IV estimations using $\mathrm{ICAP}_{10, t-1}$ as the running variable and $\mathrm{ICAP}_{2.5, t-1}$ as an additional instrument. All estimations include 12-hour lags of pollution. Weather variables include current and 24-hour lags of quartics in humidity, temperature, wind speed, precipitation, and thermal oscillation, and dummies for year, month, dow, and hour $\times$ weekend. Standard errors robust to heteroskedasticity and to 24-hour serial correlation in parentheses. Significance levels: ${ }^{*} p<0.10,{ }^{* *} p<0.05,{ }^{* * *} p<0.001$. 
Table D5: Alerts and Pre-emergencies Impact on Hourly Max Vehicle Trips

\begin{tabular}{|c|c|c|c|c|c|c|c|c|c|}
\hline \multirow[b]{2}{*}{ Bandwidth } & \multicolumn{3}{|c|}{ Peak Hours } & \multicolumn{3}{|c|}{ Early Off-Peak Hours } & \multicolumn{3}{|c|}{ Late Off-Peak Hours } \\
\hline & $k=50$ & $k=25$ & Optimal & $k=50$ & $k=25$ & Optimal & $k=50$ & $k=25$ & Optimal \\
\hline 1 [Alerts] & $\begin{array}{c}-0.019 \\
(0.016)\end{array}$ & $\begin{array}{c}0.030^{*} \\
(0.016)\end{array}$ & $\begin{array}{l}-0.001 \\
(0.015)\end{array}$ & $\begin{array}{c}0.002 \\
(0.038)\end{array}$ & $\begin{array}{c}0.008 \\
(0.040)\end{array}$ & $\begin{array}{c}0.057 \\
(0.037)\end{array}$ & $\begin{array}{l}-0.021 \\
(0.025)\end{array}$ & $\begin{array}{l}-0.029 \\
(0.029)\end{array}$ & $\begin{array}{l}-0.001 \\
(0.028)\end{array}$ \\
\hline $\mathrm{N}$ & 4,897 & 2,610 & 994 & 5,119 & 2,728 & 1,038 & 5,119 & 2,728 & 1,038 \\
\hline $1[$ Pre-emergencies $]$ & $\begin{array}{c}-0.045^{* *} \\
(0.021)\end{array}$ & $\begin{array}{c}-0.060^{* *} \\
(0.023)\end{array}$ & $\begin{array}{c}-0.093^{* * *} \\
(0.020)\end{array}$ & $\begin{array}{c}0.005 \\
(0.060)\end{array}$ & $\begin{array}{c}0.020 \\
(0.065)\end{array}$ & $\begin{array}{l}-0.056 \\
(0.042)\end{array}$ & $\begin{array}{l}-0.003 \\
(0.043)\end{array}$ & $\begin{array}{c}-0.009 \\
(0.040)\end{array}$ & $\begin{array}{l}-0.054 \\
(0.042)\end{array}$ \\
\hline $\mathrm{N}$ & 1,917 & 945 & 352 & 2,003 & 988 & 368 & 2,003 & 988 & 368 \\
\hline
\end{tabular}

Notes: Local linear GMM-IV estimations of the residuals from the (full) regressions of hourly max vehicle trips (in $\operatorname{logs}$ ) using $\mathrm{ICAP}_{10, t-1}$ as the running variable and $\mathrm{ICAP}_{2.5, t-1}$ as an additional instrument. All regressions include current and 24-hour lags of quartics in humidity, temperature, wind speed, precipitation, and thermal oscillation, and dummies for year, month, dow, and hour $\times$ weekend. Optimal bandwidth estimated using a common MSEoptimal bandwidth selector based on Calonico et al. (2014), Calonico et al. (2017), and Calonico et al. (2018a). Standard errors robust to heteroskedasticity and to 2-hour serial correlation in parentheses. Significance levels: ${ }^{*} p<0.10,{ }^{* *} p<0.05,{ }^{* * *} p<0.001$. 
Table D6: Alerts and Pre-emergencies Impact on Hourly Max Pollution

\begin{tabular}{|c|c|c|c|c|c|c|c|c|c|}
\hline \multirow[b]{2}{*}{ Bandwidth } & \multicolumn{3}{|c|}{ Peak Hours } & \multicolumn{3}{|c|}{ Early Off-Peak Hours } & \multicolumn{3}{|c|}{ Late Off-Peak Hours } \\
\hline & $k=50$ & $k=25$ & Optimal & $k=50$ & $k=25$ & Optimal & $k=50$ & $k=25$ & Optimal \\
\hline \multicolumn{10}{|l|}{ Panel a) $\mathrm{PM}_{10}$ : } \\
\hline 1 [Alerts] & $\begin{array}{c}-0.029^{* *} \\
(0.009)\end{array}$ & $\begin{array}{c}-0.019^{* *} \\
(0.009)\end{array}$ & $\begin{array}{c}-0.026^{* *} \\
(0.009)\end{array}$ & $\begin{array}{c}-0.056^{* *} \\
(0.020)\end{array}$ & $\begin{array}{c}-0.056^{* *} \\
(0.019)\end{array}$ & $\begin{array}{c}0.006 \\
(0.018)\end{array}$ & $\begin{array}{c}0.00003 \\
(0.017)\end{array}$ & $\begin{array}{l}-0.011 \\
(0.017)\end{array}$ & $\begin{array}{c}0.006 \\
(0.018)\end{array}$ \\
\hline $\mathrm{N}$ & 5,227 & 2,770 & 3,341 & 5,454 & 2,890 & 3,486 & 5,454 & 2,890 & 3,486 \\
\hline 1[Pre-Emergencies] & $\begin{array}{l}0.027^{* *} \\
(0.011)\end{array}$ & $\begin{array}{c}-0.002 \\
(0.008)\end{array}$ & $\begin{array}{l}-0.009 \\
(0.008)\end{array}$ & $\begin{array}{c}-0.090^{* *} \\
(0.029)\end{array}$ & $\begin{array}{c}-0.048^{* *} \\
(0.019)\end{array}$ & $\begin{array}{c}-0.059^{* *} \\
(0.019)\end{array}$ & $\begin{array}{c}0.049^{*} \\
(0.029)\end{array}$ & $\begin{array}{c}0.004 \\
(0.018)\end{array}$ & $\begin{array}{c}-0.002 \\
(0.018)\end{array}$ \\
\hline $\mathrm{N}$ & 2,013 & 989 & 989 & 2,100 & 1,032 & 1,032 & 2,100 & 1,032 & 1,032 \\
\hline \multicolumn{10}{|l|}{ Panel b) $\mathrm{PM}_{25}$ : } \\
\hline 1[Alerts] & $\begin{array}{c}-0.024^{* *} \\
(0.009)\end{array}$ & $\begin{array}{c}-0.025^{* *} \\
(0.010)\end{array}$ & $\begin{array}{c}-0.034^{* * *} \\
(0.010)\end{array}$ & $\begin{array}{c}0.006 \\
(0.016)\end{array}$ & $\begin{array}{l}-0.020 \\
(0.017)\end{array}$ & $\begin{array}{l}-0.017 \\
(0.019)\end{array}$ & $\begin{array}{c}0.008 \\
(0.016)\end{array}$ & $\begin{array}{c}0.042^{* *} \\
(0.017)\end{array}$ & $\begin{array}{l}0.029^{*} \\
(0.018)\end{array}$ \\
\hline $\mathrm{N}$ & 5,227 & 2,770 & 3,341 & 5,454 & 2,890 & 3,486 & 5,454 & 2,890 & 3,486 \\
\hline 1[Pre-Emergencies] & $\begin{array}{c}0.014 \\
(0.011)\end{array}$ & $\begin{array}{c}-0.009 \\
(0.008)\end{array}$ & $\begin{array}{c}0.033^{* * *} \\
(0.007)\end{array}$ & $\begin{array}{l}-0.017 \\
(0.029)\end{array}$ & $\begin{array}{l}-0.002 \\
(0.020)\end{array}$ & $\begin{array}{l}0.046^{* *} \\
(0.021)\end{array}$ & $\begin{array}{c}0.028 \\
(0.028)\end{array}$ & $\begin{array}{c}-0.020 \\
(0.019)\end{array}$ & $\begin{array}{c}0.007 \\
(0.016)\end{array}$ \\
\hline $\mathrm{N}$ & 2,013 & 989 & 736 & 2,100 & 1,032 & 768 & 2,100 & 1,032 & 768 \\
\hline \multicolumn{10}{|l|}{ Panel c) CO: } \\
\hline $1[$ Alerts $]$ & $\begin{array}{c}-0.033^{* * *} \\
(0.009)\end{array}$ & $\begin{array}{c}-0.027^{* *} \\
(0.009)\end{array}$ & $\begin{array}{c}-0.032^{* * *} \\
(0.008)\end{array}$ & $\begin{array}{l}-0.034^{*} \\
(0.018)\end{array}$ & $\begin{array}{c}-0.054^{* *} \\
(0.017)\end{array}$ & $\begin{array}{c}-0.047^{* *} \\
(0.017)\end{array}$ & $\begin{array}{c}-0.007 \\
(0.018)\end{array}$ & $\begin{array}{c}-0.001 \\
(0.019)\end{array}$ & $\begin{array}{c}0.005 \\
(0.019)\end{array}$ \\
\hline $\mathrm{N}$ & 5,227 & 2,770 & 2,467 & 5,454 & 2,890 & 2,574 & 5,454 & 2,890 & 2,574 \\
\hline $1[$ Pre-Emergencies $]$ & $\begin{array}{l}0.038^{* *} \\
(0.012)\end{array}$ & $\begin{array}{c}0.003 \\
(0.008)\end{array}$ & $\begin{array}{c}0.005 \\
(0.009)\end{array}$ & $\begin{array}{l}-0.036 \\
(0.032)\end{array}$ & $\begin{array}{c}0.041^{*} \\
(0.023)\end{array}$ & $\begin{array}{c}0.026 \\
(0.023)\end{array}$ & $\begin{array}{c}0.056^{* *} \\
(0.028)\end{array}$ & $\begin{array}{c}0.083^{* * *} \\
(0.019)\end{array}$ & $\begin{array}{c}0.065^{* * *} \\
(0.019)\end{array}$ \\
\hline $\mathrm{N}$ & 2,013 & 989 & 1,035 & 2,100 & 1,032 & 1,080 & 2,100 & 1,032 & 1,080 \\
\hline \multicolumn{10}{|l|}{ Panel d) $\mathrm{NO}_{X}$ : } \\
\hline $1[$ Alerts] & $\begin{array}{c}-0.023^{* *} \\
(0.010)\end{array}$ & $\begin{array}{c}-0.022^{* *} \\
(0.010)\end{array}$ & $\begin{array}{c}-0.029^{* *} \\
(0.010)\end{array}$ & $\begin{array}{c}-0.098^{* * *} \\
(0.024)\end{array}$ & $\begin{array}{c}-0.084^{* * *} \\
(0.024)\end{array}$ & $\begin{array}{c}-0.095^{* * *} \\
(0.025)\end{array}$ & $\begin{array}{c}-0.048^{* *} \\
(0.020)\end{array}$ & $\begin{array}{c}-0.059^{* *} \\
(0.025)\end{array}$ & $\begin{array}{c}-0.056^{* *} \\
(0.024)\end{array}$ \\
\hline $\mathrm{N}$ & 5,227 & 2,770 & 3,433 & 5,454 & 2,890 & 3,582 & 5,454 & 2,890 & 3,582 \\
\hline 1[Pre-Emergencies] & $\begin{array}{c}0.051^{* * *} \\
(0.013)\end{array}$ & $\begin{array}{c}0.021^{* *} \\
(0.010)\end{array}$ & $\begin{array}{l}0.021^{* *} \\
(0.010)\end{array}$ & $\begin{array}{c}-0.069^{*} \\
(0.036)\end{array}$ & $\begin{array}{c}0.005 \\
(0.025)\end{array}$ & $\begin{array}{c}0.004 \\
(0.025)\end{array}$ & $\begin{array}{c}0.030 \\
(0.039)\end{array}$ & $\begin{array}{c}0.041 \\
(0.030)\end{array}$ & $\begin{array}{c}0.036 \\
(0.031)\end{array}$ \\
\hline $\mathrm{N}$ & 2,013 & 989 & 989 & 2,100 & 1,032 & 1,032 & 2,100 & 1,032 & 1,032 \\
\hline
\end{tabular}

Notes: Local linear GMM-IV estimations of the residuals from the (full) regressions of hourly max pollution concentrations (in logs) using $\operatorname{ICAP}_{10, t-1}$ as the running variable and $\operatorname{ICAP}_{2.5, t-1}$ as an additional instrument. All estimations include 12-hour lags of pollution. Weather variables include current and 24-hour lags of quartics in humidity, temperature, wind speed, precipitation, and thermal oscillation, and dummies for year, month, dow, and hour $\times$ weekend. Optimal bandwidth estimated using a common MSE-optimal bandwidth selector based on Calonico et al. (2014), Calonico et al. (2017), and Calonico et al. (2018a). Standard errors robust to heteroskedasticity and to 24 -hour serial correlation in parentheses. Significance levels: ${ }^{*} p<0.10,{ }^{* *} p<0.05$, ${ }^{* * *} p<0.001$. 
Table D7: Episodes Impact on Hourly Pollution Using False Cutoffs

\begin{tabular}{|c|c|c|c|c|c|c|c|c|}
\hline & \multicolumn{2}{|c|}{$\mathrm{PM}_{10}$} & \multicolumn{2}{|c|}{$\mathrm{PM}_{2.5}$} & \multicolumn{2}{|c|}{$\mathrm{CO}$} & \multicolumn{2}{|c|}{$\mathrm{NO}_{X}$} \\
\hline & Early & Late & Early & Late & Early & Late & Early & Late \\
\hline \multicolumn{9}{|c|}{ Panel a) Pooling Episodes: } \\
\hline 1[Episodes] & $\begin{array}{c}1.056 \\
(1.064)\end{array}$ & $\begin{array}{l}-1.342 \\
(1.116)\end{array}$ & $\begin{array}{c}0.652 \\
(0.928)\end{array}$ & $\begin{array}{l}-1.087 \\
(1.000)\end{array}$ & $\begin{array}{l}-0.618 \\
(1.141)\end{array}$ & $\begin{array}{l}-0.560 \\
(0.743)\end{array}$ & $\begin{array}{c}1.457 \\
(1.620)\end{array}$ & $\begin{array}{l}-0.987 \\
(1.066)\end{array}$ \\
\hline $\mathrm{N}$ & 25,715 & 25,715 & 30,425 & 30,425 & 37,096 & 37,096 & 37,096 & 37,096 \\
\hline \multicolumn{9}{|c|}{ Panel b) Heterogeneous Episodes: } \\
\hline $1[$ Alerts $]$ & $\begin{array}{c}0.851 \\
(1.463)\end{array}$ & $\begin{array}{l}-1.169 \\
(1.085)\end{array}$ & $\begin{array}{c}1.739 \\
(1.459)\end{array}$ & $\begin{array}{l}-1.173 \\
(1.075)\end{array}$ & $\begin{array}{c}0.400 \\
(1.470)\end{array}$ & $\begin{array}{l}-0.179 \\
(0.675)\end{array}$ & $\begin{array}{l}-1.692 \\
(3.566)\end{array}$ & $\begin{array}{l}-0.477 \\
(0.906)\end{array}$ \\
\hline $\mathrm{N}$ & 30,443 & 30,443 & 30,425 & 30,425 & 37,096 & 37,096 & 37,096 & 37,096 \\
\hline 1[Pre-Emergencies] & $\begin{array}{c}-0.010 \\
(0.584)\end{array}$ & $\begin{array}{c}0.405 \\
(0.484)\end{array}$ & $\begin{array}{c}0.095 \\
(0.462)\end{array}$ & $\begin{array}{c}0.818 \\
(0.684)\end{array}$ & $\begin{array}{c}0.466 \\
(0.492)\end{array}$ & $\begin{array}{c}0.737 \\
(0.607)\end{array}$ & $\begin{array}{c}3.778 \\
(2.494)\end{array}$ & $\begin{array}{c}2.178 \\
(1.564)\end{array}$ \\
\hline $\mathrm{N}$ & 8,979 & 8,979 & 8,979 & 8,979 & 9,411 & 9,411 & 14,787 & 14,787 \\
\hline
\end{tabular}

Notes: Local linear GMM-IV estimations of the residuals from the (full) regressions of off-peak hourly pollution concentrations (in logs) using optimal bandwidths. Standard errors robust to heteroskedasticity and to 24 -hour serial correlation in parentheses. Significance levels: ${ }^{*} p<0.10,{ }^{* *} p<0.05,{ }^{* * *} p<0.001$. 